University of Texas at El Paso

\title{
DigitalCommons@UTEP
}

Open Access Theses \& Dissertations

2018-01-01

\section{Geospatial Relationship of Intelligent Compaction Measurement Values with In-Situ Testing for Quality Assessment of Geomaterials}

Luis Alberto Lemus

University of Texas at El Paso, lalemus08@gmail.com

Follow this and additional works at: https://digitalcommons.utep.edu/open_etd

Part of the Civil Engineering Commons, Geotechnical Engineering Commons, and the Transportation Commons

\section{Recommended Citation}

Lemus, Luis Alberto, "Geospatial Relationship of Intelligent Compaction Measurement Values with In-Situ Testing for Quality Assessment of Geomaterials" (2018). Open Access Theses \& Dissertations. 101.

https://digitalcommons.utep.edu/open_etd/101 


\title{
GEOSPATIAL RELATIONSHIP OF INTELLIGENT COMPACTION MEASUREMENT VALUES WITH IN-SITU TESTING FOR QUALITY ASSESSMENT OF GEOMATERIALS
}

\author{
LUIS ALBERTO LEMUS \\ Master's Program in Civil Engineering
}

APPROVED:

Soheil Nazarian, Ph.D., Chair

Cesar Tirado, Ph.D.

Vladik Kreinovich, Ph.D.

Mehran Mazari, Ph.D.

Charles Ambler, Ph.D.

Dean of the Graduate School 


\section{Dedication}

I dedicate this thesis to my loving parents and sister. 


\title{
GEOSPATIAL RELATIONSHIP OF INTELLIGENT COMPACTION MEASUREMENT VALUES WITH IN-SITU TESTING FOR QUALITY ASSESSMENT OF GEOMATERIALS
}

\author{
by \\ LUIS ALBERTO LEMUS, BSCE
}

\section{THESIS}

\author{
Presented to the Faculty of the Graduate School of \\ The University of Texas at El Paso \\ in Partial Fulfillment \\ of the Requirements \\ for the Degree of
}

MASTER OF SCIENCE

Department of Civil Engineering

THE UNIVERSITY OF TEXAS AT EL PASO

December 2018 


\section{Acknowledgements}

I want to extend my appreciation to my thesis and project advisor, Dr. Soheil Nazarian for giving me the opportunity to work for him, and for the guidance he offered me throughout these past years. I also want to extend my heartfelt gratitude to Dr. Cesar Tirado for his friendship, patience and guidance during my time working at the Center for Transportation and Infrastructure Systems (CTIS). I am also grateful to the staff at CTIS, especially to Sergio Rocha for his companionship and support throughout these past years, and Dr. Imad Abdallah for giving me the opportunity to be part of the CTIS team. I would also like to thank Dr. Vladik Kreinovich who kindly accepted to serve as members of my thesis committee. My sincere gratitude also extends to the Texas Department of Transportation (TxDOT) for funding the research projects used for these studies. Special thanks to Dr. Jimmy Si for all his help.

I would also like to thank my friends Luiza Barros, Diana Cabrera, Erika Carpinteyro, Melissa Escalante, Alejandra Escajeda, and Mauricio Valenzuela who kept giving me the strength to continue towards the completion of this goal. Lastly, I want to thank my family: my mother, Maria Aide Lemus, my father, Jose Luis Lemus, and my sister, Claudia Aide Lemus for all their support. 


\begin{abstract}
The implementation of Intelligent Compaction (IC) in the construction of transportation infrastructure as a tool for quality control of compacted geomaterials has attracted the attention of a number of highway agencies. Compaction quality has been conventionally assessed using density, and to a less extent, modulus-based spot measurements at selected locations along the roadway section. While spot measurements do not provide a thorough rendition of the level of compaction of the roadway, IC technology is effective in meeting full coverage requirements. IC roller measurements are accelerometer-based measurements recording machine-ground interaction assumed to be indicative of the stiffness of the compacted geomaterial. Different studies have attempted to relate IC measurement values with traditional deflection-based in situ moduli with mixed success. Weak correlations between IC measurements and in-situ spot test measurements have been attributed to variation in material properties such as moisture content, influence of depth of spot test penetration and the variation in underlying support, in addition to the uncertainty in the spatial location of the nearest IC data point. In this study, an approach is presented for establishing a spatial relationship between IC and spot test measurements using different nondestructive tests such as the Light-Weight Deflectometer, and the Dynamic Cone Penetrometer, by implementing a fixed interval analysis for the collected IC data that meets a lot size that is suited for contractor rework. This approach shows that a relationship exists between the IC measurements and the spot test measurements.
\end{abstract}




\section{Table of Contents}

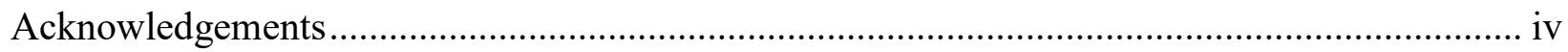

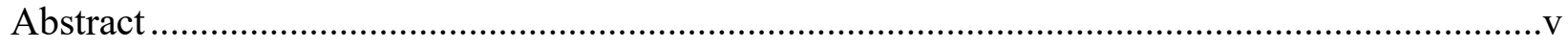

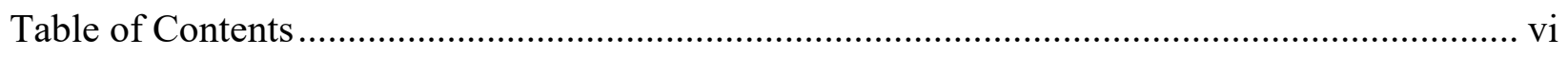

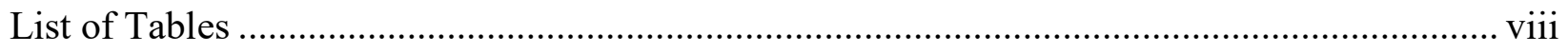

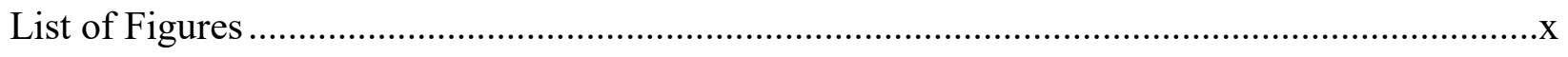

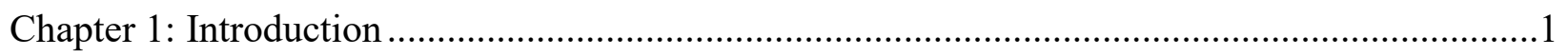

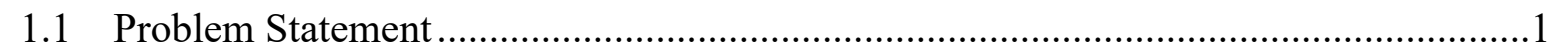

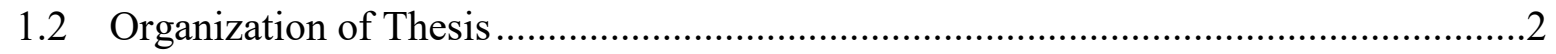

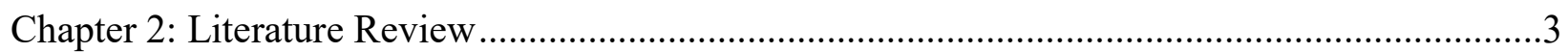

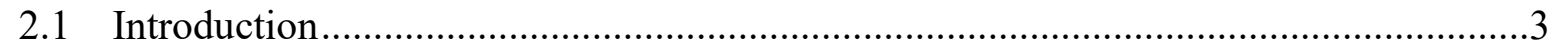

2.2 Factors Impacting Properties of Compacted Geomaterials .....................................

2.3 Intelligent Compaction Measurement Values...............................................................5

2.4 Modulus and Deflection-Based Devices...........................................................6

2.5 ICMV Correlations With Modulus and Deflection-Based Devices ..........................9

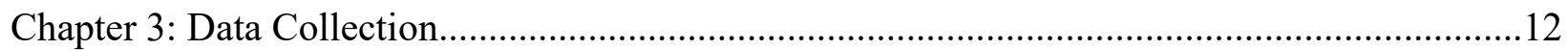

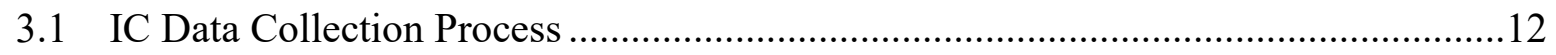

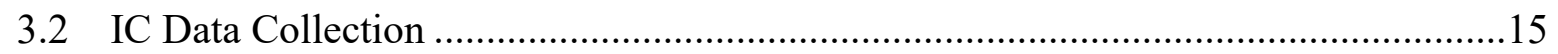

3.3 In-Situ Spot Tests Procedure .........................................................................17

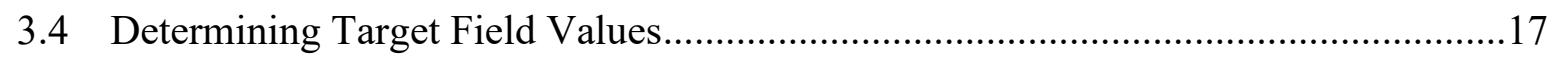

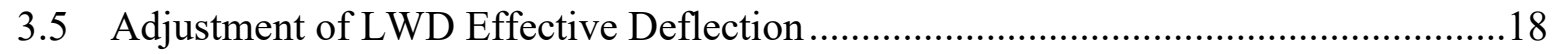

3.6 Geospatial Analysis of IC Data and In-Situ Spot Tests ........................................19

3.7 Optimization Process for Identifying Less Stiff Areas Using IC ............................22

Chapter 4: Evaluation of IC Data in Fort Worth, IH 35W …..............................................25

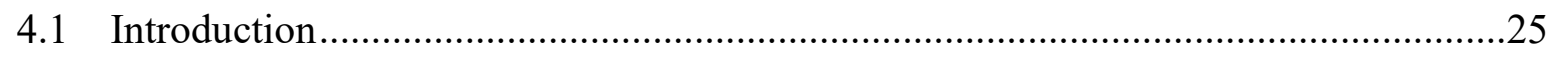

4.2 Field Testing Program............................................................................................26

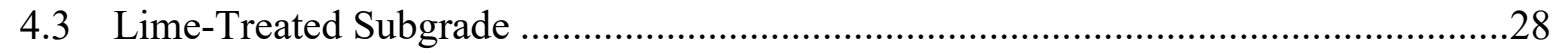

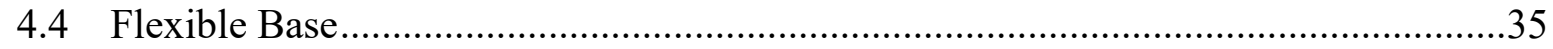

4.5 Geospatial Classification for Developing Optimized Color-Coded Maps .................39 
Chapter 5: Evaluation of IC Data in Georgetown, FM1460 .44

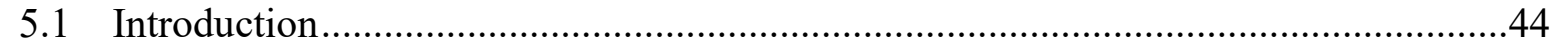

5.2 Field Testing Program.................................................................................45

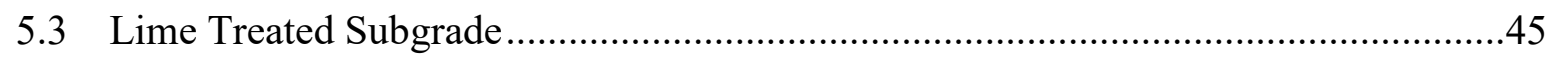

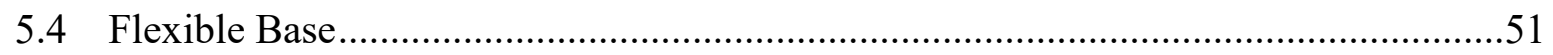

5.5 Implementation of Optimization Process for Identifying Low Stiff Areas using IC ...55

Chapter 6: Evaluation of IC Data in Irving, Texas ....................................................................56

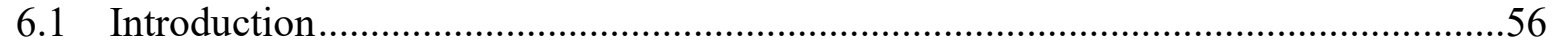

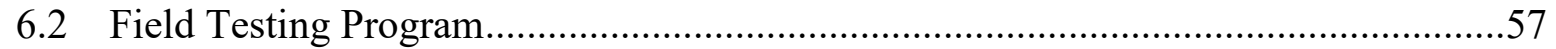

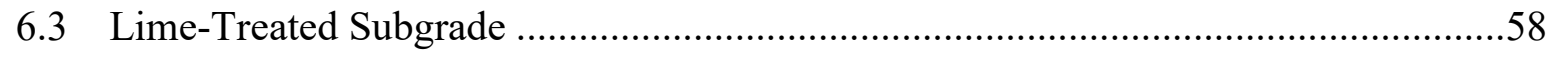

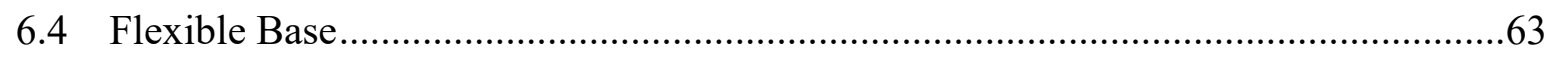

6.5 Implementation of Optimization Process for Identifying Low Stiff Areas using IC ......67

Chapter 7: Evaluation of IC Data in Victoria, US-77 Highway ............................................69

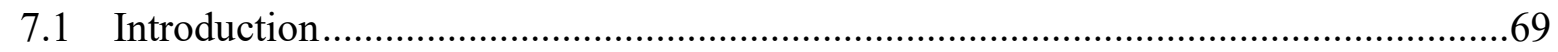

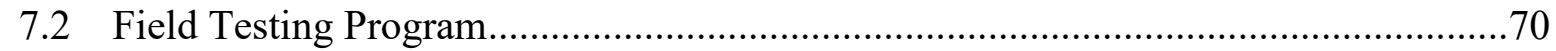

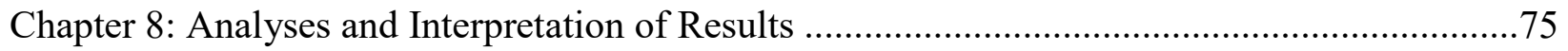

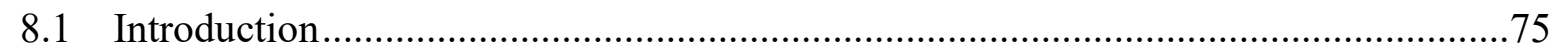

8.2 Optimization Process for Identifying Less Stiff Areas using IC .............................82

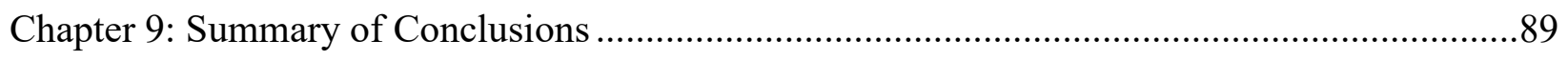

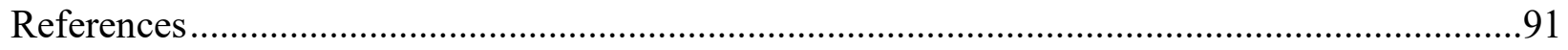

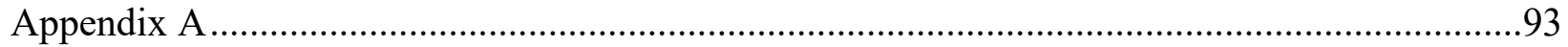

A.1 Evaluation of IC Roller Prediction of Less-Stiff Areas on Subgrade Material ...........94

A.2 Evaluation of IC Roller Prediction of Less-Stiff Areas on Flexible Base Material.....97

Vita .100 


\section{List of Tables}

Table 2.1 - Comparison of Tools for Measuring Modulus ....................................................... 7

Table 3.1 - Criterion for Color-Coded Maps......................................................................... 23

Table 3.2 - Percentage of Misestimated Roller Measurements (Rectangular Buffered Areas

CMVs) with Respect to LWD Measurements Based on Different Percentages of Average

Measurements for the Identification of Less-Stiff (Red) Areas............................................. 24

Table 4.1. Criterion for Color-Coded Maps........................................................................... 30

Table 4.2 - Percentage of Disagreement in Rectangular Buffered Areas between CMV and LWD

Modulus Based on Different Color-Criteria for the Less-Stiff (Red) Areas. ............................ 43

Table 5.1 - Percentage of Mis-Estimated CMV Less-Stiff when Compared to Less-Stiff Areas as

Predicted by the LWD Surface Deflection in LTS layer. ..................................................... 55

Table 5.2 - Percentage of Mis-Estimated CMV Less-Stiff when Compared to Less-Stiff Areas as

Predicted by the DCP in Subgrade...................................................................................... 55

Table 6.1 - Percentage of Mis-Estimated CMV Less-Stiff when Compared to Less-Stiff Areas as

Predicted by the LWD Surface Deflection in LTS layer. ..................................................... 68

Table 6.2 - Percentage of Mis-Estimated CMV Less-Stiff when Compared to Less-Stiff Areas as

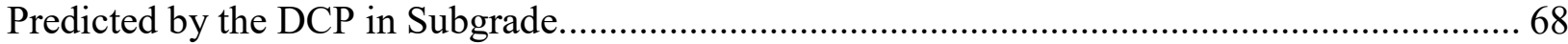

Table 8.1 - Percentage of Misestimated Roller Measurements (Rectangular Buffered Areas

CMVs) with Respect to LWD Deflection-Based Measurements Based on Different Percentages

of Average Measurements for Identification of Less-Stiff (Red) Areas.................................. 84

Table 8.2 - Percentage of Mis-estimated Roller Measurements (Rectangular Buffered Areas

CMVs) with respect to DCP Measurements Based on Different Percentages of Average

Measurements for Identification of Less-Stiff (Red) Areas. .................................................. 85

Table 8.3 - Optimized Class-Break Criterion for Color-Coded Maps. .................................... 85

Table 8.4 - Percentage of Misestimated Roller Measurements (Rectangular Buffered Areas

CMVs) with Respect to LWD Deflection-Based Measurements Based on Different Percentages

of Average Measurements for Identification of Less-Stiff (Red) Areas.

Table 8.5 - Percentage of Misestimated Roller Measurements (Rectangular Buffered Areas

CMVs) with Respect to LWD Deflection-Based Measurements Based on Different Percentages

of Average Measurements for Identification of Less-Stiff (Red) Areas.................................. 87

Table 8.6 - Summary of Percentage of Mis-estimated Areas by IC Roller Optimized Class-Break

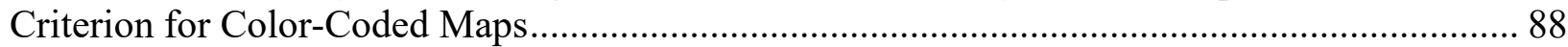

Table A.1 - Field Test Sites............................................................................................. 93

Table A.2 - Percentage of Mis-Estimated CMV Less-Stiff when Compared to Less-Stiff Areas

as Predicted by the LWD Surface Modulus in Subgrade ..................................................... 94

Table A.3 - Percentage of Mis-Estimated CMV Less-Stiff when Compared to Less-Stiff Areas as Predicted by the LWD Surface Deflection in Subgrade .................................................... 95

Table A.4 - Percentage of Mis-Estimated CMV Less-Stiff when Compared to Less-Stiff Areas

as Predicted by the DCP in Subgrade ................................................................................... 96

Table A.5 - Percentage of Mis-Estimated CMV Less-Stiff when Compared to Less-Stiff Areas

as Predicted by the LWD Surface Modulus in Flexible Base .................................................. 97

Table A.6 - Percentage of Mis-Estimated CMV Less-Stiff when Compared to Less-Stiff Areas

as Predicted by the LWD Surface Deflection in Flexible Base .............................................. 98 
Table A.7 - Percentage of Mis-Estimated CMV Less-Stiff when Compared to Less-Stiff Areas

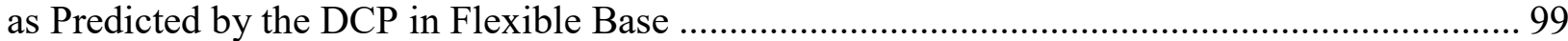




\section{List of Figures}

Figure 2.1 - Forcing frequency and vibration harmonics for a soft layer (Nazarian et al, 2015) ... 5

Figure 2.2 - Forcing frequency and vibration harmonics for a stiff layer (Nazarian et al, 2015)... 6

Figure 2.3 - Dynamic Cone Penetrometer (DCP) test............................................................. 8

Figure 2.4 - Light-Weight Deflectometer (LWD) ............................................................ 9

Figure 3.1: Data Collection Steps a) Test Section Selection b) GPS Set-Up c) Roller

Instrumentation d) LWD Field Testing e) DCP Field Testing 13

Figure 3.2 - Field Site Instrumentation of Roller Compactor: (a) RTK GPS and Wiring of Accelerometers to Data Acquisition System and (b) Installation of both Accelerometers to Measure Vertical and Horizontal Vibration on Roller Compactor Drum Frame. ......................... 16 Figure 3.3 - IC Data Points Collected During Mapping of a Test Layer (SH 183 in Irving). ..... 17

Figure 3.4 - Schematic of a Typical Test Section and Locations of Spot Tests.......................... 17 Figure 3.5 - Color-coded Map Depicting IC Data in Terms of CMV on Lime-Treated Subgrade Test Section Using (a) Quantile, (b) Natural Breaks, and (c) Percentage of Average ICMV Data Using Red: ICMV $<75 \%$ of Average ICMV Data and Green: ICMV > Average ICMV. ......... 21 Figure 3.6 - Schematic of test section divided in rectangular buffered areas. ............................ 22 Figure 3.7 - Color-Coded Map Comparison between (a) CMV, (b) LWD Mass Drop Deflection and (c) Number of DCP Blows to Penetrate 24 in. as Obtained in Lime-Treated Subgrade at Site

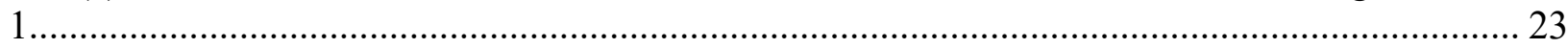

Figure 4.1 - Location of Field Evaluation Site on I-35 in Fort Worth, TX................................ 25

Figure 4.2 - Pavement Structure of Test Section ………………………………...................... 26

Figure 4.3 a) Schematic of the Typical Test Section and Location of Spot Tests and b) Diagram

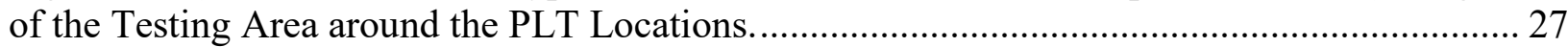

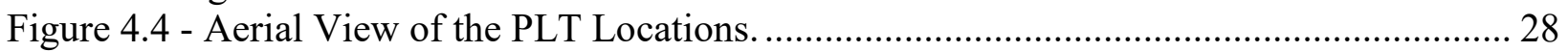

Figure 4.5 - Spatial Distribution of (a) Raw and (b) Rectangular Buffered CMV Data Collected

by IC Roller during Proof-Rolling of LTS Layer..................................................................... 29

Figure 4.6 - Distribution of CMV Data Collected by IC Roller during Proof-Rolling of LTS

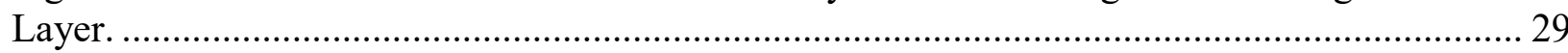

Figure 4.7 - Spatial Distribution of LWD Modulus on LTS Layer............................................... 31

Figure 4.8 - Spatial Distribution of Number of DCP Blows on LTS Layer. ............................... 31

Figure 4.9 - Spatial Distribution of Moisture Content of LTS Layer. ......................................... 32

Figure 4.10 - Relationship between averaged (a) LWD Modulus and (b) Number of DCP blows

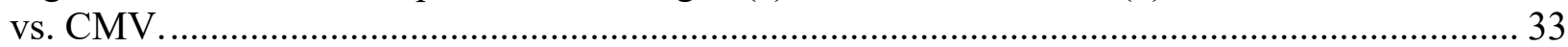

Figure 4.11 - Spatial Distribution of LWD at Different PLT locations. ..................................... 34

Figure 4.12 - Spatial Distribution of (a) Raw and (b) Rectangular Buffered CMV Data Collected

by IC Roller during Proof-Rolling of Flexible Base Layer. ....................................................... 35

Figure 4.13- Distribution of CMV Data Collected by IC Roller during Proof-Rolling of Flexible

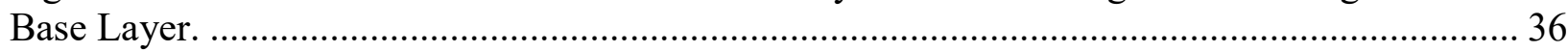

Figure 4.14 - Spatial Distribution of LWD Modulus of Flexible Base Layer. ............................ 36

Figure 4.15 - Spatial Distribution of Number of DCP Blows of Flexible Base Layer to Penetrate

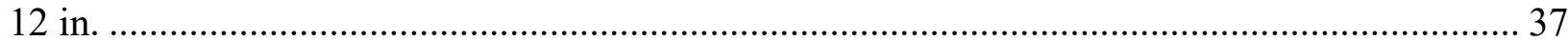

Figure 4.16 - Spatial Distribution of Moisture Content of Flexible Base Layer.......................... 38 Figure 4.17 - Relationship between Averaged (a) LWD Modulus and (b) Number of DCP Blows

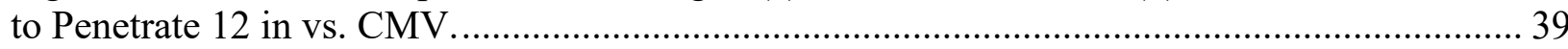


Figure 4.18 - Schematic of Location of Georeferenced LWD and DCP Spot Tests.................. 41

Figure 4.19 - Color-Coded Map Comparison between a) CMV and b) LWD Surface Modulus. 42 Figure 4.20 - Optimized Color-Coded Map Comparison between (a) CMV Using Less-Stiff (Red) Areas when CMV $<75 \%$ of Average of CMVs, and (b) LWD Using Less-Stiff (Red)

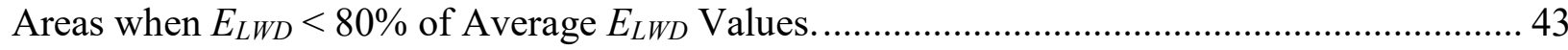

Figure 5.1 - Location of Field Evaluation Site on FM140 in Georgetown, TX. ...................... 44

Figure 5.2 - Pavement Structure of Test Section ............................................................. 45

Figure 5.3 - Schematic of the Typical Test Section and Location of Spot Tests for (a) LimeTreated Subgrade and (b) Flexible Base Layer................................................................... 46 Figure 5.4 - Spatial Distribution of (a) Raw and (b) Rectangular Buffered CMV Data Collected by IC Roller during Proof-Rolling of LTS Layer. ................................................................. 47 Figure 5.5 - Distribution of CMV Data Collected by IC Roller during Proof-Rolling of LTS

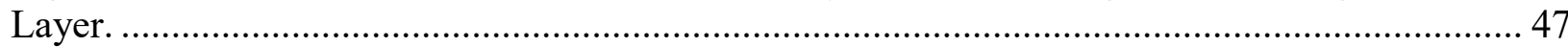

Figure 5.6 - Spatial Distribution of LWD Modulus on LTS Layer........................................ 48

Figure 5.7 - Spatial Distribution of Number of DCP Blows on LTS Layer. ............................ 49

Figure 5.8 - Spatial Distribution of Moisture Content of LTS Layer. ..................................... 50

Figure 5.9 - Relationship between Averaged (a) LWD Modulus and (b) Number of DCP Blows

vs. Average CMV per Station...................................................................................... 50

Figure 5.10 - Spatial Distribution of (a) Raw and (b) Square Buffered CMV Data Collected by

IC Roller during Proof-Rolling of Flexible Base Layer. ................................................... 51

Figure 5.11 - Distribution of CMV Data Collected by IC Roller during Proof-Rolling of Flexible

Base Layer. ............................................................................................................ 51

Figure 5.12 - Spatial Distribution of LWD Modulus of Flexible Base Layer. .......................... 52

Figure 5.13 - Spatial Distribution of Number of DCP Blows of FB Layer. ............................ 53

Figure 5.14 - Spatial Distribution of Moisture Content of Flexible Base Layer....................... 53

Figure 5.15 - Relationship between Averaged (a) LWD Modulus and (b) Number of DCP Blows

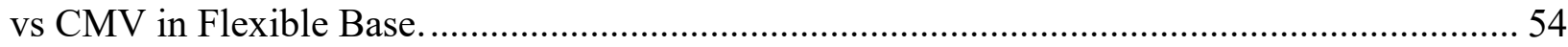

Figure 6.1 - Location of Field Evaluation Site on TX-183 in Irving, TX................................ 56

Figure 6.2 - Pavement Structure of Test Section ................................................................ 57

Figure 6.3 - (a) Schematic of the Test Section, (b) Site View with Grid Overimposed over Test

Section and (c) Satellite View Showing Spot Test Points.................................................... 57

Figure 6.4 - IC Data Points Collected During Proof-Mapping of Subgrade Layer .................... 58

Figure 6.5 - Distribution of CMV Data Collected by IC Roller on top of LTS Layer. ............... 58

Figure 6.6 - Spatial Variation Comparison between (a) CMV and (b) LWD Deflection........... 60

Figure 6.7 - Spatial Variation of Coefficient of Variation of CMV within each Buffered Area. 60 Figure 6.8 - Spatial Variation Comparison between (a) CMV and (b) Number of DCP Blows to Penetrate 18 in. on LTS Layer.

Figure 6.9 - Relationship between Averaged (a) LWD Surface Deflection and (b) Number of

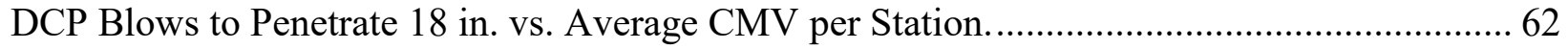

Figure 6.10 - Spatial Distribution of Moisture Content of LTS Layer. .................................... 63 Figure 6.11 - Distribution of CMV Data Collected by IC Roller during Proof-Rolling of Flexible Base Layer. 63

Figure 6.12 - Data Collected by IC Roller on top of Base Divided in Rectangular Buffered Areas.

Figure 6.13 - Spatial Variation Comparison between (a) CMV and (b) LWD....................... 65

Figure 6.14 - Spatial Variation Comparison between (a) CMV and (b) Recreated LWD.......... 65 
Figure 6.15 - Spatial Variation of Coefficient of Variation of CMVs within each Buffered Area

Figure 6.16 - Relationship between Averaged LWD Surface Deflection and vs. Average CMV per Station.

Figure 6.17 - Spatial Distribution of Moisture Content of FB Layer. 66

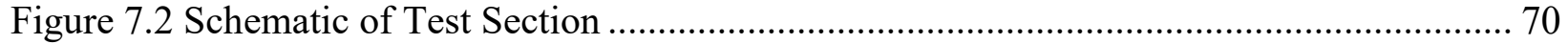

Figure 7.3 - Distribution of CMV Collected by IC Roller during Proof-Rolling of CTB Layer.. 71

Figure 7.4 - Spatial Variation Comparison between a) CMV and b) LWD................................. 72

Figure 7.5 - Relationship between Averaged LWD Modulus vs CMV ..................................... 72

Figure 7.6 - Spatial Variation of Coefficient of Variation of CMV within each Buffered Area. 73

Figure 7.7 - Spatial Variation Comparison between a) LWD and b) FWD................................ 74

Figure 8.1 - Relationship between CMV and Deflections Measured from LWD Mass Drops in

Lime-Treated Subgrade Materials ...................................................................................... 76

Figure 8.2 - Relationship between CMV and Deflections Measured from LWD Mass Drops in

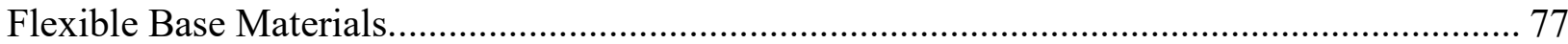

Figure 8.3 - Relationship between CMV and Number of DCP Blows to Penetrate the Indicated Depth in Lime Treated Subgrades. .................................................................................... 78

Figure 8.4 - Relationship between CMV and Dynamic Cone Penetration Index (DCPI) in

Flexible Base Materials..................................................................................................... 79

Figure 8.5 - Relationship between CMV and LWD Mass Drop Deflection per Station in Lime Treated Subgrade Materials. .................................................................................................... 80

Figure 8.6 - Relationship between CMV and No. of DCP Blows per Station in Lime Treated

Subgrade Materials. ..................................................................................................... 81

Figure 8.8 - Color-Coded Map Comparison between (a) CMV, (b) LWD Deflection and (c)

Number of DCP Blows to Penetrate 24 in. at Site 1 Subgrade................................................. 83

Figure 8.9 - Optimized Color-Coded Map Comparison between (a) CMV, (b) LWD Mass Drop Deflection and (c) Number of DCP Blows to Penetrate 24 in. as Obtained in Lime-Treated

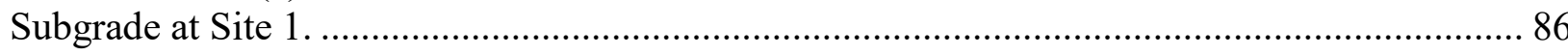




\section{Chapter 1: Introduction}

\subsection{Problem Statement}

The modulus of geomaterials is one of the main design parameters used in modern mechanistic-empirical pavement design guidelines. The mechanical properties of compacted geomaterial layers can be estimated either from laboratory or from in-situ test methods. Among the field methods, the Falling Weight Deflectometer (FWD), Plate Load Test (PLT) and Dynamic Cone Penetrometer (DCP) stand out. Along with laboratory test methods, deflection-based in-situ test methods have been under continuous improvement. The Light-Weight Deflectometer (LWD), a portable spot-testing device based on similar principles to the FWD, has gained popularity over the past years due to its low cost, portability and ease of setup compared to the more time consuming PLT.

A move toward a deflection- and/or modulus-based quality management through nondestructive testing (NDT) has been under continuous development during the past decades. Technological improvement of construction technologies has resulted in the rise of the Intelligent Compaction (IC) technology - a vibratory roller-based technology — that provides continuous evaluation of compaction. The application of the IC in the construction of transportation infrastructure as a more rigorous quality management procedure has attracted the attention of a number of highway agencies and departments of transportation (DOTs).

A number of researchers have been involved in studying the correlation between Intelligent Compaction Measurement Values (ICMV) and in situ modulus with mixed success as documented in White et al. (2005), White et al. (2006), Hossain et al. (2006), and Mooney et al. (2006). Since it is impractical to estimate the exact position of the roller (due to its size), it is virtually impossible 
to estimate ICMV at a specific point so that it can be related to in situ modulus-based measurements. This thesis proposes an approach for comparing ICMV and the spot test moduli obtained with LWD and DCP, using data collected at different test sites. This approach provides a basis for utilizing IC measurements in quality control operations. In order to establish a method to compare the in-situ measurements with those of IC, a fixed interval analysis for ICMVs based on the size of area for contractor's rework is proposed.

\subsection{Organization OF THESIS}

This thesis is organized in nine chapters. The current introductory chapter describes the problem statement of previous compaction methods and the primary objective of this thesis. Chapter 2 presents a literature review of the intelligent compaction technology, the definition of IC measurement values, and the different nondestructive spot tests performed during the sites data collection. Chapter 3 summarizes the process of data collection during the implementation of IC in test sites. It also includes the selection of test sections, spots tests, and geospatial analysis

processes. Chapters 4 through 7 describe a detailed summary of activities, test results, and correlations obtained in test sites which consist of different pavement layers. Chapter 8 compiles a series of relationships found between the modulus-based point measurements and ICMV in all sites for all different pavement layers. Chapter 9 contains a summary of the thesis, conclusions and recommendations for future work. 


\section{Chapter 2: Literature Review}

\section{$2.1 \quad$ INTRODUCTION}

The estimation of soil properties during and after compaction via integrated vibratory measurement systems onboard roller compactors is gaining acceptance in the U.S. earth work and design and construction community. Intelligent Compaction is an emerging technology for monitoring the compaction process for HMA, base and soil layers and for managing the compaction data to improve the quality of compacted layers and to avoid under/over compaction. The advantages of intelligent compaction are reported as (Mooney et al. 2010, White and Vennapusa 2010):

- Improved quality and uniformity of compaction

- Reduced over/under compaction

- Identification of soft or weak spots

The following section contains a literature survey of factors affecting properties of compacted geomaterials, IC measurement values (ICMVs) and their definitions, different modulus-based NDE, and ICMV correlations with spot test measurements.

\subsection{Factors Impacting Properties of Compacted Geomaterials}

Mechanistic properties of soil and base materials are used as input parameters for the design and evaluation of pavement structures. The construction quality assessment of compacted geomaterials is traditionally based on the density and moisture content measurements. There is a consensus on the major factors that could affect the properties of geomaterials (Puppala, 2008). These factors generally include, but are not limited to stress state, moisture content (including degree of saturation or suction), and density. 
RReviews of the impact of moisture content on modulus can be found in Richter (2006), Cary and Zapata (2010) and Siekmeier (2011). Typically an increase in moisture content will decrease matric suction, will increase resilient deformation and hence will decrease the modulus. Several recent studies have demonstrated that the difference between the moisture content at compaction and testing impacts the modulus more than the moisture content at the time of compaction (Khoury and Zaman, 2004, Pacheco and Nazarian, 2011).

The impact of density on modulus has not been studied as extensively as the impact of moisture content. A strong correlation between modulus and density has not been observed in many field studies (Mooney et al., 2010; and Von Quintus et al., 2010). Pacheco and Nazarian (2011) attributed the lack of a strong correlation to the complex interaction between the moisture content, density and degree of saturation of a given material.

Texas Department of Transportation (TxDOT) current practice for field compaction quality control and acceptance for soil and base layers is to determine the compacted density and occasionally moisture content by nuclear density gauge (NDG). TxDOT has considered several stiffness-based devices to replace density measurement because stiffness parameters are more relevant to pavement design. Since density is typically measured with spot tests, it cannot represent the quality and uniformity of compaction in a continuous manner. Continuous assessment of mechanistic soil properties (stiffness or modulus) through roller parameters (frequency, amplitude and speed) integrated with global positioning system (defined as Intelligent Compaction) can provide a complete compaction and geographic information. 


\subsection{Intelligent Compaction Measurement Values}

The concept of correlating stiffness of the compacted layer to the excitation frequency (Mooney and Adam, 2007) initiated the use of accelerometers to monitor the compaction process. This idea was further improved and became the basis of measurement for some of the roller vendors. Caterpillar (CAT) uses this concept as Compaction Meter Value (CMV) while HAMM utilizes that as HAMM Measurement Value (HMV). These measurement values are defined as (Mooney et al, 2010):

$$
C M V=300 \times\left(\frac{A_{4}}{A_{2}}\right)
$$

where $A_{2}$ is the acceleration of the forcing component of the vibration and $A 4$ is the acceleration of the first harmonic of the vibration. As indicated in Figure 2.1, the CMV only takes the forcing frequency and first harmonic into account. However, if the compacted layer becomes stiffer, the other harmonics (A1 through A6 in Figure 2.2) could also be identified during the compaction process.

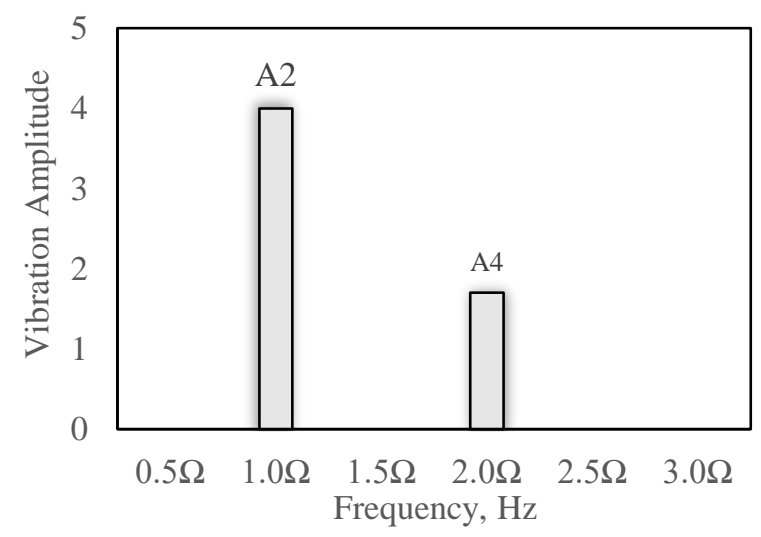

Figure 2.1 - Forcing frequency and vibration harmonics for a soft layer (Nazarian et al, 2015) 


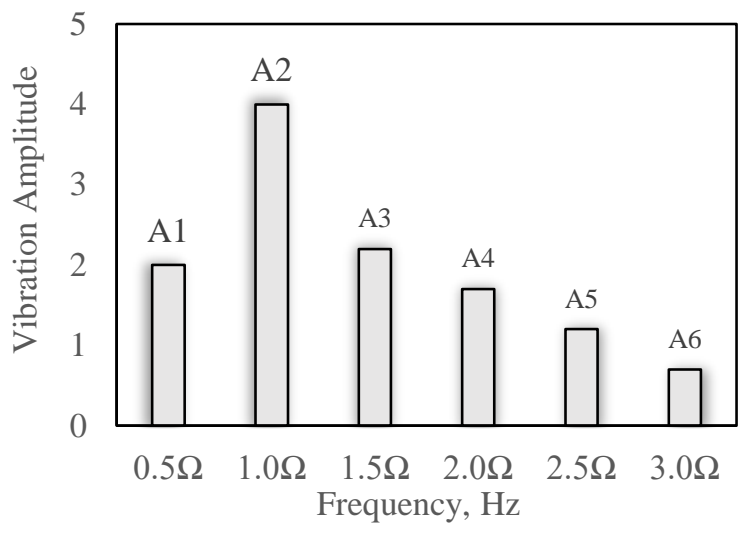

Figure 2.2 - Forcing frequency and vibration harmonics for a stiff layer (Nazarian et al, 2015)

The SAKAI Compaction Control Value (CCV) utilizes the following equation to estimate the layer stiffness:

$$
C C V=100 \times\left[\frac{A_{1}+A_{3}+A_{4}+A_{5}+A_{6}}{A_{1}+A_{2}}\right]
$$

Assuming that the rotational frequency of the forcing mode of the vibration is $\Omega$, parameters $A_{l}$ through $A_{6}$ in Equation 2.2 represent the acceleration of vibration at $0.5 \Omega, \Omega, 1.5 \Omega, 2 \Omega, 2.5 \Omega$ and $3 \Omega$, respectively.

\subsection{Modulus AND DeFlection-BASEd DeVices}

Among the most common portable modulus-based devices available in the market, the Dynamic Cone Penetrometer (DCP), Electro-Mechanical Stiffness Device (Geogauge), Lightweight Deflectometer (LWD), Falling Weight Deflectometer (FWD), Plate Bearing Test, and Portable Seismic Property Analyzer (PSPA) stand out. Table 2.1 compares the costs, speed and ease of use of the more portable devices. Many DOTs have moved away from the Plate Bearing Test because of the time necessary to perform the test and the popularity of FWD. On the other hand, the logistics of the statewide implementation of the FWD may be problematic. For this 
reason, the use of faster and more portable devices is on the rise. For instance, LWDs work on the same principles at a small fraction of the FWD cost.

Table 2.1 - Comparison of Tools for Measuring Modulus

\begin{tabular}{||c|c|c|c|c||}
\hline Device & DCP & Geogauge & LWD & PSPA \\
\hline Parameter Reported & Penetration Rate & Modulus & $\begin{array}{c}\text { Deflection/ } \\
\text { Modulus }\end{array}$ & Modulus \\
\hline $\begin{array}{c}\text { ASTM Standard } \\
\begin{array}{c}\text { Expertise needed for data } \\
\text { collection and } \\
\text { interpretation }\end{array}\end{array}$ & D-6951 & D-6758 & E-2583 & None \\
\hline User-friendliness & Easy & Moderate & Moderate & $\begin{array}{c}\text { more than other } \\
\text { devices }\end{array}$ \\
\hline Speed & 10 minutes & 2 minutes & 2 minutes & Easy \\
\hline Initial Costs & $\$ 3,000$ & $\$ 6,000$ & $\$ 15,000$ & seconds \\
\hline \hline
\end{tabular}

The Dynamic Cone Penetrometer (DCP) test, shown in Figure 2.3, involves driving a cone shaped probe into the soil using a dynamic load and measuring the advancement of the device for each applied blow or interval of blows. The depth of penetration is directly impacted by the drop height of the weight, cone size, and cone shape. Also, the resistance to penetration is dependent on the strength of the material. The strength, in turn, is dependent on density, moisture, and material type of the layer evaluated. Detailed documentation of the history and applications of the DCP is provided by Amini (2003). They also summarized relationships of DCP penetration rate with CBR, resilient modulus and strength. Chen et al. (2001) indicated that the DCP was useful for determining the layer thickness, and could be a useful tool when the FWD backcalculated moduli were not accurate. Correlations of measurements with the DCP to other devices, such as LWD and FWD were studied by Siekmeier et al. (1999), Abu-Farsakh et al. (2005) and Von Quintus et al. (2009). The latter also found DCP was successful in locating areas with anomalies at an acceptable rate and the results were more dependent on aggregate sizes than other NDT devices. 

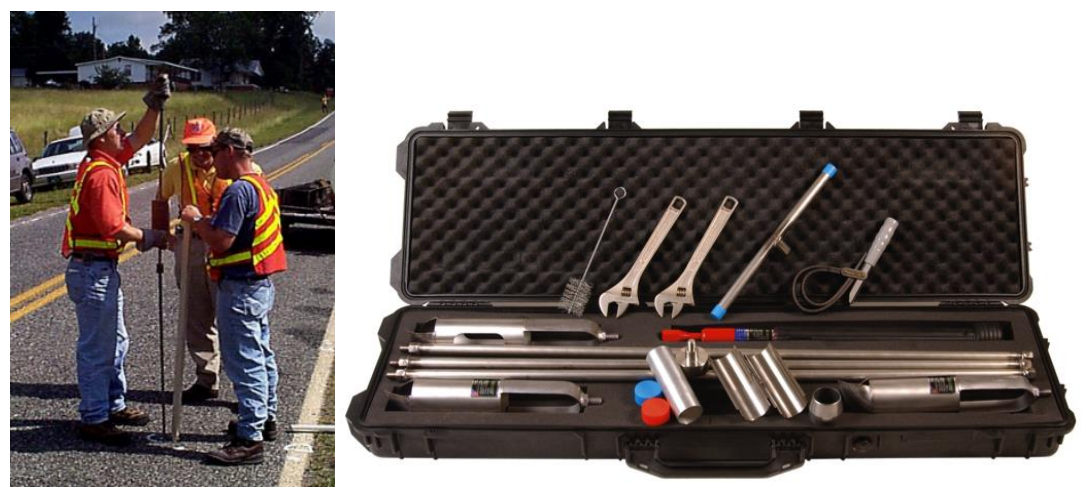

Figure 2.3 - Dynamic Cone Penetrometer (DCP) test

The Light Weight Deflectometer (LWD), shown in Figure 2.4, is a portable Falling Weight Deflectometer (PFWD) that has been developed as an alternative in-situ testing device to the plate load test. Generally, the LWD consists of a loading device that produces a defined load pulse, a loading plate, one center displacement sensor (and up to two optional additional sensors) to measure the center deflection or a deflection bowl. Similar to FWD, the LWD determines the stiffness of pavement system by measuring the material's response under the impact of a load with a known magnitude and dropped from a known height. Its potential use of the LWD as a quality control/quality assessment device for testing subgrades, base courses, and compacted soil layers has been assessed by Alshibli et al. (2005) and Fleming et al. (2007). Both studies concluded that the device was a useful and versatile field quality control and pavement investigation tool if an understanding of the device issues was considered by the data users. Yet Petersen et al. (2007) found that the equivalent predicted moduli from laboratory resilient modulus tests did not correlate with the in-situ stiffness moduli. Vennapusa and White (2009) evaluated key features of 8 commonly used LWD devices and found that LWD moduli are affected by the size of loading plate, plate contact stresses, type and location of deflection sensor; plate rigidity, loading rate, and buffer stiffness. Tirado et al. (2015) using finite element modeling showed the variation of results 
are related to the design of the devices. Vennapusa and White (2009) also compiled extensive relationships between the different LWD devices and other spot test devices.
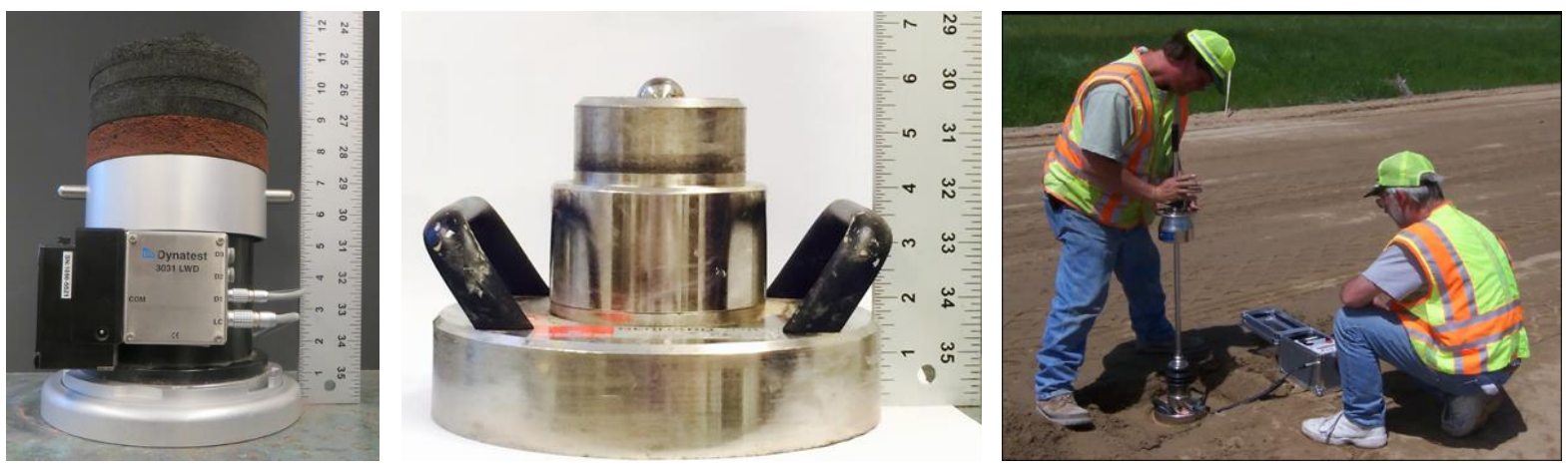

Figure 2.4 - Light-Weight Deflectometer (LWD)

Falling Weight Deflectometer (FWD) is a nondestructive field test to assess the material properties under simulated traffic loads when performed on top of the finished pavement. The FWD measures the pavement deflection at seven points (with $12 \mathrm{in.} \mathrm{interval)} \mathrm{for} \mathrm{a} \mathrm{given} \mathrm{load.} \mathrm{The}$ pavement layer parameters, FWD load and measured deflections are used to backcalculate the modulus of each pavement layer.

Plate Load Test (PLT) is a field test for determining the ultimate bearing capacity of soil and the likely settlement under a given load. The Plate Load Test consists of loading a steel plate placed at the foundation level and recording the settlements corresponding to each load increment.

\subsection{ICMV CORRelations With Modulus ANd DEFlection-BaSEd DeViceS}

Many research efforts have been focused on investigating the relationships between ICMVs and in situ mudulus. Barman et al. (2016) assessed the Intelligent Compaction Analyzer (ICA) for quality control and quality improvement during compaction of stabilized subgrade. The study showed that ICA correlated moderately well with the subgrade modulus backcalculated from 
FWD $\left(\mathrm{R}^{2}=0.63\right)$, fairly with the DCP test results $\left(\mathrm{R}^{2}=0.50\right)$ and remarkably well with the in situ subgrade resilient modulus $\left(\mathrm{R}^{2}=0.72\right.$ to 0.97$)$.

White and Thompson (2008) investigated the correlation between ICMVs and in situ measurements of dry unit weight, DCP index and LWD modulus in granular materials. After statistical averaging for the entire test strip to reduce measurement variability, the authors obtained relationships between coefficients of variation for CMV and in situ test measurements. They indicated that the CMV coefficients of variation are similar to DCP and LWD compaction test data.

Mooney et al. (2010) evaluated different IC soil compaction systems, and correlated in situ spot moduli to ICMVs measured on a granular base material. The authors were able to obtain good regression relationships between the spatially nearest point roller ICMVs and DCP results, while poor correlations were obtained with the LWD moduli. They noticed that in situ point measurements might not correlate well with ICMVs when nonuniform subsurface conditions are evident at depths greater than the influence depth of the point measurements.

White et al. (2011) examined the factors influencing ICMV correlations with the spot test measurements. Some of those factors were the heterogeneity in underlying layer, moisture content variation, narrow range of measurements, machine operation setting variation and nonuniform drum/soil contact conditions. As part of their study for developing a modulus-based construction specification for compaction of earthwork and unbound aggregates, Nazarian et al. (2014) did not find a strong correlation between ICMV and in situ moisture content as measured by the Nuclear Density Gauge (NDG). Based on the data from the same study, Siddagangaiah et al. (2013) also did not find a strong correlation between ICMV and in-situ spot measurements. They indicated that the measurements with different devices were either sensitive to variation in material 
properties such as moisture content and density and that the difference in depth of influence and the variation in underlying support reduced the strength of the relationships.

The development of empirical correlations between LWD modulus and ICMV were taken into consideration in different studies (Rahman et al.; 2012; Cai et al., 2017). They demonstrated the potential benefits of IC technology in identifying less stiff areas, and the sensitivity of the roller measurements to moisture content variation. 


\section{Chapter 3: Data Collection}

This chapter summarizes the procedures employed at different test sites to collect IC and NDT data, and also describes the geospatial analysis of data to identify less-stiff areas in each test section.

\subsection{IC Data Collection Process}

The field test protocol performed by the research team at each test bed for each layer is summarized in the following steps:

1. Identify test strip. The research team coordinated with a contractor to identify a 250 $\mathrm{ft}$ (minimum) to $500 \mathrm{ft}$ (maximum) long, full width test strip. An example of a test section is shown in Figure 3.1a.

2. Set up GPS. The research team set up a GPS base station as shown in Figure 3.1b.

3. Set up IC roller. The research team coordinated with the contractor to setup the IC roller for proper data collection. This included verification of operating frequency, speed and amplitude. Compactor was instrumented with UTEP developed data acquisition system (DAQ). A picture of an instrumented roller can be seen in Figure 3.1c.

4. Carry out construction as normally done. The research team observed the construction and compaction of test section but did not interfere with the operation. Shortly after compaction the following steps were performed at a time that was least disruptive to the contractor. 


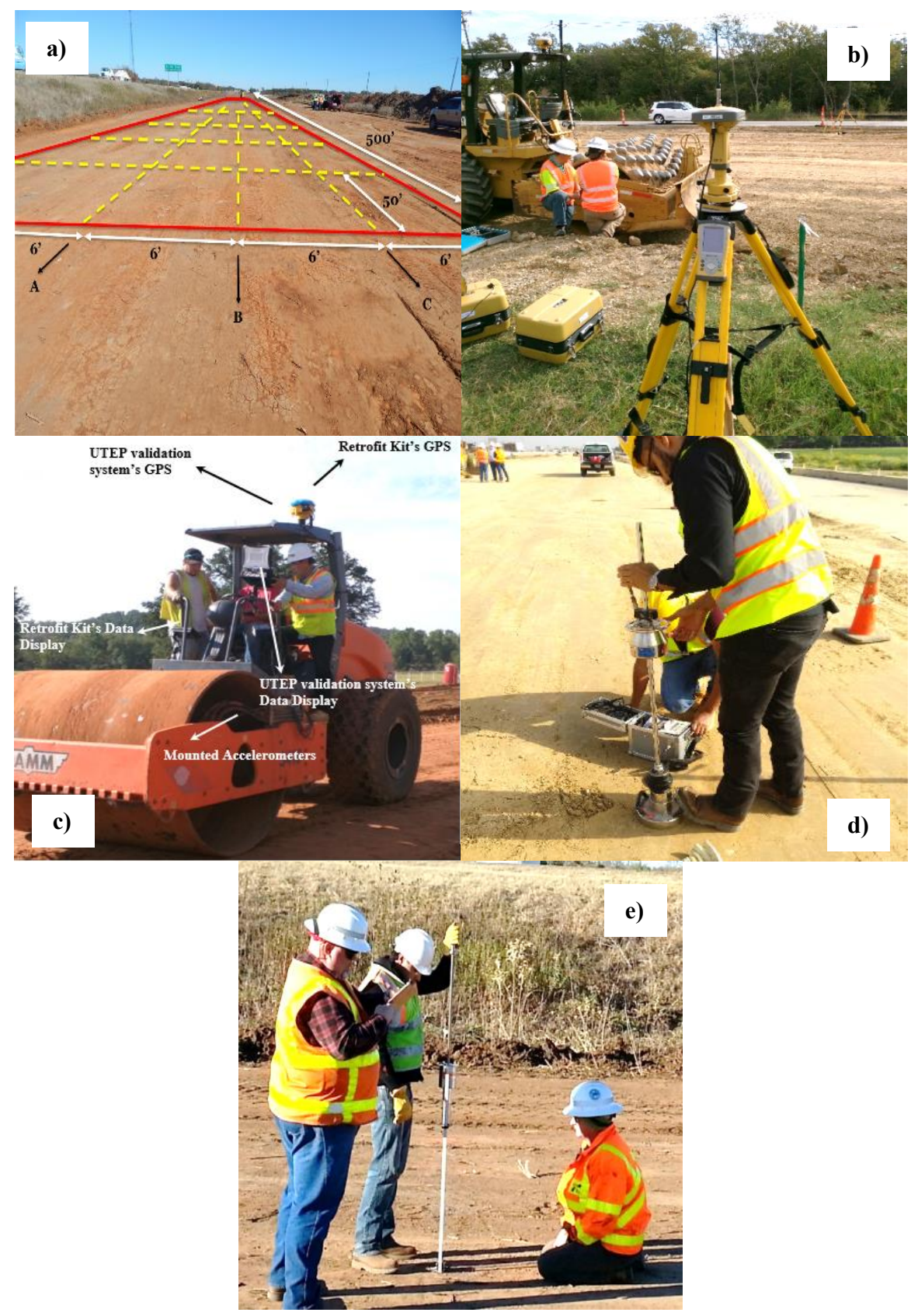

Figure 3.1: Data Collection Steps a) Test Section Selection b) GPS Set-Up c) Roller Instrumentation d) LWD Field Testing e) DCP Field Testing

5. Identify spot test locations. Using the test section layout, the research team identified about 44 locations for NDT spot test arranged as grid consisting of four rows along the full width, each consisting of 11 points. Each row was located at the below the coverage of each roller pass. All rows were equally spaced, adjusted to 
meet the full width of the site. The selected number of spot test was used to establish the variability in the measurements.

6. Proof-map test strip. The research team and contractor personnel proof-mapped the compacted subgrade with IC roller or instrumented roller after compaction. Test section was proof-mapped using one forward pass of the IC roller shortly after compaction.

7. Perform modulus-based NDT field tests. NDT field tests were performed by the research team using modulus-based NDT devices (i.e., LWD as shown in Figure 3.1d. and DCP as shown in Figure 3.1e), on prepared subgrade after proofmapping.

8. Perform in-situ moisture measurements. Contractor performed nuclear density gauge (NDG) testing on the underlying layer.

9. Retrieve samples for determination of moisture in the laboratory. The research team collected samples for further laboratory testing to validate NDG moisture results.

10. Prepare and compact the base layer. The contractor carried out construction of base layer. The research team did not interfere with the operation.

11. Proof-map the completed base with an IC roller after compaction. After setup of GPS and IC roller (Steps 2 through 3) by the research team in coordination with the contractor, the proof-mapping of the test section was performed where prior evaluation of the subgrade had carried out. 
12. Perform modulus-based NDT field tests. NDT field tests were performed by the research team using LWD and when available FWD, on prepared base after proofmapping.

13. Perform in-situ moisture measurements. Contractor or TxDOT personnel performed NDG testing on the underlying layer.

14. Retrieve samples for determination of moisture in the laboratory. The research team collected samples for further laboratory testing to validate NDG moisture results.

\subsection{IC DATA COLLECTION}

At each construction site, the contractor's routine compaction process was followed by a proof mapping. The goal of the proof mapping, also known as final coverage, was to evaluate the compaction uniformity through the identification of less stiff spots and to ensure the complete coverage of the compacted section. A map with IC data, in the generic form of Intelligent Compaction Measurement Values (ICMV), is rendered by vibratory compactors with IC technology. However, the research team had foreseen that IC rollers may not be readily available in construction sites. For that reason, a data acquisition system (DAQ) developed at UTEP was used to collect vibration data and ground response during IC operations. The system consisted of two accelerometers that were mounted on the roller (drum), a data acquisition box, a real time kinematic (RTK) GPS antenna and receiver, a power supply and a laptop computer to monitor the data collection process. Instrumentation of IC rollers is illustrated in Figure 3.2. 

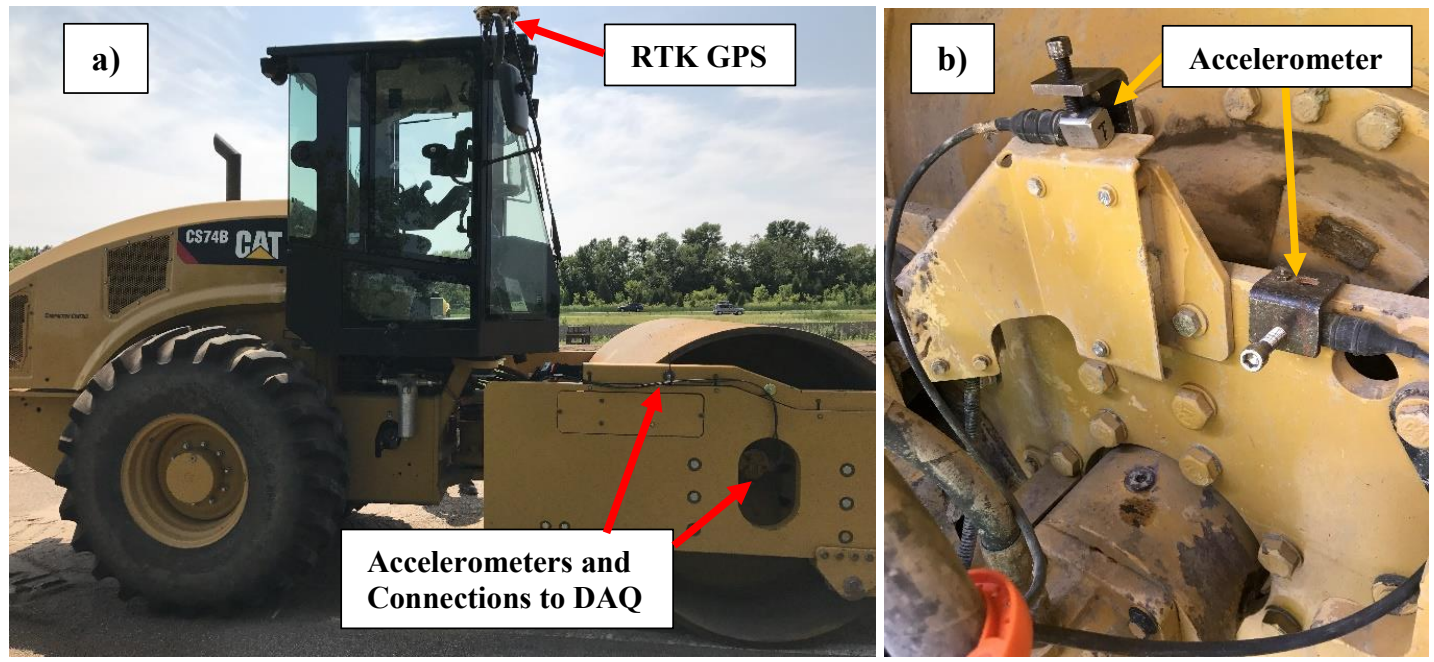

Figure 3.2 - Field Site Instrumentation of Roller Compactor: (a) RTK GPS and Wiring of Accelerometers to Data Acquisition System and (b) Installation of both Accelerometers to Measure Vertical and Horizontal Vibration on Roller Compactor Drum Frame.

Geo-statistical and geospatial data analysis techniques were employed to visualize and interpret the IC data by means of color-coded maps. These maps display the geo-referenced or spatial data on a map in which each class is separated by different colors. In this study, three colors, green, yellow and red, were used for creating a color-coded map. The goal of using the ICMV color-coded maps was to identify the less stiff areas (usually marked as red spots) throughout the construction area.

Figure 3.3 shows a map of the IC data points where ICMVs were obtained by the UTEP DAQ system during the mapping of in a section on State Highway 183 in Irving, Texas. Four passes, in both forward and reverse directions of the roller, are discernible. Each line, i.e. roller pass, is comprised by a series of points representing a GPS location where an ICMV reading is recorded. The UTEP DAQ system records five ICMV readings per second. For a roller speed of 3 mph, ICMVs are recorded at a rate of about $0.9 \mathrm{fps}$. 


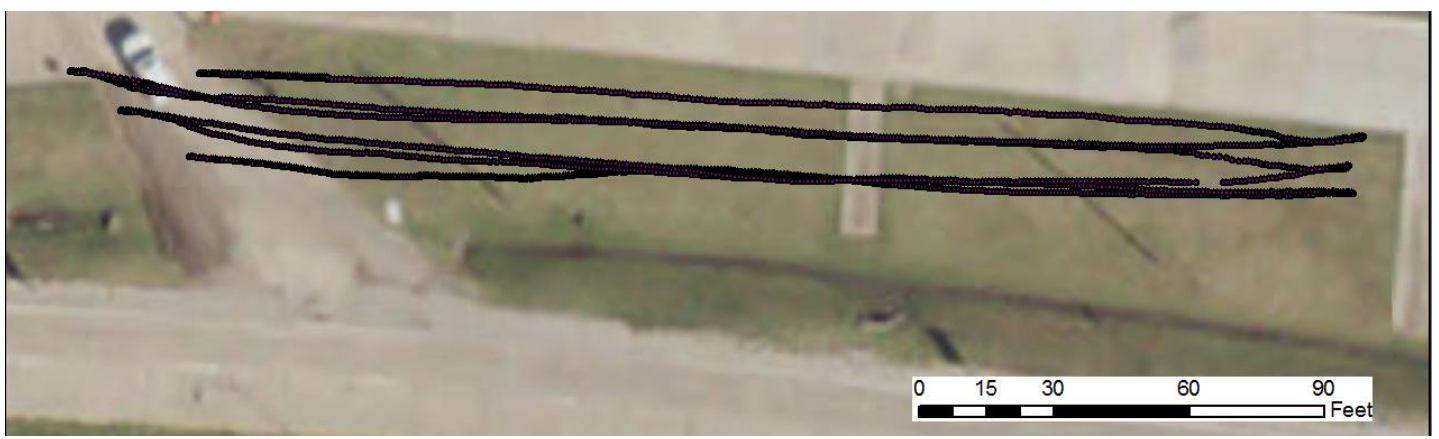

Figure 3.3 - IC Data Points Collected During Mapping of a Test Layer (SH 183 in Irving).

\subsection{In-Situ Spot Tests Procedure}

Figure 3.4 illustrates the schematic of a typical test section and spot test grid. The research team usually marked 44 test points for spot testing.

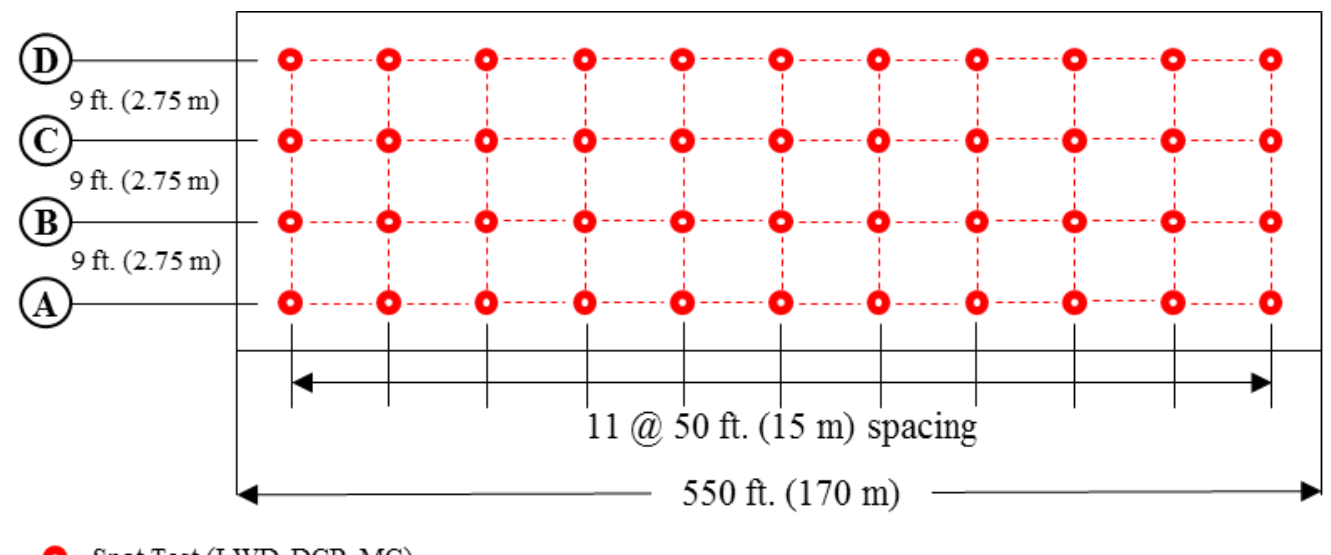

- Spot Test (LWD, DCP, MC)

Figure 3.4 - Schematic of a Typical Test Section and Locations of Spot Tests.

\subsection{Determining TARget Field VALUES}

For a robust modulus verification process, the target field values should be set in conjunction with establishing the design moduli, with consideration of the moisture content at the time of compaction and the state of stress imparted by the testing technology to the geomaterial layer. The target value should be the deflection for LWD and/or the rate of penetration for DCP. Most of the deflection-based devices measure the stiffness of the pavement system, and the 
reported modulus is based on an elastic-half space Boussinesq theory. This is particularly critical for a multi-layered system being tested with deflection.

Nazarian et al. (2014) developed a multi-layered equivalent-linear algorithm that makes use of an iterative process to consider the nonlinear behavior of the pavement materials using the modified MEPDG constitutive model described by Equation 3.1 to determine LWD target deflection.

$$
M R=k_{1}^{\prime} P_{a}\left[\frac{\theta}{P_{a}}+1\right]^{k_{2}^{\prime}}\left[\frac{\tau_{o c t}}{P_{a}}+1\right]^{k_{3}^{\prime}},
$$

where $\theta=$ bulk stress, $\tau_{o c t}=$ octahedral shear stress, $P_{a}=$ Atmospheric pressure, and $k_{1,2,3}^{\prime}=$ regression constants from laboratory resilient modulus test results.

\subsection{AdJUSTMENT OF LWD EFFECTIVE DEFLECTION}

Moisture variation has been proven over time to affect significantly the responses of unbounded geomaterials. To account the changes in moisture content in the subgrade over the design life of a pavement the model proposed by Witczak et al. (2002) using the enhanced integrated climatic model (EICM) can be incorporated to adjust the effective LWD deflection, $d_{e f f}$, as follows:

$$
d_{\text {adj } M E P D G}=d_{e f f} \times F_{U}
$$

where $F_{U}$ is determined from:

$$
\log F_{U}=\left[a+\frac{b-a}{\left.1+e^{\left[\ln \left(\frac{-b}{a}\right)+k_{m} \times\left(S-S_{\text {opt }}\right)\right.}\right]}\right],
$$

where $a=-0.3123$ for coarse-grained materials and $a=-0.5934$ for fine-grained materials (minimum of $\left.\log F_{U}\right), b=0.3010$ for coarse-grained materials and $b=0.3979$ for fine-grained materials (maximum of $\left.\log F_{U}\right), k_{m}=$ regression parameter $(6.8157$ and 6.1324 for coarse and fine- 
grained materials, respectively), and $S_{\text {opt }}=$ degree of saturation at optimum moisture content and $S=$ degree of saturation at compaction moisture content, expressed in decimal.

Further development of this model by Cary and Zapata (2010) yielded the following approach where a composite environmental adjustment factor $F_{e n v}$ is calculated. The measured LWD deflection, $d_{e f f}$, can be converted to adjusted deflection, $d_{a d j}$, from

$$
d_{a d j}=d_{e f f} / F_{e n v},
$$

where $F_{e n v}$ is calculated from:

$$
\log F_{e n v}=\left[-0.40535+\frac{1.20693}{\left.1+e^{\left[0.68184+1.33194 \times\left(\frac{S-S_{\text {opt }}}{100}\right)\right.}\right]}\right] .
$$

The degree of saturation of the compacted soil samples was determined using the following equation:

$$
S=\frac{M C}{\left(\frac{G_{s} \cdot \gamma_{w}}{\gamma_{d}}-1\right)},
$$

where $M C$ is moisture content at compaction (\%), $G_{s}$ is specific gravity, $\gamma_{w}$ is unit weight of water and $\gamma_{d}$ is dry unit weight of soil. Moisture content from the soil samples obtained from the spot test locations was obtained from Tex-113-E test procedure. Likewise, the dry density was estimated from the moisture-density (M-D) curve as per Tex-113-E.

\subsection{Geospatial ANalysis of IC Data ANd In-Situ Spot Tests}

The variation of ICMV at a given section is best visualized as color-coded maps. Although the use of more than three colors is common in many geospatial analyses, the use of three colors (i.e. red, yellow and green) is considered practical for ICMV. The ultimate goal of using the ICMV color-coded maps is to identify the less-stiff areas (usually highlighted in red). 
The proper interpretation of the geospatial IC data depends on the optimal selection of the class breaks. Different geospatial classification techniques have been proposed by researchers for this purpose. Brewer and Pickle (2002) evaluated the impact of a few classification methods on the interpretation of the georeferenced data and recommended the Quantile method followed by the Natural Breaks and a modified version of the Equal Intervals method. The Quantile method classifies data by placing equal number of data points in each class, while the Natural Breaks method classifies data based on the maximization of the difference or variance-minimization between the groups of data (Jenks and Caspall, 1971). Mazari et al. (2017) evaluated different classification techniques on the basis of the information theory concept of minimizing the information loss ratio for proposing a technique to find optimal class breaks. However, most available papers have preferred the use of a screening criterion based on a predetermined percentage of the average ICMVs. Figure 3.5 shows the IC color-coded maps obtained from field testing of a subgrade applying the three aforementioned methods. The third approach used the following class breaks:

- $\operatorname{red}($ less-stiff) $<75 \%$ of average of ICMV,

- yellow: 75\% of average ICMV $\leq$ ICMV $<$ average ICMV, and

- green: ICMV $\geq$ average ICMV.

Different classification methods yield different distribution of the identified less-stiff areas.

The current ICMV analysis programs incorporate various processes in order to extrapolate the ICMV data points over the width of the roller prior to generating the color-coded maps. Some of the extrapolation techniques that are used include the Inverse Distance Weighting (IDW), spline and ordinary kriging. The use of these methods enhance the visualization of the data by smoothing the color-coded contours and by filling gaps in information. Unfortunately, ICMV data is affected 

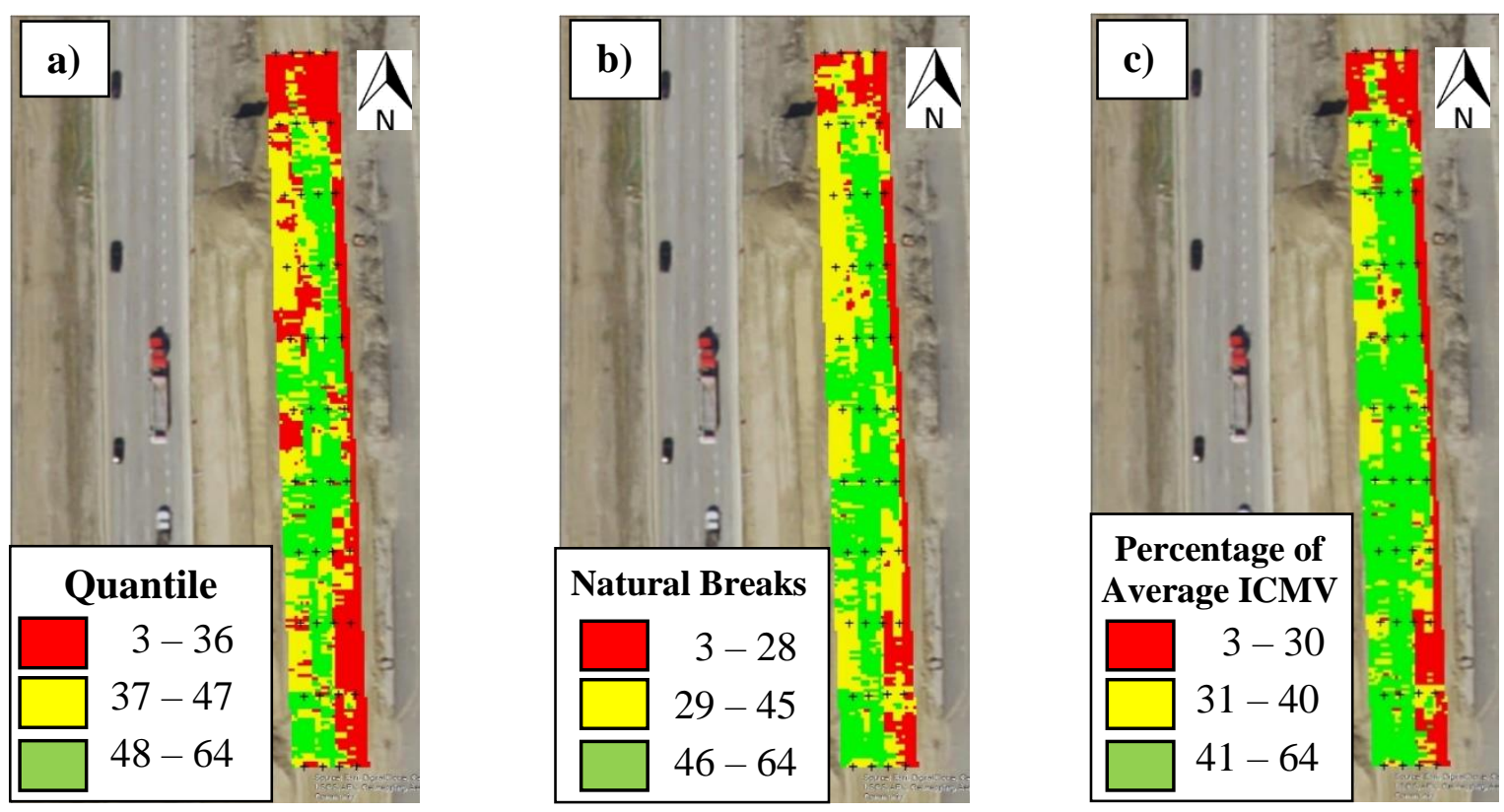

Figure 3.5 - Color-coded Map Depicting IC Data in Terms of CMV on Lime-Treated Subgrade Test Section Using (a) Quantile, (b) Natural Breaks, and (c) Percentage of Average ICMV Data Using Red: ICMV < $75 \%$ of Average ICMV Data and Green: ICMV > Average ICMV.

by the inclusion of these tools, as ICMV outliers can be cropped resulting in reduced ranges of ICMVs. Kriging, for instance, does not pass through any of the point values and causes interpolated values to be greater or less than real values. Spline interpolation does not work well when sample points have extreme differences in magnitude and are close together. As compacted geomaterials may exhibit high spatial variability in their mechanical properties, a different approach that does not need to make use of any interpolation techniques would be desirable.

For this purpose, a rectangular grid was established equal to the width of the roller and the length equal the minimum length of the compacted section that is practical to rework, e.g., $25 \mathrm{ft}$. The schematic of the gridded test section is shown in Figure 3.6. All ICMVs falling inside each rectangular buffered area can be statistically analyzed by means of average or other summary statistics to represent the level of compaction and uniformity of that area. The coefficient of variation of the ICMVs in each grid will represent the variability of the compaction quality. 


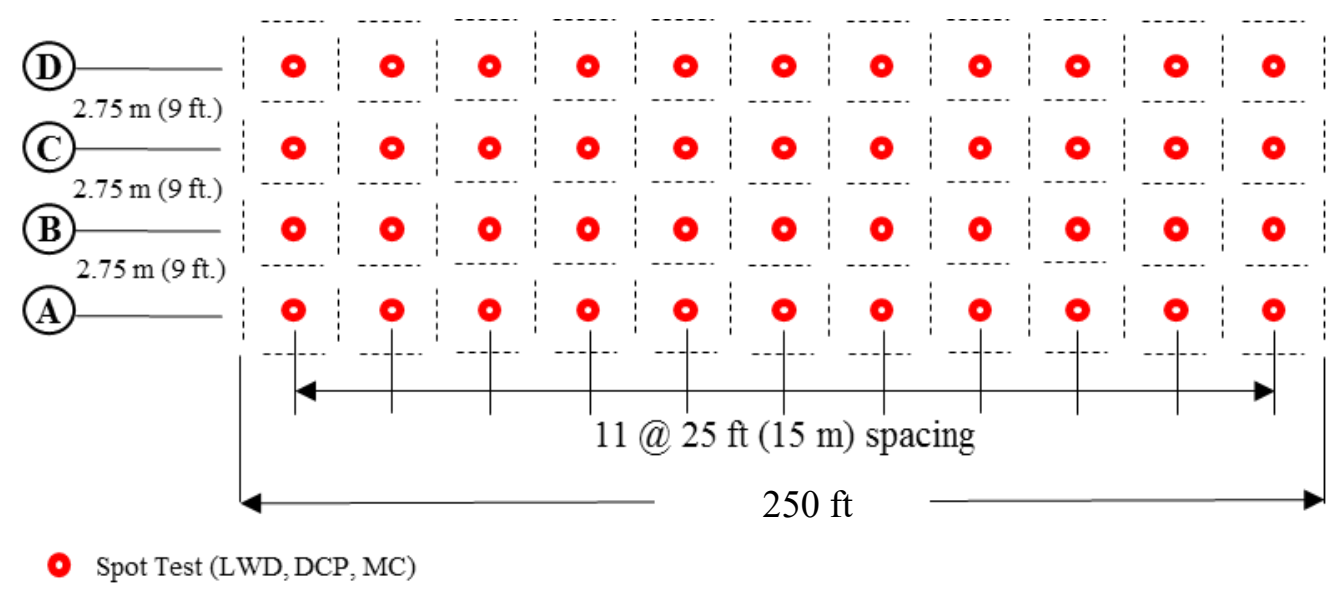

Figure 3.6 - Schematic of test section divided in rectangular buffered areas.

This approach can also be applied to the spot tests to obtain similar color-coded maps by performing modulus-based nondestructive measurements in the vicinity of the center of each rectangular area. This serves the purpose of studying the relationship of the stiffness of the material as measured by these NDT devices with ICMV measurements as obtained after proof-mapping with IC technology.

\subsection{Optimization Process For IdENTIFying Less STIFF AREAS USING IC}

Figure 3.7 provides the result of the process implemented over a lime-treated subgrade (LTS) along IH 35 in Fort Worth, Texas. The $500 \mathrm{ft}$ long and $36 \mathrm{ft}$ wide test section was gridded using $50 \mathrm{ft}$ by $9 \mathrm{ft}$ rectangular buffer areas as shown in Figure 3.6. The criteria shown in Table 3.1 were used to color-code the graphs. Less-stiff areas are identified as those areas with measurements below $75 \%$ the average measurements (being CMV or number of DCP blows). For the particular case of LWD deflection, since larger deflections occur in less-stiff areas, the criterion was reversed, i.e. less-stiff areas are identified when LWD deflections were greater than $125 \%$ of the mean LWD deflections. The IC roller map shows a total of nine cells with CMVs below $75 \%$ of the mean CMV (marked in red). Seven of these nine areas identified by the roller were marked as less-stiff on the LWD color-coded map. The rectangular areas enclosed by a blue border indicate 
the areas identified as less-stiff in the CMV map but not in the LWD deflection map. This indicates that $22 \%$ of less-stiff areas spotted in the CMV map were not in agreement with the less-stiff areas found in the LWD map. The percentage of mis-estimated areas increased to $56 \%$ when CMVs are compared to the number of DCP blows to penetrate 24 in. into the subgrade.

$\mathbf{a}$

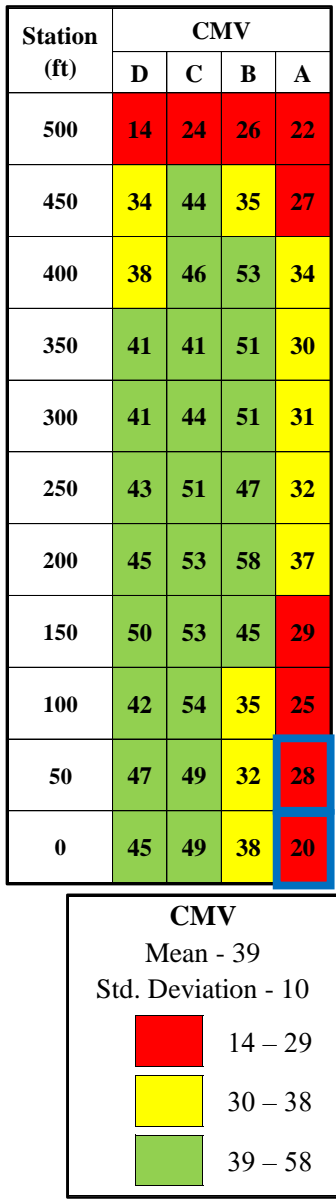

b

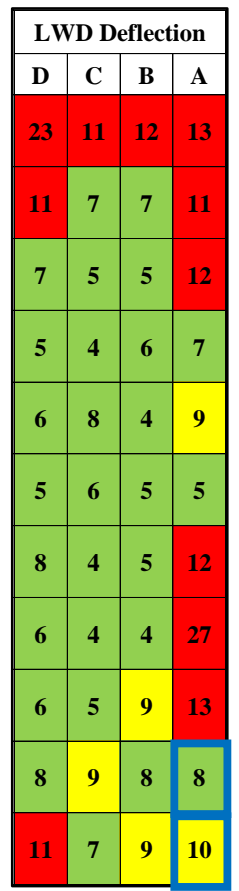

LWD Deflection, mils

Mean - 8

Std. Deviation - 4.5

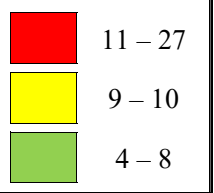

c)

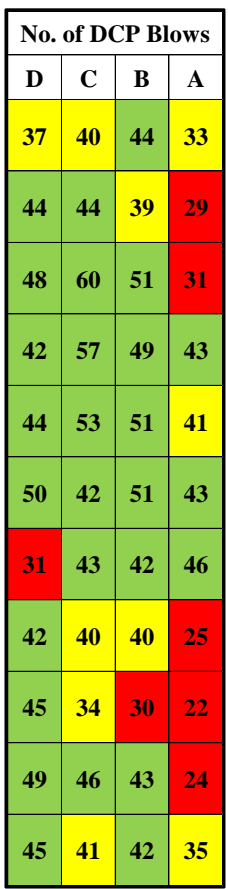

No. of DCP Blows Mean - 42

Std. Deviation - 8

$22-31$

$32-41$

$42-60$

Figure 3.7 - Color-Coded Map Comparison between (a) CMV, (b) LWD Mass Drop Deflection and (c) Number of DCP Blows to Penetrate 24 in. as Obtained in Lime-Treated Subgrade at Site 1.

Table 3.1 - Criterion for Color-Coded Maps.

\begin{tabular}{|c|c|c||}
\hline Color & $\begin{array}{c}\text { Criterion for CMV and } \\
\text { No. of DCP Blows }\end{array}$ & $\begin{array}{c}\text { Criterion for LWD } \\
\text { Deflection }\end{array}$ \\
\hline Red & $<75 \%$ Mean & $>125 \%$ Mean \\
\hline Yellow & $75 \%$ Mean - Mean & Mean $-125 \%$ Mean \\
\hline Green & $>$ Mean & $<$ Mean \\
\hline
\end{tabular}


The color-coding criteria should also consider the number of data points per cell as well as the level of certainty in the reported values. To reduce the percentage of mis-estimated areas, a systematic search for a different coloring criteria for identifying less-stiff areas was carried out. The color-coded criteria optimization approach consisted of varying the class-break for identifying the less-stiff areas for both the CMV and the spot test measurements. This criterion varied within a range defined from $60 \%$ to $90 \%$ of the average measured values, for the ICMV data and the NDT spot test values. In the case of the LWD deflection, as the stiffness trend is reversed, a range between $110 \%$ and $140 \%$ of the average deflection was used for setting the less-stiff class-break.

Table 3.2 shows the percentage of mis-estimated areas in the subgrade of Site 1 when colorcoded maps are generated with different levels. For that particular site, the IC roller was able to predict all less-stiff areas (shaded cells in Table 3.2), when a class-break criteria were set at $70 \%$ of the average CMV (or lower) and at $120 \%$ of the average LWD deflection (or lower).

Table 3.2 - Percentage of Misestimated Roller Measurements (Rectangular Buffered Areas CMVs) with Respect to LWD Measurements Based on Different Percentages of Average Measurements for the Identification of Less-Stiff (Red) Areas

\begin{tabular}{|c|c|c|c|c|c|c|c|c|}
\hline \multirow{2}{*}{\multicolumn{2}{|c|}{$\begin{array}{l}\text { Percentage of IC Roller } \\
\text { Misestimated Areas }\end{array}$}} & \multicolumn{7}{|c|}{ Less-Stiff (Red) Area Above \% of Average LWD Deflection } \\
\hline & & \multirow{2}{*}{$\begin{array}{c}110 \\
41\end{array}$} & \multirow{2}{*}{$\frac{115}{41}$} & \multirow{2}{*}{$\begin{array}{c}\mathbf{1 2 0} \\
41\end{array}$} & \multirow{2}{*}{$\begin{array}{c}\mathbf{1 2 5} \\
47\end{array}$} & \multirow{2}{*}{$\begin{array}{c}\mathbf{1 3 0} \\
47\end{array}$} & \multirow{2}{*}{$\begin{array}{c}\mathbf{1 3 5} \\
53\end{array}$} & \multirow{2}{*}{$\begin{array}{r}140 \\
65 \\
\end{array}$} \\
\hline \multirow{7}{*}{ 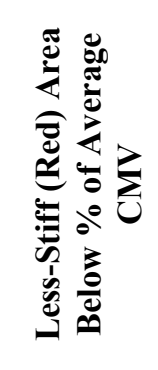 } & 90 & & & & & & & \\
\hline & 85 & 38 & 38 & 38 & 46 & 46 & 54 & 62 \\
\hline & 80 & 27 & 27 & 27 & 36 & 36 & 45 & 55 \\
\hline & 75 & 11 & 11 & 11 & 22 & 22 & 33 & 44 \\
\hline & 70 & 0 & 0 & 0 & 14 & 14 & 29 & 43 \\
\hline & 65 & 0 & 0 & 0 & 17 & 17 & 17 & 33 \\
\hline & 60 & 0 & 0 & 0 & 33 & 33 & 33 & 33 \\
\hline
\end{tabular}




\section{Chapter 4: Evaluation of IC Data in Fort Worth, IH 35 W}

\subsection{INTRODUCTION}

Field evaluation was performed on a north-bound frontage road section along $\mathrm{IH}-35 \mathrm{~W}$ in Fort Worth, Texas, where reconstruction of the road was taking place. Figure 4.1 shows an aerial view alongside a map with the location of the test section.

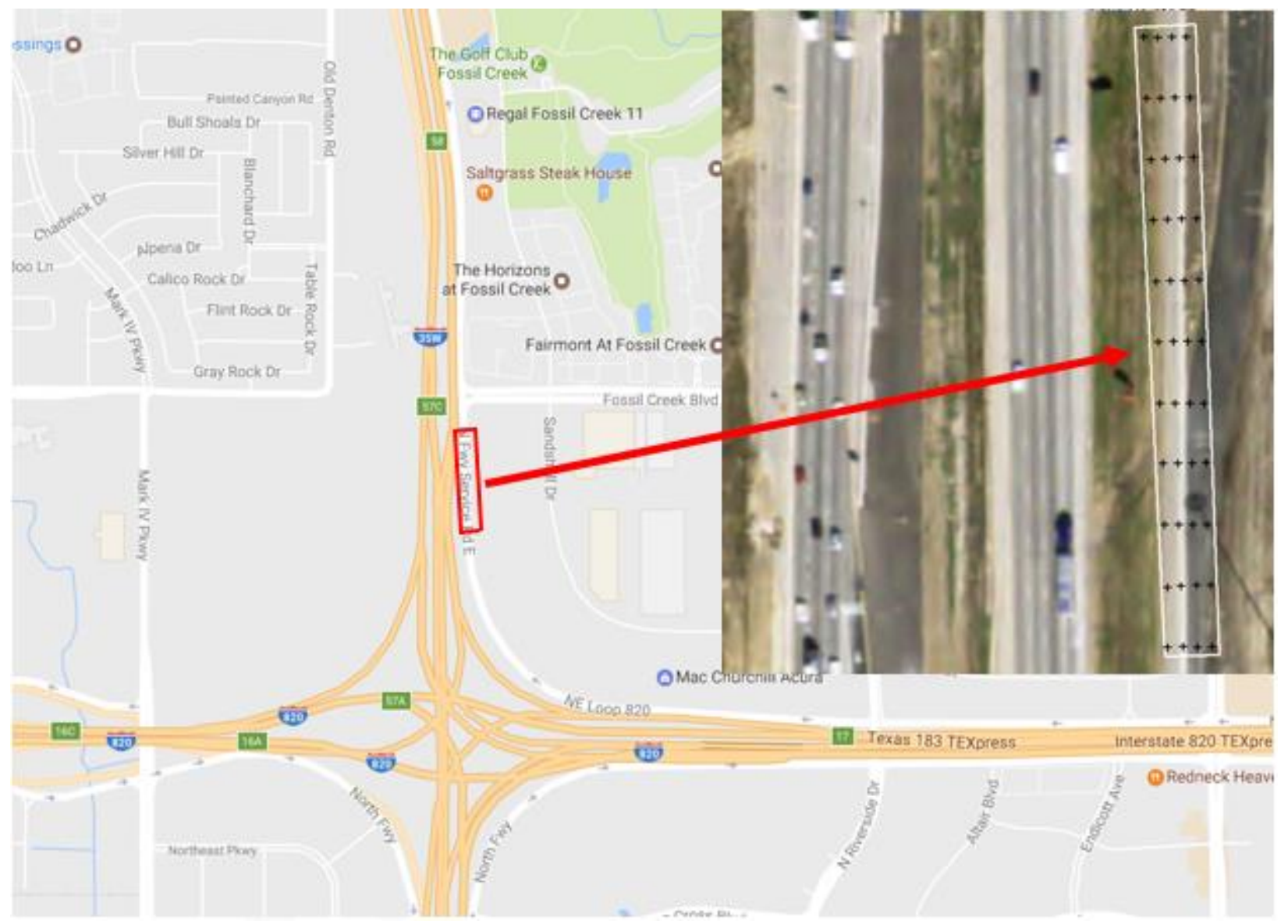

Figure 4.1 - Location of Field Evaluation Site on I-35 in Fort Worth, TX.

Two layers were evaluated for this study as shown in Figure 4.2. The first layer consisted of a lime-treated subgrade (LTS) with a design thickness of 36 in. Field assessment of the LTS by the UTEP team took place on April 14, 2016. The second layer evaluated in this section was a 
Flexible Base with design thickness of 12 in. Field evaluation for the Flexible Base was carried out on May 13, 2016. A figure representative of the pavement structure is shown in Figure 4.2.

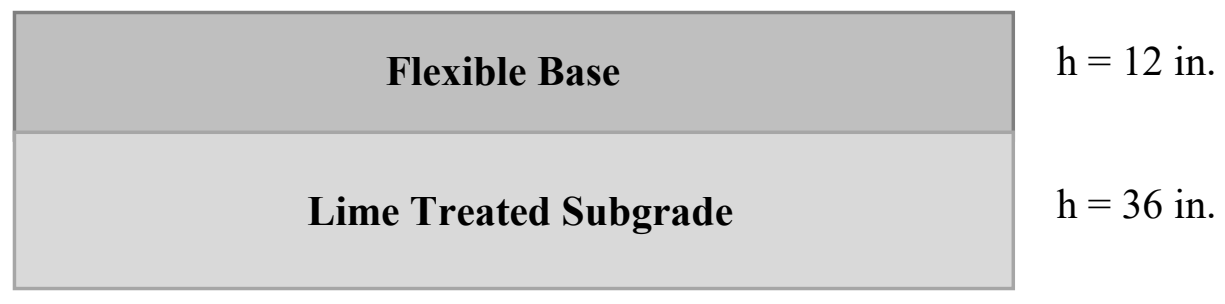

Figure 4.2 - Pavement Structure of Test Section

\subsection{Field Testing Program}

Modulus-based nondestructive spot testing was carried out along a $500 \mathrm{ft}-$ long and $27 \mathrm{ft}$ wide section. For this purpose, a grid of spot tests was arranged on the test section along 4 rows, each row consisting of 11 spot tests, yielding a total of 44 measurements. Rows of spot test measurements follows the paths of the IC roller line passes. The grid was designed to have a spacing of $50 \mathrm{ft}$ between measurements longitudinally, and a spacing of 9-ft between each transverse point as shown in Figure 4.3a. The following tests were performed on the test section:

- Light Weight Deflectometer (LWD). LWD testing was performed on all 44 points on the grid. At each location, two consecutive LWD drops were performed and their surface displacement measurements were averaged. In those cases where the consecutive measurements exceeded $10 \%$ of change in deflection, a third LWD measurement was recorded. In addition to the spot testing on the grid, LWD testing was also performed at 15 spots surrounding each location where the Plate Load Tests were performed. The grid formed by these 15 spots is shown in Figure $4.3 b$. 


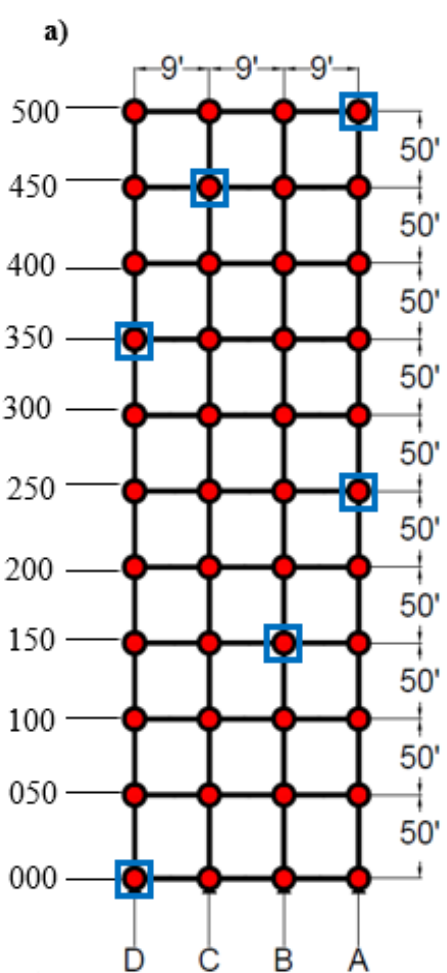

- LWD, DCP, MC

NDG b)

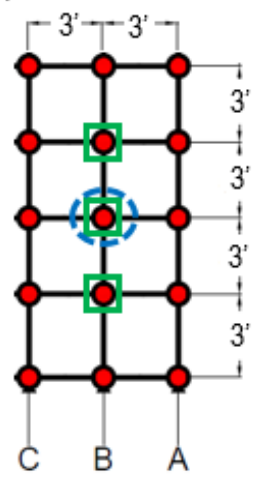

- LWD

$\square$ DCP

() PLT

Figure 4.3 a) Schematic of the Typical Test Section and Location of Spot Tests and b) Diagram of the Testing Area around the PLT Locations.

- Dynamic Cone Penetrometer (DCP). The lime-treated subgrade layer was tested with the DCP in all 44 points of the grid. Similar to LWD, DCP was also performed on three locations adjacent to the spots where the Plate Load Tests were conducted, as shown in Figure 4.3b.

- Nuclear Density Gauge (NDG). NDG readings were obtained from 6 different spots selected by the contractor. The location of these spots are shown in Figure 4.3a.

- Plate Load Test (PLT). PLT was performed at five different spots on top of the subgrade layer. These points were chosen by TxDOT personnel based on the mapping of CMVs, provided by the contractor. The Plate Load Tests locations are shown in Figure 4.4. 
- Moisture Content (MC). Samples of the lime-treated subgrade from 44 gridded points shown in Figure 4.3a were collected to measure their moisture contents.

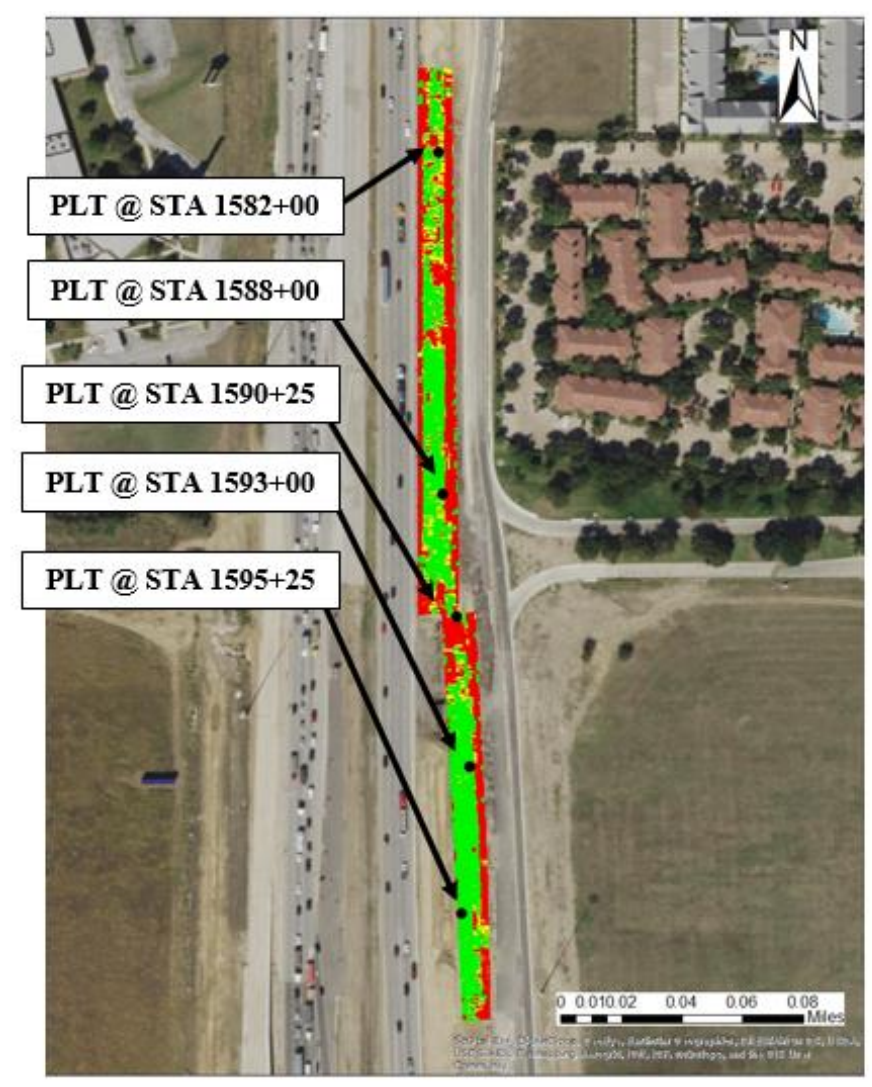

Figure 4.4 - Aerial View of the PLT Locations.

\subsection{LIME-TREATED SUbGRADE}

The lime-treated subgrade layer was mapped using a smooth CAT roller equipped with a Trimble ${ }^{\circledR}$ IC retrofit kit. The first phase of the construction work was involved with stabilizing the subgrade soil using hydrated lime. The spatial distribution of the CMVs collected during the mapping of the LTS layer is shown in Figure 4.5a. Kriging was used to create the extrapolated colored figure with CMV values. Figure 4.5b shows the spatial distribution of averaged buffered CMVs when the entire section was divided into 44 rectangular areas measuring $9 \mathrm{ft} \times 50 \mathrm{ft}$. The location of the less stiff areas on both maps are comparable. The histogram of the mapped CMVs is presented in Figure 4.6. The maximum CMV is around 75 for the spatial distribution of the raw 
data and 58 for the averaged data. The coefficient of variation (COV) of the raw collected CMVs is $49 \%$ for the LTS layer as shown in Figure 4.6.

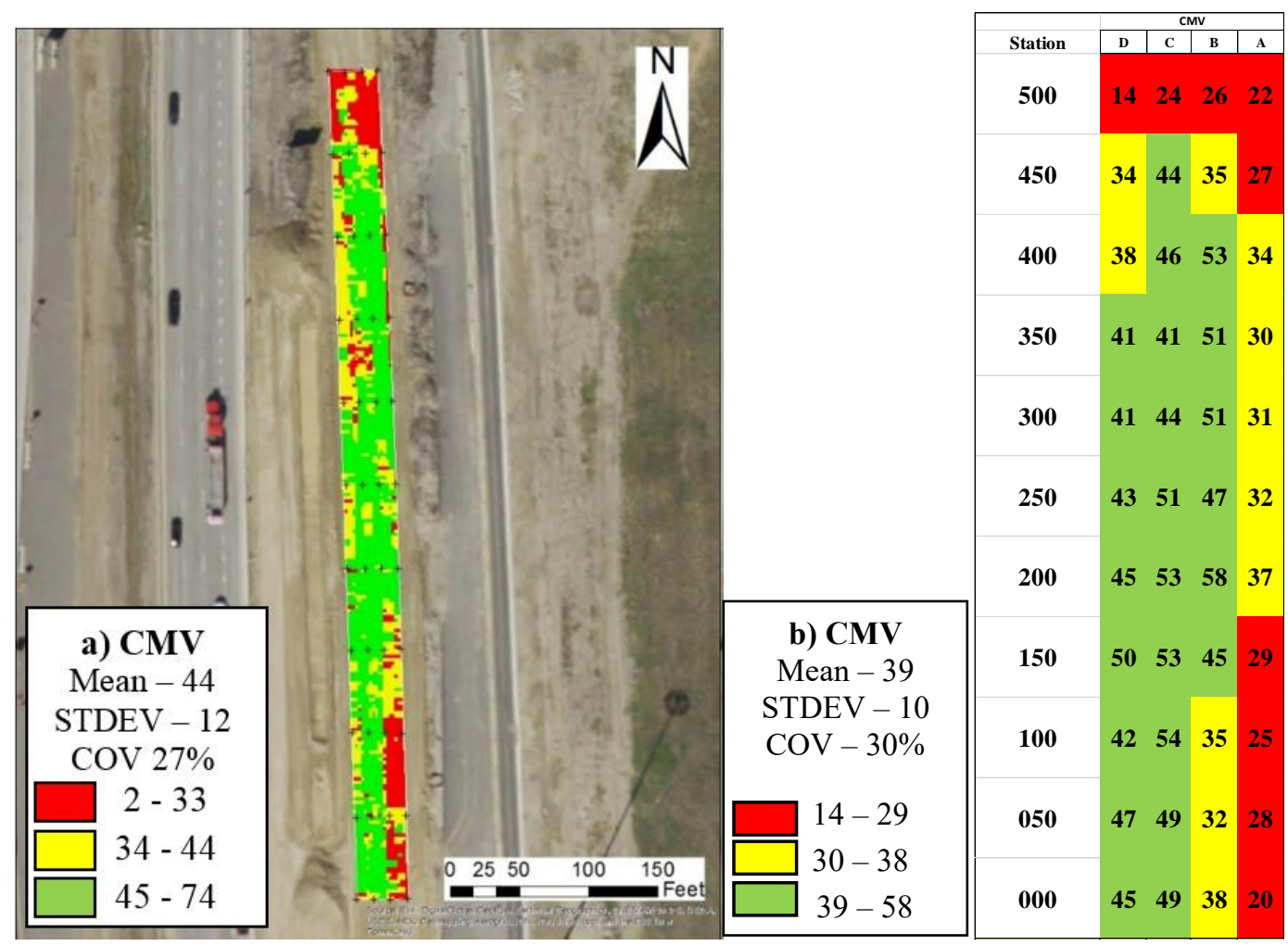

Figure 4.5 - Spatial Distribution of (a) Raw and (b) Rectangular Buffered CMV Data Collected by IC Roller during Proof-Rolling of LTS Layer.

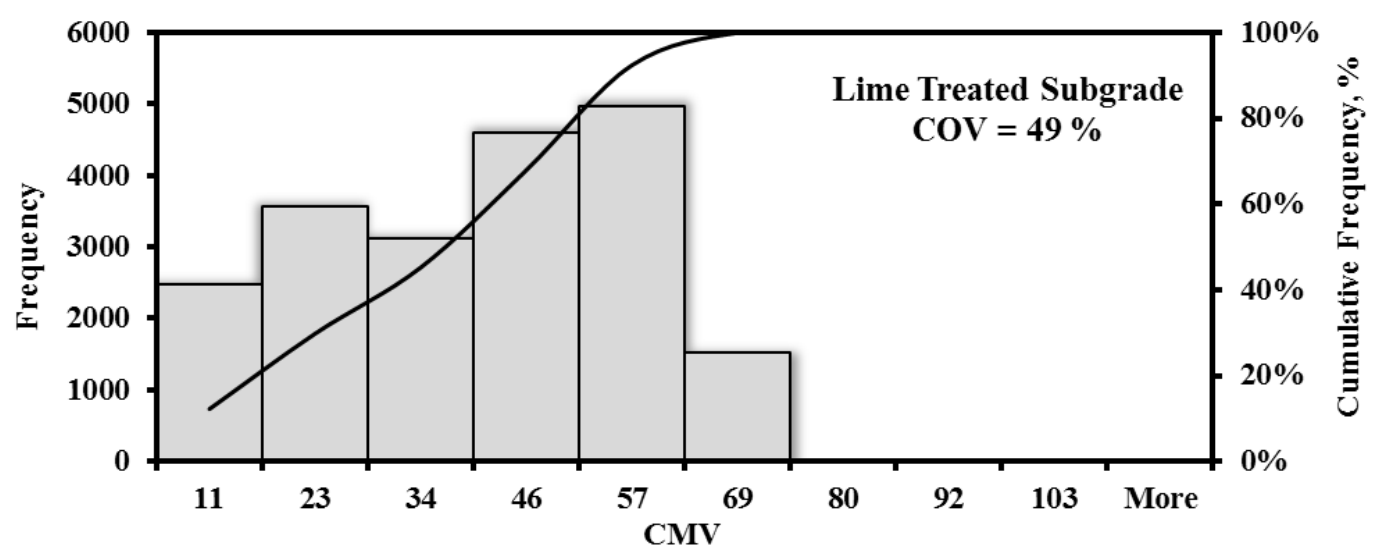

Figure 4.6 - Distribution of CMV Data Collected by IC Roller during Proof-Rolling of LTS Layer. 
Once the compaction and mapping of the lime-treated subgrade were completed, field testing was performed with the LWD, NDG, PLT and DCP on the compacted layer at 44 points shown in 4.3a. The collected spot test data were imported into ArcGIS software to generate colorcoded geospatial distribution maps. The spline spatial interpolation algorithm was employed for the process of spatial interpolation. The classification method for the color criterion was based on the mean as obtained for all the different spot test measurements as shown in Table 4.1.

Table 4.1. Criterion for Color-Coded Maps

\begin{tabular}{|c|c|}
\hline Color & Criterion \\
\hline Red & $<0.75$ Mean \\
\hline Yellow & 0.75 Mean - Mean \\
\hline Green & $>$ Mean \\
\hline
\end{tabular}

Figure 4.7 illustrates the spatial distribution of the LWD modulus on top of the compacted LTS layer. The LWD moduli varied from 9 ksi to $57 \mathrm{ksi}$ with an average of $33 \mathrm{ksi}$ and a COV of $36 \%$. The northern and southeastern areas of the test section showed lower LWD moduli which is in agreement with the CMV data in Figures $4.5 \mathrm{a}$ and $4.5 \mathrm{~b}$.

Figure 4.8 summarizes the DCP results on the compacted LTS layer. The estimated DCP number of blows required to penetrate to a depth of 24 in. ranged from 22 blows to 60 blows with an average of 42 blows and a COV of $19 \%$. The DCP is a layer specific device since it reflects the properties of the layer of interest as compared to LWD that reports a composite modulus of the underlying layers. Similar to LWD, the southeastern parts required fewer DCP blows than the midsection, where the LTS is stiffer. This is in agreement with the LWD geospatial distribution shown in Figure 4.6 and bears resemblance to the CMV geospatial distribution shown in Figure 4.5b. 


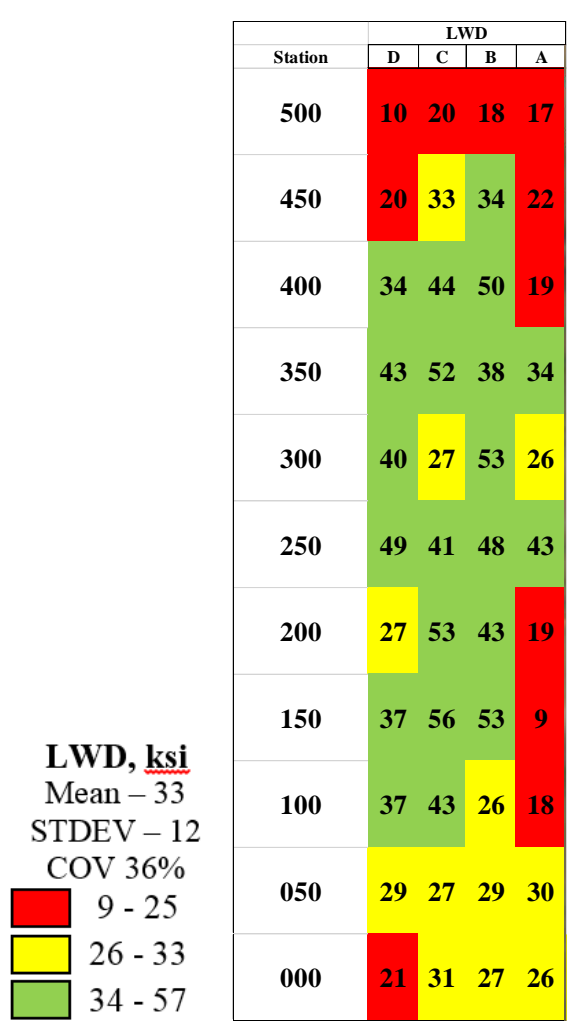

Figure 4.7 - Spatial Distribution of LWD Modulus on LTS Layer.

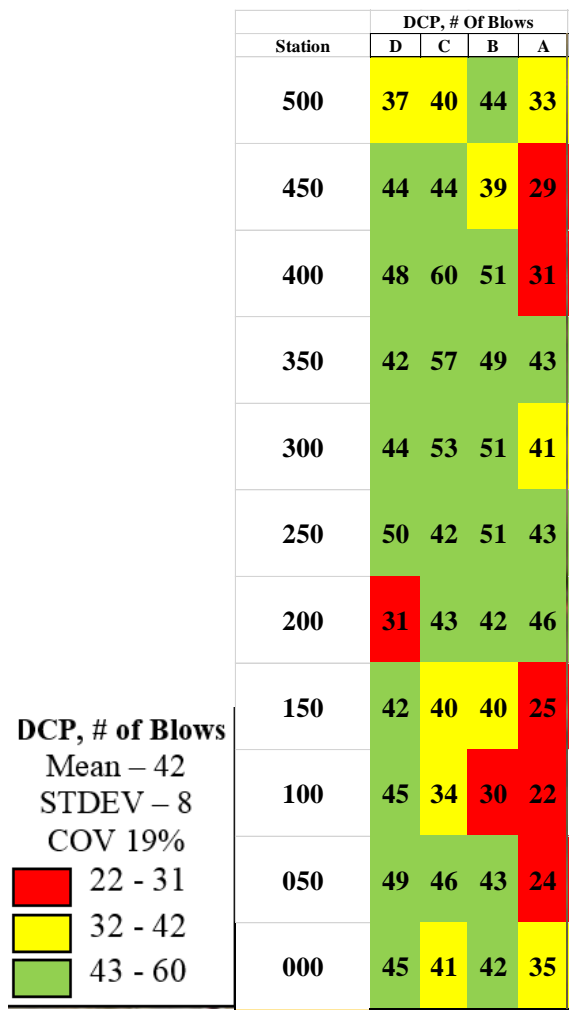

Figure 4.8 - Spatial Distribution of Number of DCP Blows on LTS Layer. 
Figure 4.9 illustrates the spatial distribution of the moisture content found at the surface of the LTS layer. The moisture content varied from $15 \%$ to $24 \%$ with an average of $19 \%$ and a COV of $38 \%$. Throughout the test section the areas with lower moisture content are in agreement with the stiffer areas found in the CMV data.

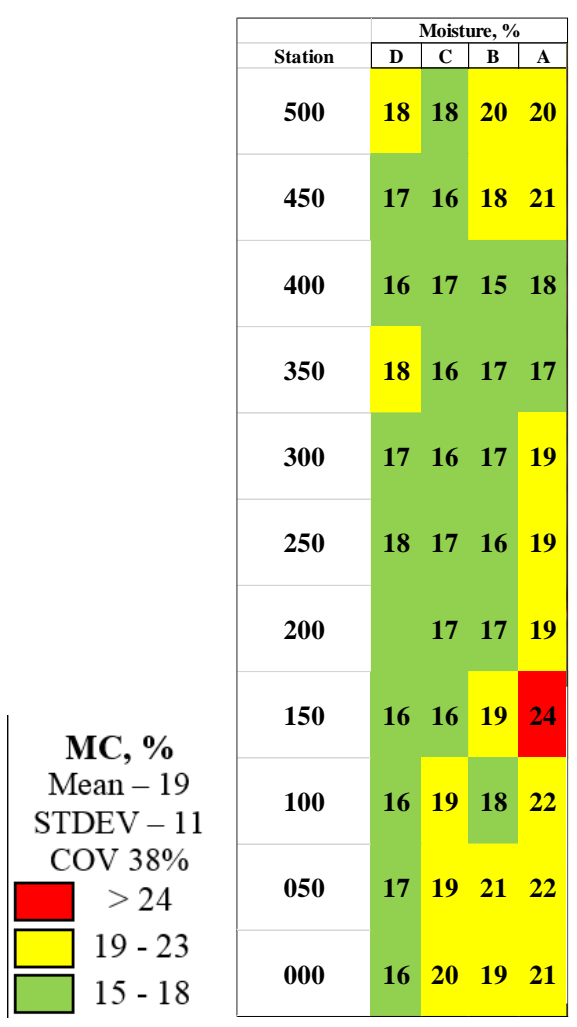

Figure 4.9 - Spatial Distribution of Moisture Content of LTS Layer.

A comparison between the LWD modulus and the CMV data at different stations is illustrated in Figure 4.10a. An LWD target modulus of $32 \mathrm{ksi}$, which was determined using a multilayer linear elastic analysis, is included in Figure 4.10a. Both data sets show similar trends. The center part of the test section showed higher LWD modulus and CMVs than the northern and southern ends of the test section. In addition, average LWD moduli in the center part of the section were greater than the LWD target modulus, while the values reported at the ends of the test section were lower. A similar comparison using the number of DCP blows to penetrate 24 in. in depth and 
CMV data is shown in Figure 4.10b. Though not as manifest as with LWD, some similarity in the trend may be seen between the number of DCP blows and CMV.
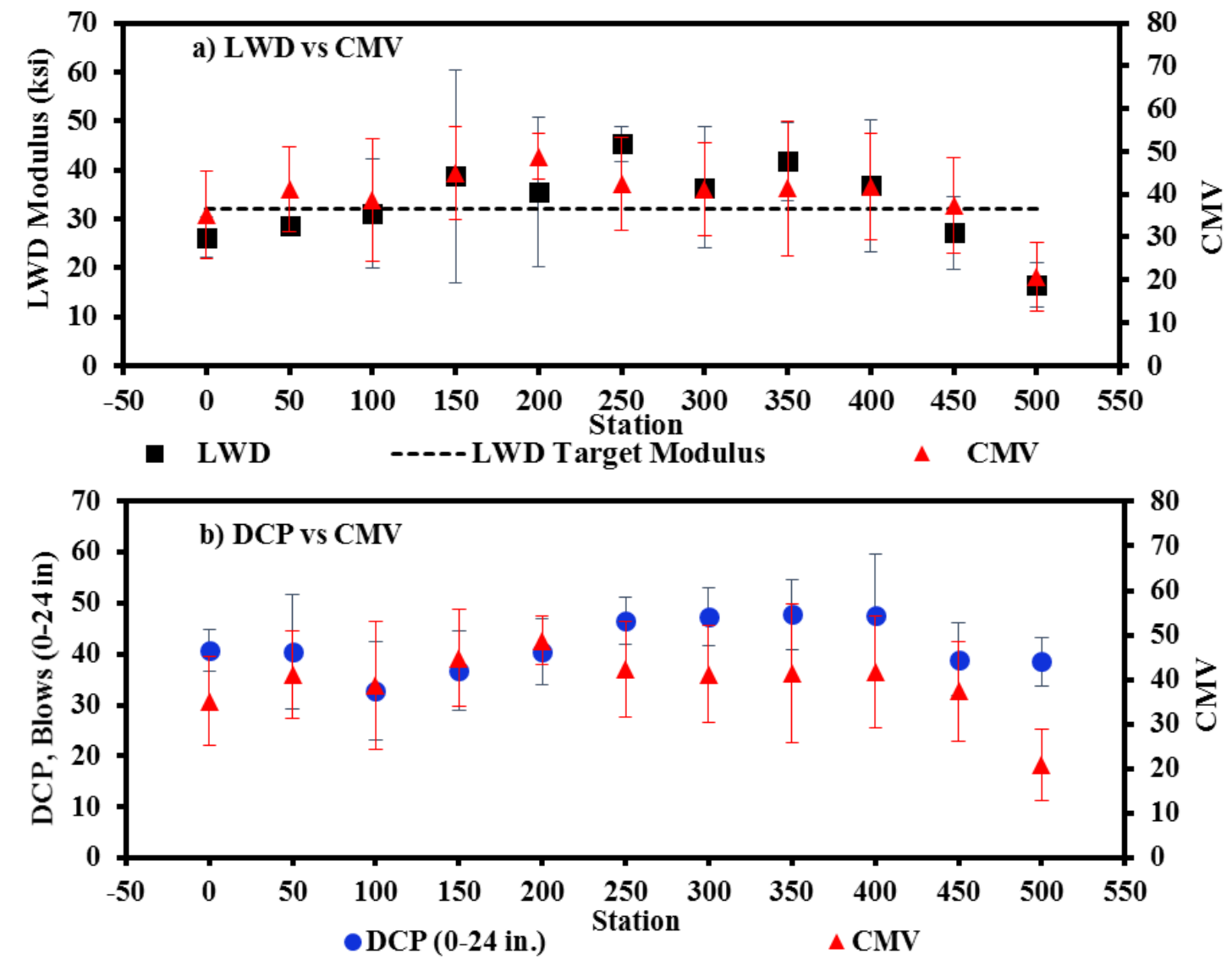

Figure 4.10 - Relationship between averaged (a) LWD Modulus and (b) Number of DCP blows vs. CMV.

Plate load tests (PLT) were performed at five different locations shown in Figure 4.4. LWD measurements were taken at fifteen points in a $12 \mathrm{ft} \times 6 \mathrm{ft}$ gridded area around the PLT test spot, as shown in Figure 4.3b. These measurements were mapped using the same criterion shown in Table 4.1. The geospatial variations of the LWD moduli around the PLT locations are shown in Figure 4.11. The PLT moduli varied from $10 \mathrm{ksi}$ to $43 \mathrm{ksi}$ with an average of $28 \mathrm{ksi}$. Descriptive statistics of LWD moduli for each rectangular buffer around the PLT location are included next to the mapped LWD moduli. 


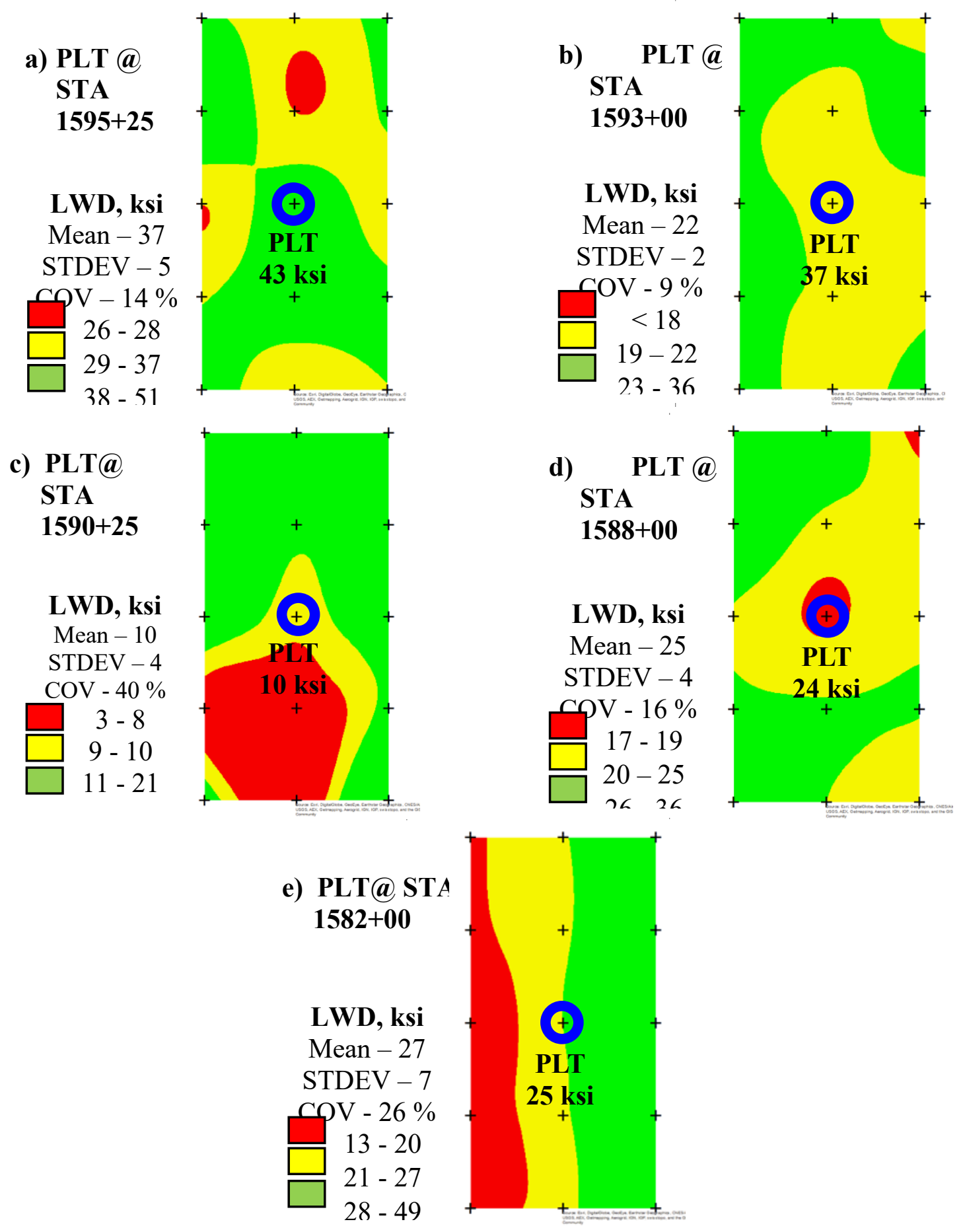

Figure 4.11 - Spatial Distribution of LWD at Different PLT locations. 
Considerable variation around the spot tests can be observed. The maximum COV of LWD moduli was $40 \%$ at station $1590+25$ as shown in Figure 4.11c. Setup of equipment and test duration of the PLT took about 2 hours per spot test, while for the LWD it took no more than 5 minutes. In general, the results in terms of moduli obtained by both NDT devices were similar in magnitude.

\subsection{FLEXIBLE BASE}

Figure 4.12a illustrates the spatial distribution of the CMV data during the mapping of the compacted base layer. Figure $4.12 \mathrm{~b}$ shows the spatial distribution of averaged buffered CMVs when the entire section was divided into 44 rectangular buffer areas measuring $9 \mathrm{ft} \times 50 \mathrm{ft}$. The histogram of the CMV distribution depicted in Figure 4.13 exhibits a considerable change in the trend of the collected CMV data. The average CMV seems to be higher than the previous layer and the $\mathrm{COV}$ is reduced to $17 \%$.

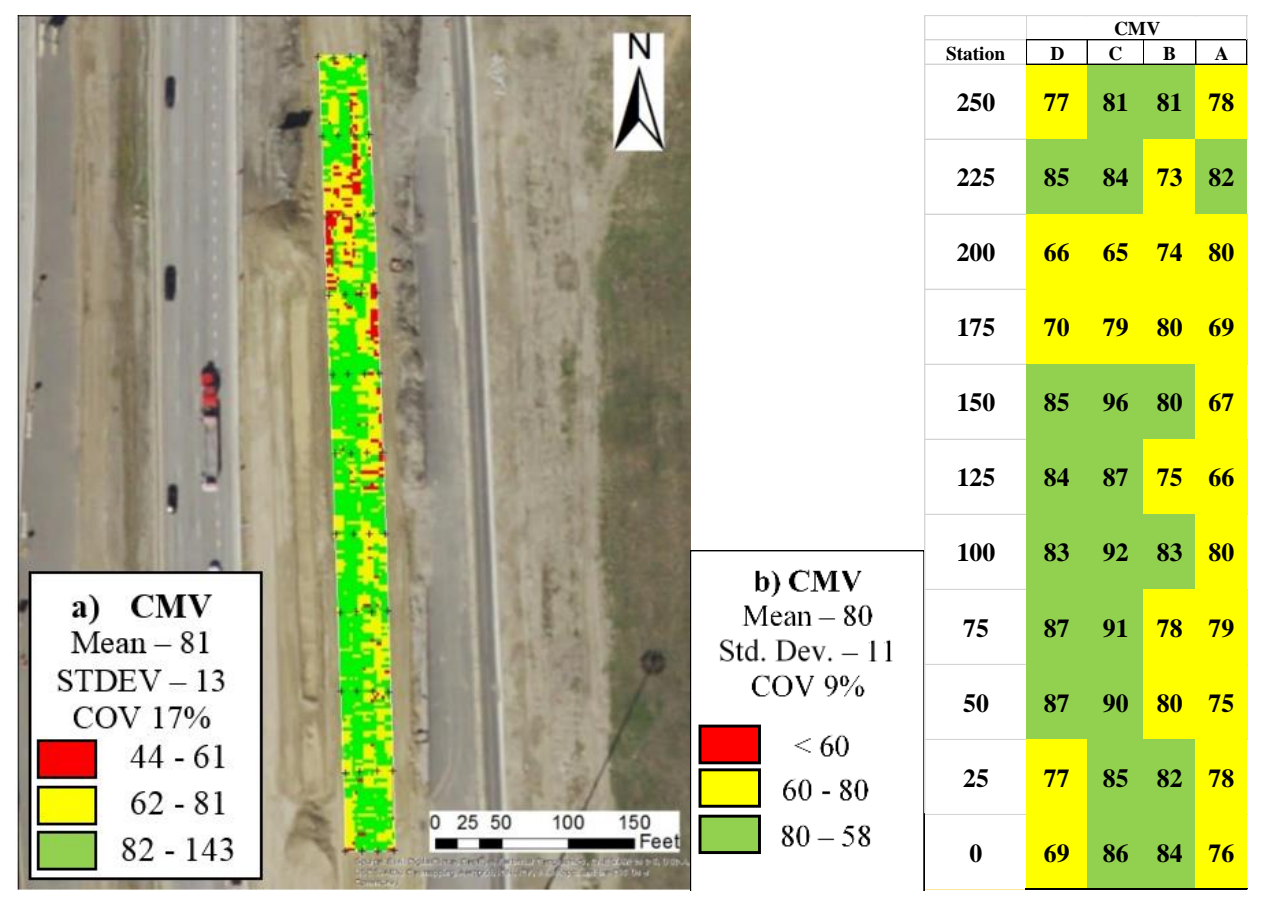

Figure 4.12 - Spatial Distribution of (a) Raw and (b) Rectangular Buffered CMV Data Collected by IC Roller during Proof-Rolling of Flexible Base Layer. 


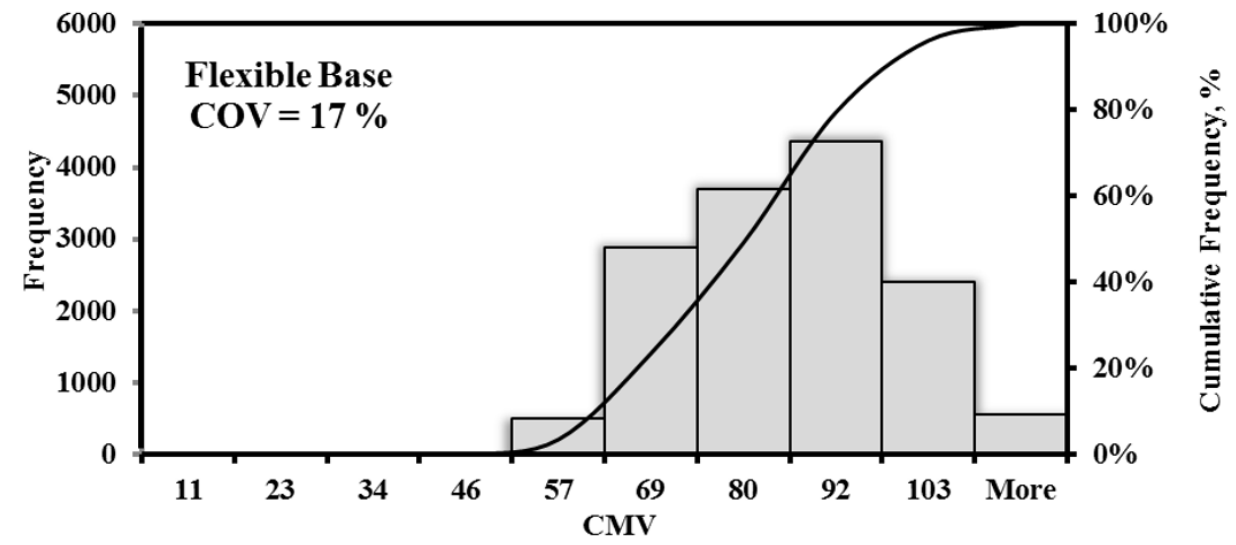

Figure 4.13- Distribution of CMV Data Collected by IC Roller during Proof-Rolling of Flexible Base Layer.

The LWD moduli measured at the 44 points vary from $12 \mathrm{ksi}$ to $52 \mathrm{ksi}$, with an average of $26 \mathrm{ksi}$ and COV of 35\% (see Figure 4.14). The areas of the test section showing higher LWD moduli are in accordance with the CMV data shown in Figure 4.12a.

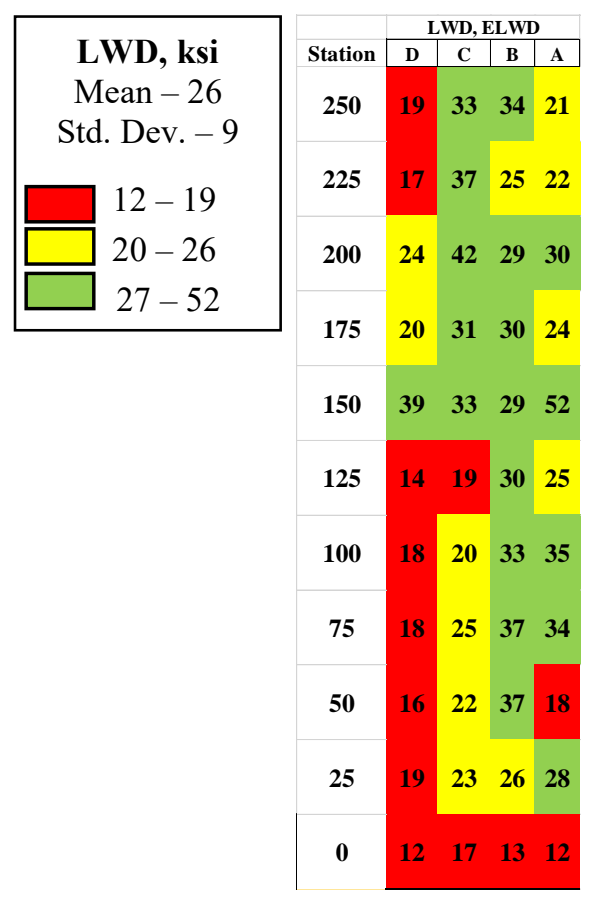

Figure 4.14 - Spatial Distribution of LWD Modulus of Flexible Base Layer. 
Figure 4.15 summarizes the DCP results on the compacted FB layer. The estimated number of DCP blows required to penetrate to a depth of 12 in. ranged from 45 blows to 155 blows with an average of 100 blows and a COV of $26 \%$.

Figure 4.16 illustrates the spatial distribution of the moisture content of the base layer. The moisture content varied from $5 \%$ to $18 \%$ with an average of $10 \%$ and a COV of $20 \%$. The moisture content was fairly constant except for a few points showing a higher level of moisture. No welldefined visual resemblance was seen between moisture content and CMV.

\begin{tabular}{|c|}
\hline DCP, \# of Blows \\
Mean -100 \\
Std. Dev. -26 \\
\\
$45-75$ \\
$46-100$ \\
$760-155$ \\
\hline
\end{tabular}

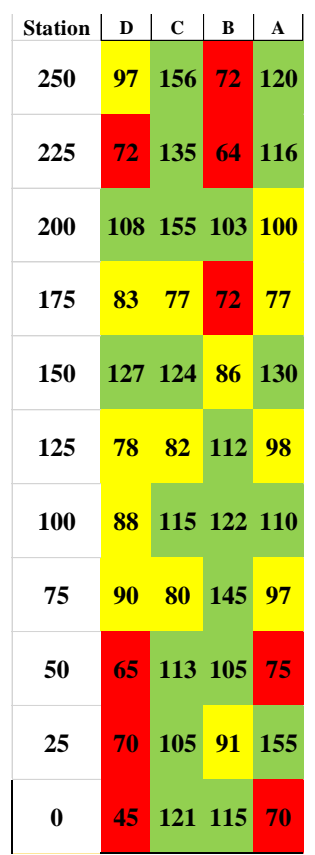

Figure 4.15 - Spatial Distribution of Number of DCP Blows of Flexible Base Layer to Penetrate 12 in. 


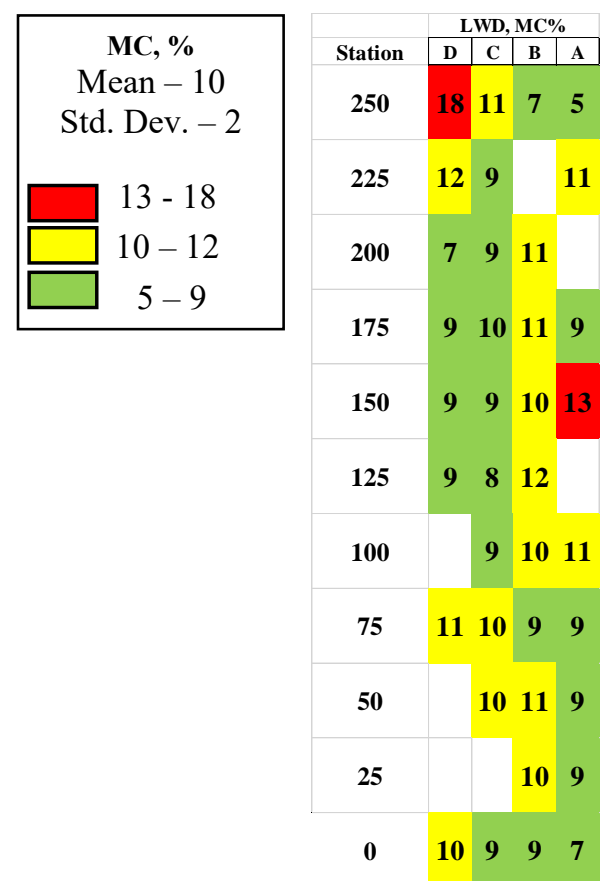

Figure 4.16 - Spatial Distribution of Moisture Content of Flexible Base Layer.

A comparison between the LWD moduli and the CMV data at different stations is illustrated in Figure 4.17a. The LWD moduli and CMV results showed some resemblance, though definitely not as strong as trends seen on the LTS, shown in Figure 4.10a. Besides, most LWD moduli were below the target LWD modulus of $32 \mathrm{ksi}$. A similar comparison using the number of DCP blows and CMV data is shown in Figure 4.17b. The trend observed for the number of blows per station was similar to LWD modulus. 

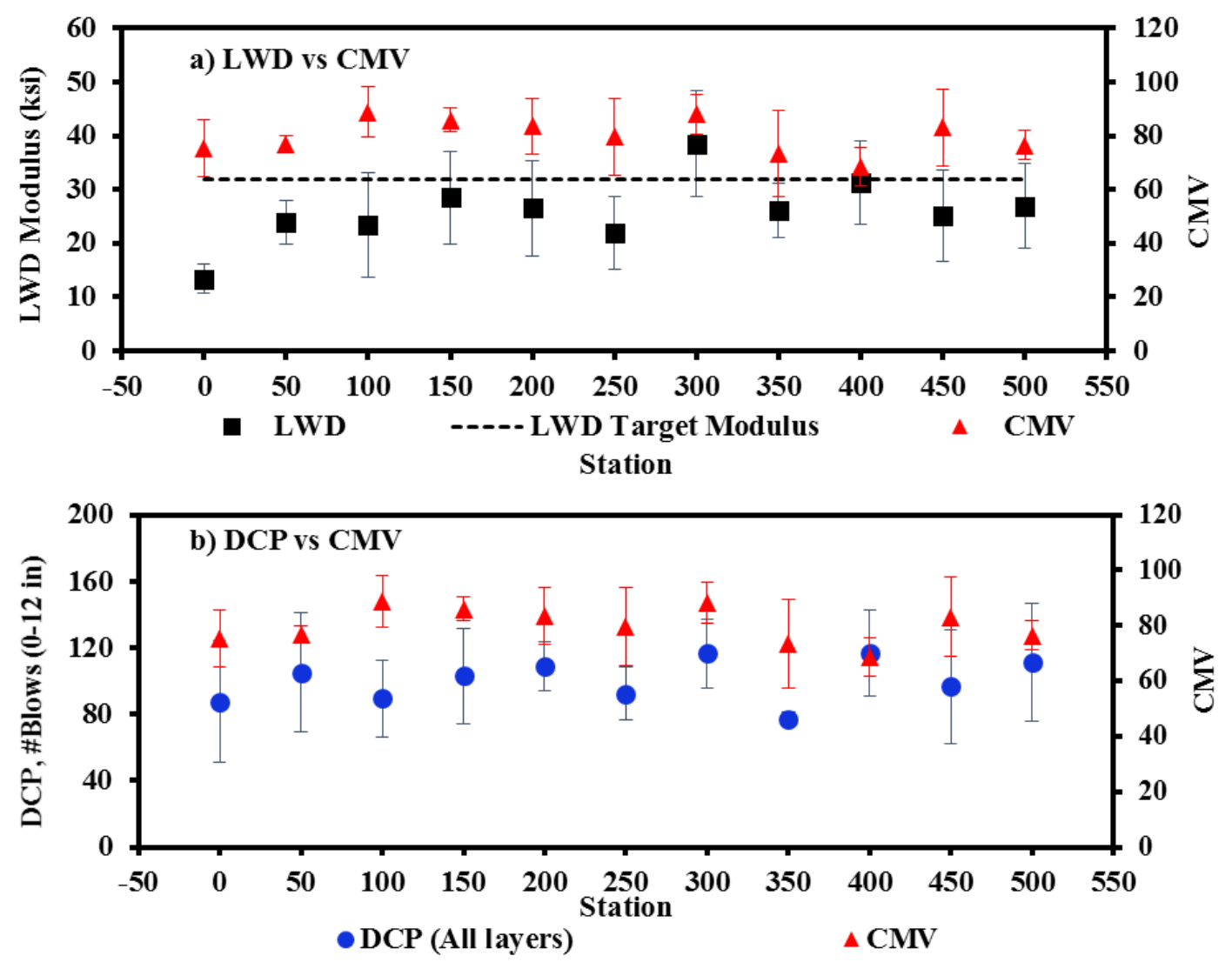

Figure 4.17 - Relationship between Averaged (a) LWD Modulus and (b) Number of DCP Blows to Penetrate 12 in vs. CMV.

\subsection{Geospatial Classification For Developing OPTIMized Color-Coded MaPS}

In an effort to reduce the number of spot test measurements based an optimal classification system it is necessary to link the spot test measurements to the collected ICMV data. As indicated before, the vibration data is collected at a discrete point on the roller. The current IC data analysis programs incorporate various interpolation processes in order to extrapolate the ICMV data points over the width of the roller prior to generating the color-coded maps. Some of the extrapolation techniques that are used include the Inverse Distance Weighting (IDW) and Spline and Ordinary Kriging. The use of these methods enhance the visualization of the data by smoothing the colorcoded contours and by filling gaps in information. Unfortunately, ICMV data is affected by the inclusion of these tools, as ICMV outliers can be cropped resulting in reduced ranges of ICMVs 
array of values. As we mentioned earlier Kriging, for instance, does not pass through any of the point values and causes interpolated values to be higher or lower than real values. Spline interpolation does not work well when sample points have extreme differences in magnitude and are close together.

An optimum classification system would allow the geospatial data obtained with IC roller and the spot tests such as LWD. For this purpose, spot test measurements using LWD and DCP were performed at equidistant distances along several sites. An example of such a grid is shown in Figure 4.18. Usually, a set of 44 spots test were performed, comprising a grid of an array of elven recordings along the longitudinal direction and four along the transverse direction of the test section. Following the process discussed before, a rectangular buffer area was selected around each spot test location. The IC data measurements within each rectangular buffered area were averaged to obtain a representative CMV for that block. Color-coded maps were created for the representative CMV values and the spot test measured values, with the purpose of relating the less stiff geospatially referenced data from the two devices. This approach was implemented at several sites. 


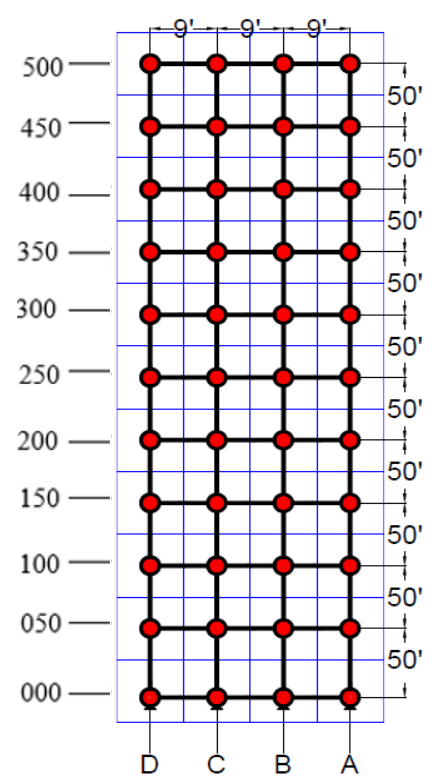

Figure 4.18 - Schematic of Location of Georeferenced LWD and DCP Spot Tests.

Figure 4.19 compares the collected and processed CMV data and LWD modulus for a 500 $\mathrm{ft}$ long and $27 \mathrm{ft}$ wide lime-stabilized layer. Using the criterion selected for previous field studies (shown in Table 4.1), some rectangular areas marked in red on the CMV map are not shown as less-stiff areas on the LWD surface modulus map. For example, in Figure 4.19a, the IC roller predicted nine rectangular areas as less-stiff. Seven of these areas were predicted to be less-stiff on the LWD map as well. As such, $22 \%$ of less-stiff areas spotted in the CMV map were not in agreement with the less-stiff areas found in the LWD map. 
a)

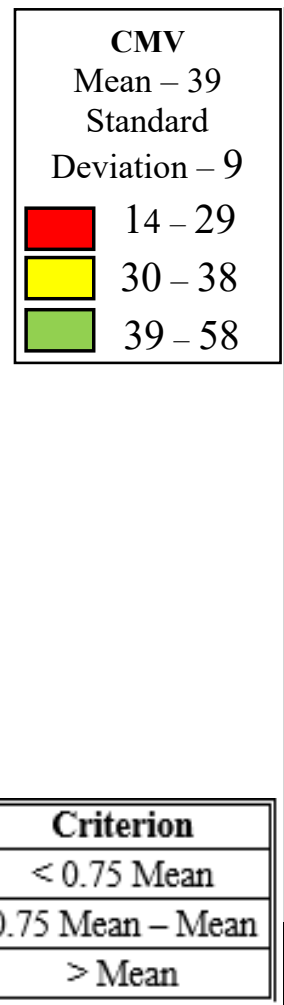

\begin{tabular}{|l|}
\hline 500 \\
\hline 450 \\
\hline 400 \\
350 \\
\hline 300 \\
\hline 250 \\
\hline 200 \\
\hline 150 \\
\hline 100 \\
\hline 50 \\
\hline 0
\end{tabular}

b)

\begin{tabular}{|c|}
\hline LWD, ksi \\
Mean -34 \\
Standard \\
Deviation -11 \\
$9-24$ \\
$925-33$ \\
$25-56$ \\
\hline$\square$
\end{tabular}

41415130

41445131

43514732

45535837

50534529

42543525

47493228

45493820

\begin{tabular}{|c|c|}
\hline Color & Criterion \\
\hline Red & $<0.75$ Mean \\
\hline Yellow & 0.75 Mean - Mean \\
\hline Green & $>$ Mean \\
\hline
\end{tabular}

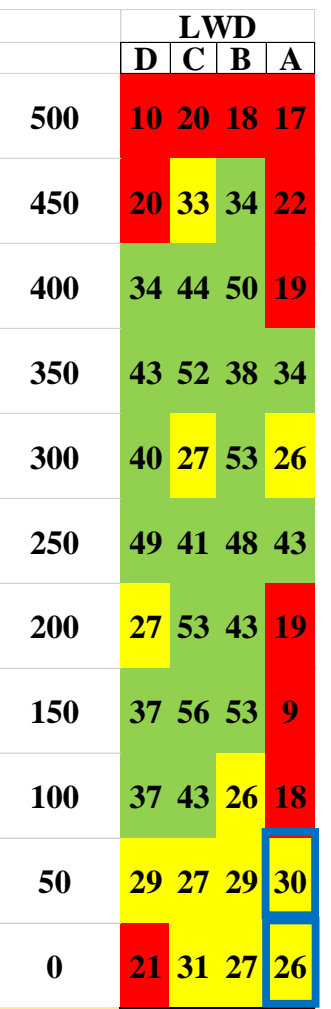

Figure 4.19 - Color-Coded Map Comparison between a) CMV and b) LWD Surface Modulus.

In an effort to reduce this percentage, a different color criterion is necessary to improve the IC roller prediction process for identifying the less-stiff areas. The approach consisted of varying the criterion for identifying the less-stiff areas for both the CMV and LWD surface modulus mappings. This criterion varied between a range of $60 \%$ to $90 \%$ of the average measured values, for the ICMV data and LWD surface moduli. Table 4.2 shows the percentage of mismatched areas of the IC roller predicted less-stiff areas. The IC roller was able to predict less-stiff areas, with confidence that all areas were also identified by the LWD as less-stiff, when a criterion mark for less-stiff is set at $70 \%$ of the average CMV (or lower), and when a criterion mark for less-stiff is set at $80 \%$ of the average LWD surface modulus (or higher). The color maps from this process is shown in Figure 4.20. This approach is currently under evaluation at other sites and with the other class breaks discussed above. 
Table 4.2 - Percentage of Disagreement in Rectangular Buffered Areas between CMV and LWD Modulus Based on Different Color-Criteria for the Less-Stiff (Red) Areas.

\begin{tabular}{|c|c|c|c|c|c|c|c|c|}
\hline & & \multicolumn{7}{|c|}{ Less-Stiff (Red) Area Below \% of Average $E_{L W D}$} \\
\hline \multirow{8}{*}{ 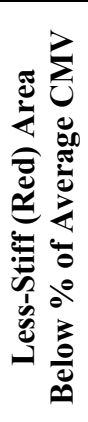 } & & 90 & 85 & 80 & 75 & 70 & 65 & 60 \\
\hline & 90 & 24 & 29 & 29 & 47 & 47 & 53 & 65 \\
\hline & 85 & 23 & 31 & 31 & 46 & 46 & 54 & 62 \\
\hline & 80 & 18 & 18 & 18 & 36 & 36 & 45 & 55 \\
\hline & 75 & 11 & 11 & 11 & 22 & 22 & 33 & 44 \\
\hline & 70 & 0 & 0 & 0 & 14 & 14 & 29 & 43 \\
\hline & 65 & 0 & 0 & 0 & 17 & 17 & 17 & 33 \\
\hline & 60 & 0 & 0 & 0 & 33 & 33 & 33 & 33 \\
\hline
\end{tabular}

a)

\begin{tabular}{|c|}
\hline $\begin{array}{c}\text { CMV } \\
\text { Mean - 39 } \\
\text { Std. Dev. - } 11\end{array}$ \\
\hline $14-27$ \\
\hline $28-38$ \\
\hline $39-58$ \\
\hline
\end{tabular}

\begin{tabular}{||c|c||}
\hline Color & Criterion \\
\hline Red & $<0.70$ Mean \\
\hline Yellow & 0.70 Mean - Mean \\
\hline Green & $>$ Mean \\
\hline \hline
\end{tabular}

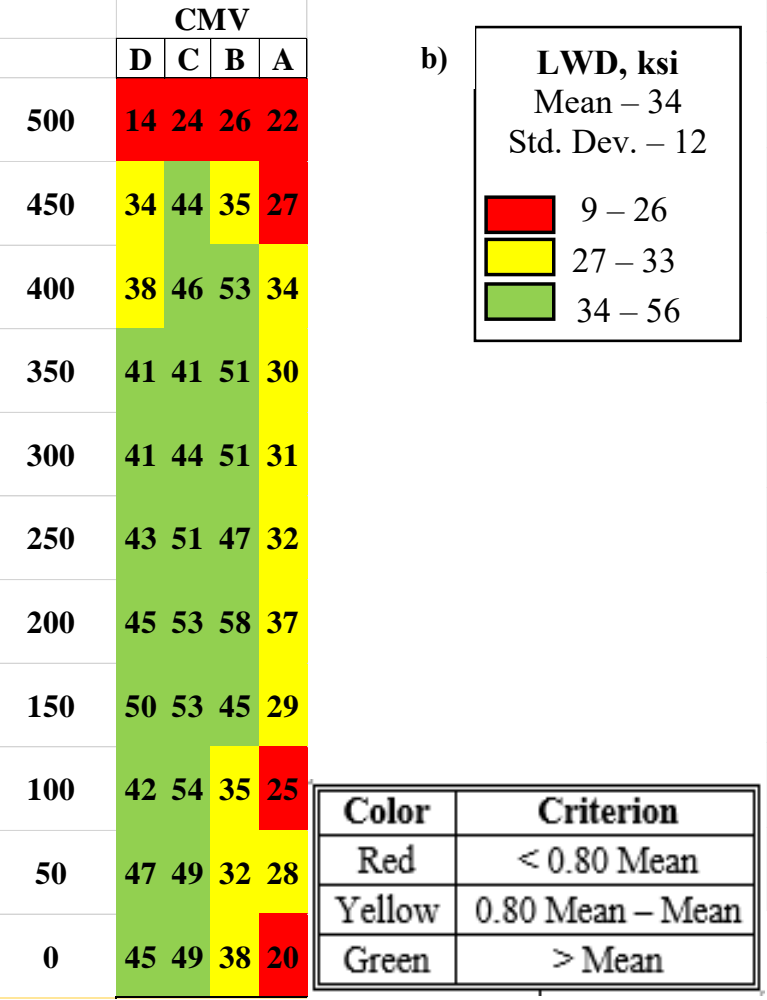

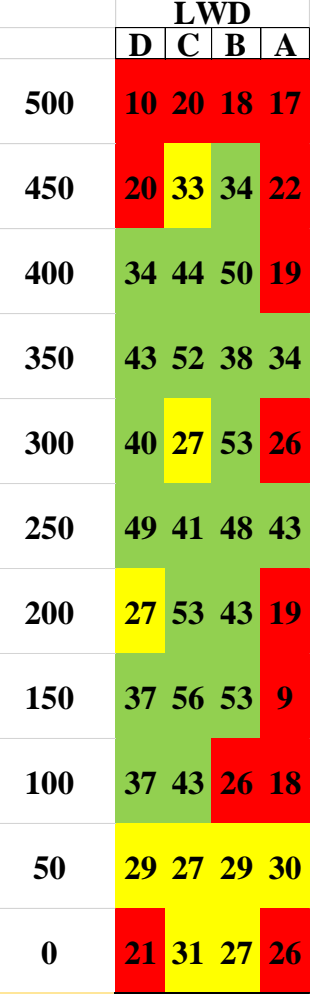

Figure 4.20 - Optimized Color-Coded Map Comparison between (a) CMV Using Less-Stiff (Red) Areas when CMV $<75 \%$ of Average of CMVs, and (b) LWD Using Less-Stiff (Red) Areas when $E_{L W D}<80 \%$ of Average $E_{L W D}$ Values. 


\section{Chapter 5: Evaluation of IC Data in Georgetown, FM1460}

\subsection{INTRODUCTION}

Field evaluation was performed on a 250 -ft section as part of an expansion of farm-tomarket road FM 1460 in Georgetown, Texas. Figure 5.1 shows an aerial view of the of the test section alongside a map with the location of the test section within the Georgetown area.

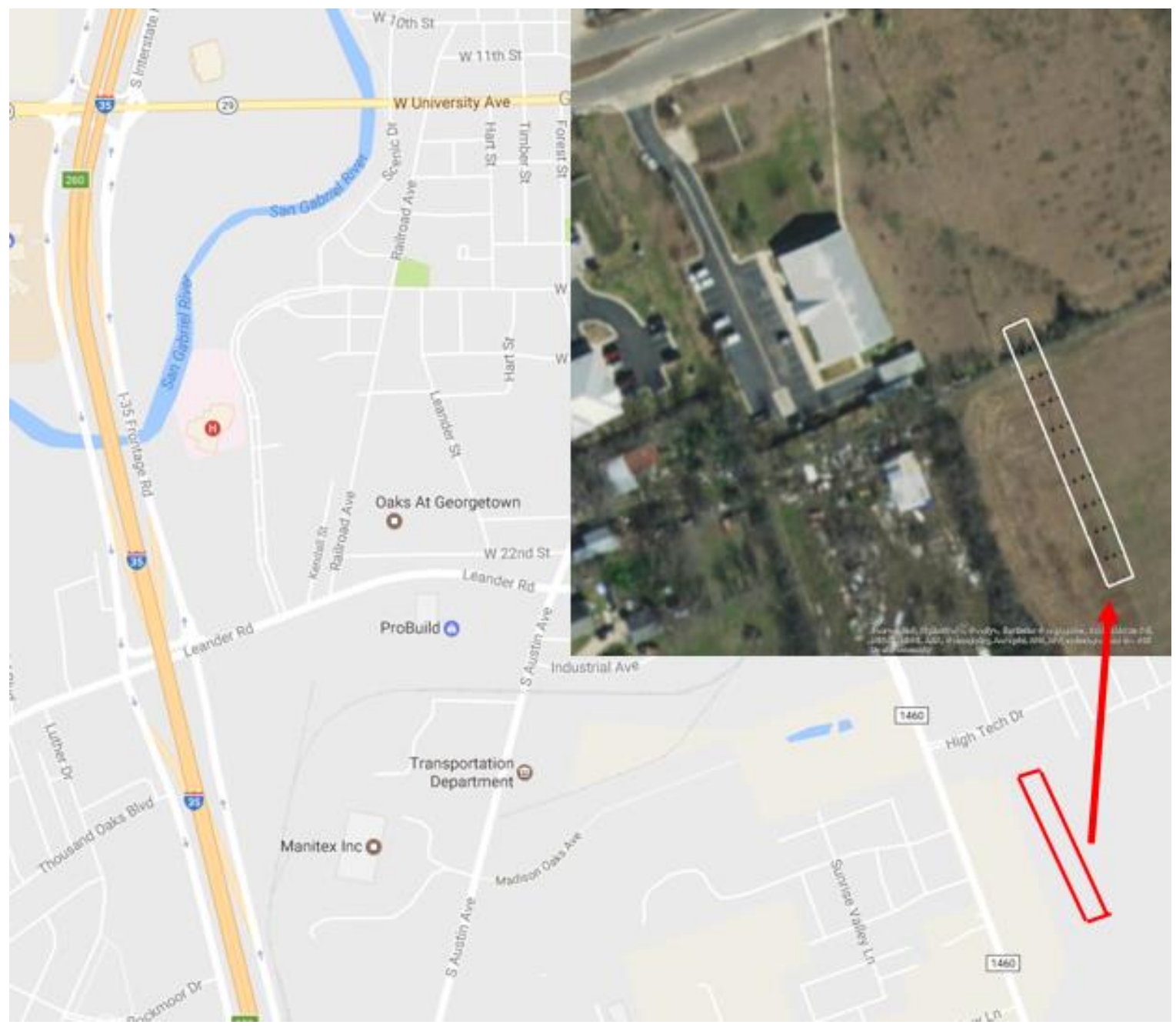

Figure 5.1 - Location of Field Evaluation Site on FM140 in Georgetown, TX.

The pavement section consisted of a 12-in. thick flexible (unbound) aggregate base layer over an 8 in. lime-treated subgrade (LTS), on top of untreated subgrade as shown in Figure 5.2. 
Mapping and field evaluation of the LTS took place on June 20, 2016. The evaluation of the base was carried out on July 15, 2016.

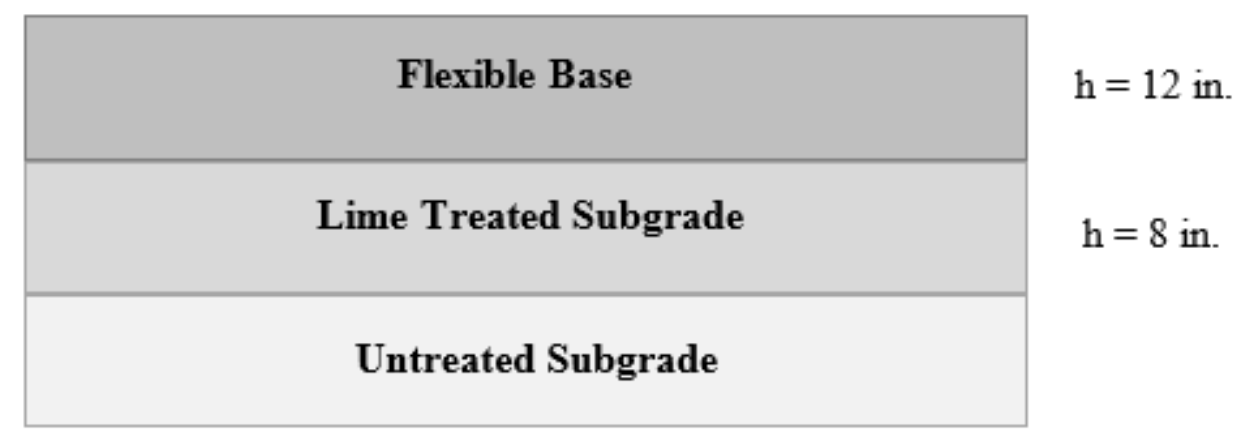

Figure 5.2 - Pavement Structure of Test Section

\subsection{Field Testing Program}

Spot testing was carried out along a $250 \mathrm{ft}$ long and $24 \mathrm{ft}$ wide section. A grid consisting of 44 points divided in 4 columns of 11 points each was selected for the location of the spot tests. The grid was designed with a spacing of $25 \mathrm{ft}$ between each of the 11 points, and a spacing of $8 \mathrm{ft}$ between each column as shown in Figure 5.3a. The evaluation of the base layer was carried out only along a $150 \mathrm{ft}$ length as shown in Figure $5.3 \mathrm{~b}$, because the rest of the section was not compacted. LWD and DCP tests were carried out at each point as discussed above. In addition, moisture content samples were collected at all test locations.

\subsection{Lime Treated SUbGRAde}

The lime treated subgrade layer was mapped using a smooth CAT roller equipped with a Trimble ${ }^{\circledR}$ IC retrofit kit. The first phase of the construction consisted of stabilizing the subgrade soil using hydrated lime. 
a)

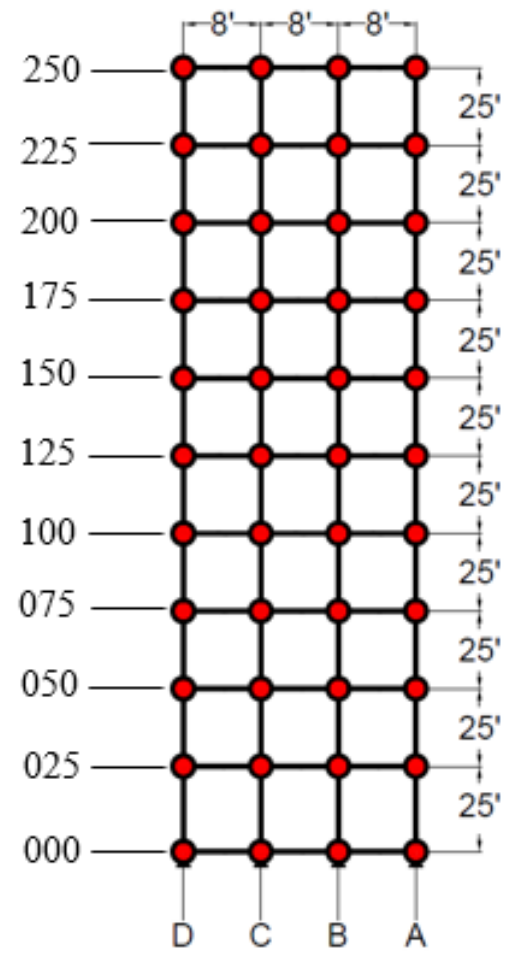

- Spot Test

${ }^{*}$ Not to Scale

b)

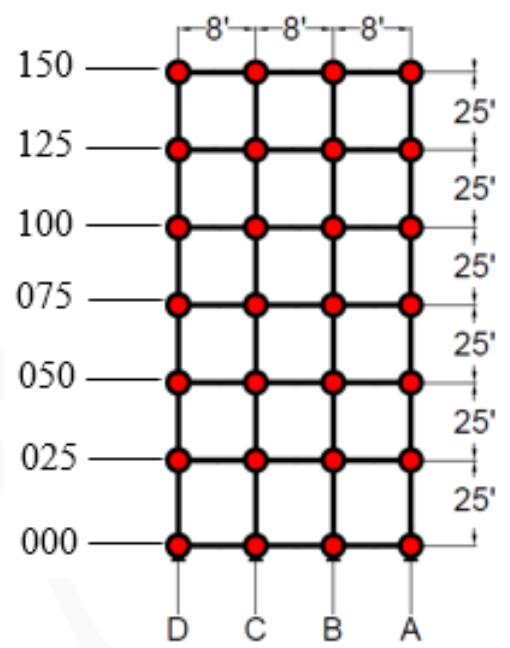

- Spot Test

${ }^{*}$ Not to Scale

Figure 5.3 - Schematic of the Typical Test Section and Location of Spot Tests for (a) Lime-Treated Subgrade and (b) Flexible Base Layer.

The spatial distribution of the CMVs collected during the mapping of the LTS layer is shown in Figure 5.4a. Figure 5.4b shows the spatial distribution of averaged buffered CMVs when the entire section was divided into 44 rectangular buffer areas measuring $8 \mathrm{ft} \times 25 \mathrm{ft}$. The location of the less stiff areas on both maps are comparable.

The histogram of the mapped CMVs is summarized in Figure 5.4. The maximum CMV was about 41 for the spatial distribution of the raw data and 36 for the averaged data. COV of CMVs was 46\%, as shown in Figure 5.5. 


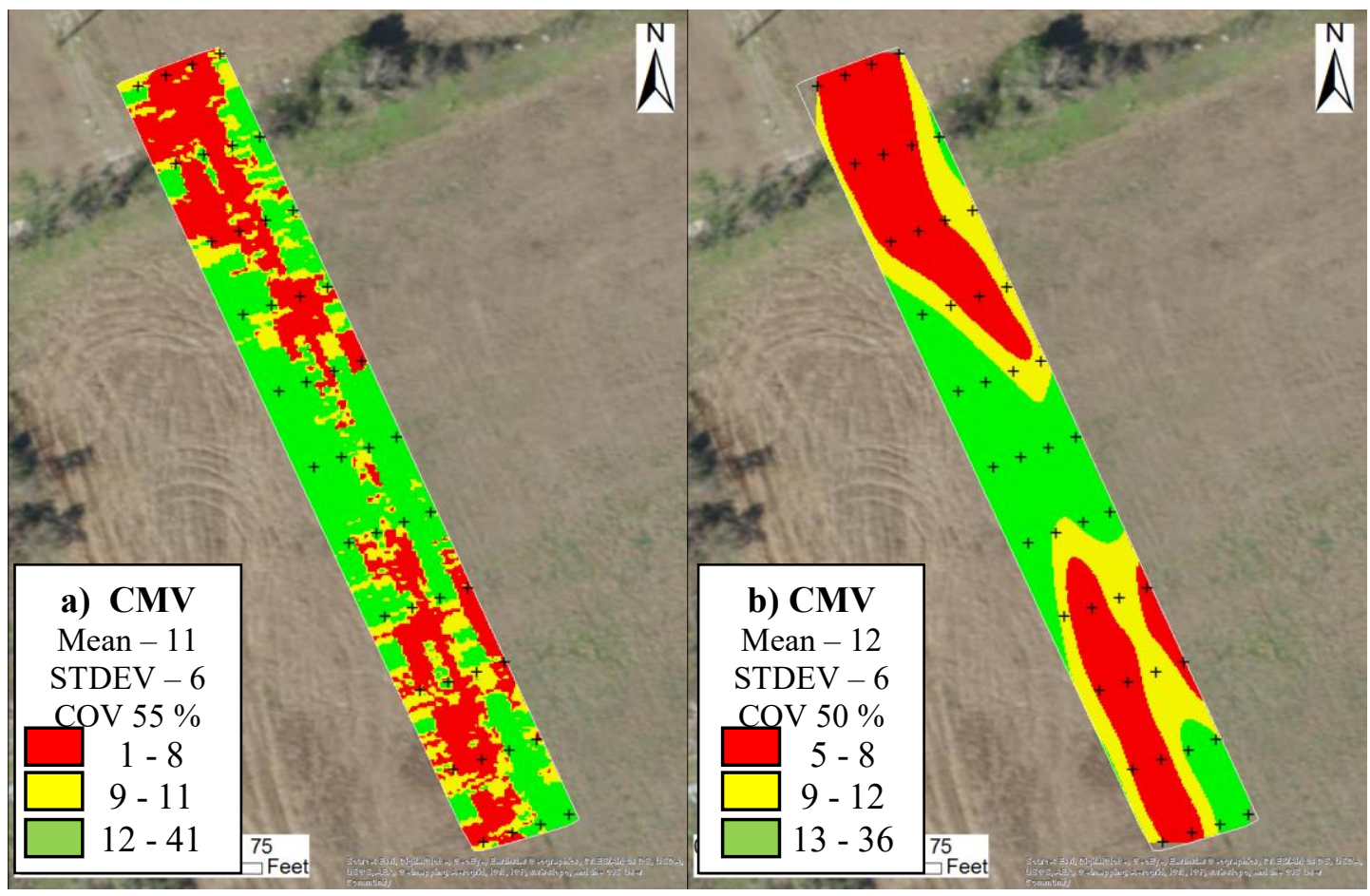

Figure 5.4 - Spatial Distribution of (a) Raw and (b) Rectangular Buffered CMV Data Collected by IC Roller during Proof-Rolling of LTS Layer.

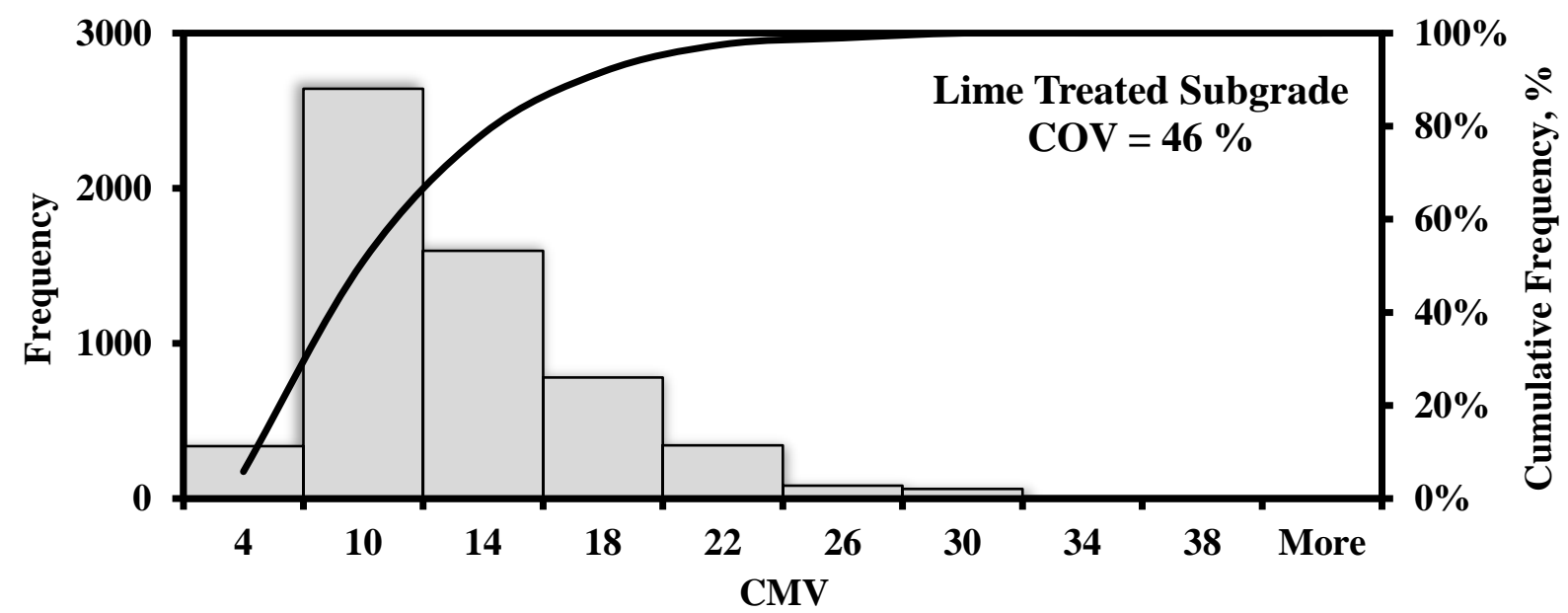

Figure 5.5 - Distribution of CMV Data Collected by IC Roller during Proof-Rolling of LTS Layer.

Once the compaction and proof-mapping of the lime-treated subgrade was completed, field testing was performed with the LWD and DCP on the compacted layer at 44 points along the test section. The collected spot test data were imported into ArcGIS software to generate color-coded geospatial distribution maps. The spline spatial interpolation algorithm was employed for the 
process of spatial interpolation. The classification method for the color criterion was based on the mean as obtained for all the different spot test measurements as shown in Table 4.1.

Figure 5.6 illustrates the spatial distribution of the LWD modulus on top of the compacted LTS layer. The LWD moduli varied from 4 ksi to $16 \mathrm{ksi}$ with an average of $7 \mathrm{ksi}$ and a COV of $29 \%$. The northern and southern parts of the test section showed lower LWD moduli which is in agreement with the CMV data shown in Figures 5.4a and 5.4b.

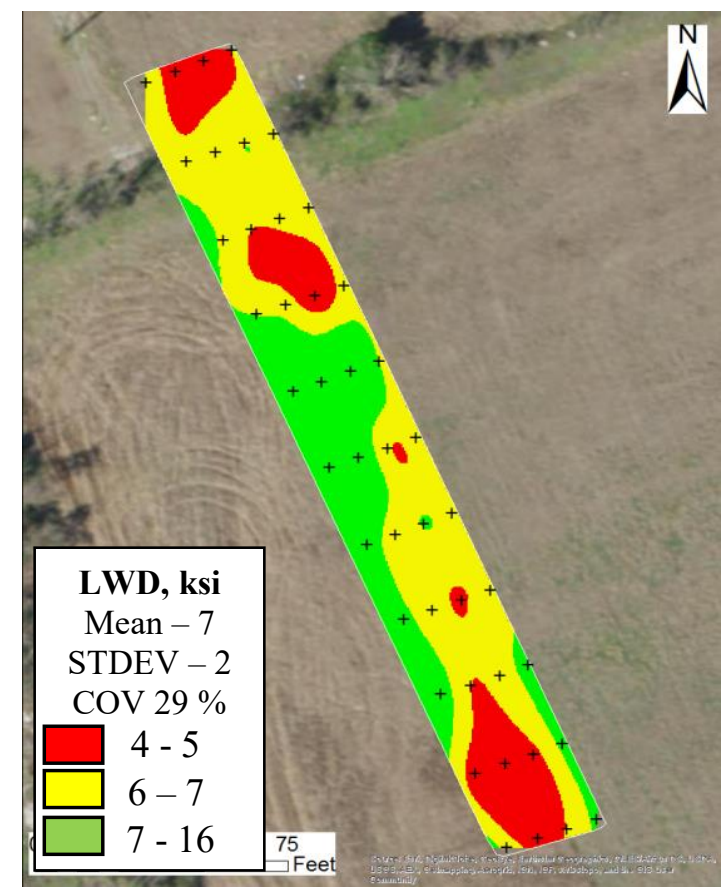

Figure 5.6 - Spatial Distribution of LWD Modulus on LTS Layer.

Figure 5.7 summarizes the DCP results on the compacted LTS layer. The numbers of DCP blows required to penetrate to a depth of 24 in. ranged from 18 blows to 92 blows with an average of 31 blows and a COV of 55\%. Similar to LWD, the northern and southern parts required fewer DCP blows than the mid-section, where the LTS is stiffer. This is in agreement with the LWD geospatial distribution, and bears resemblance to the CMV geospatial distribution. 


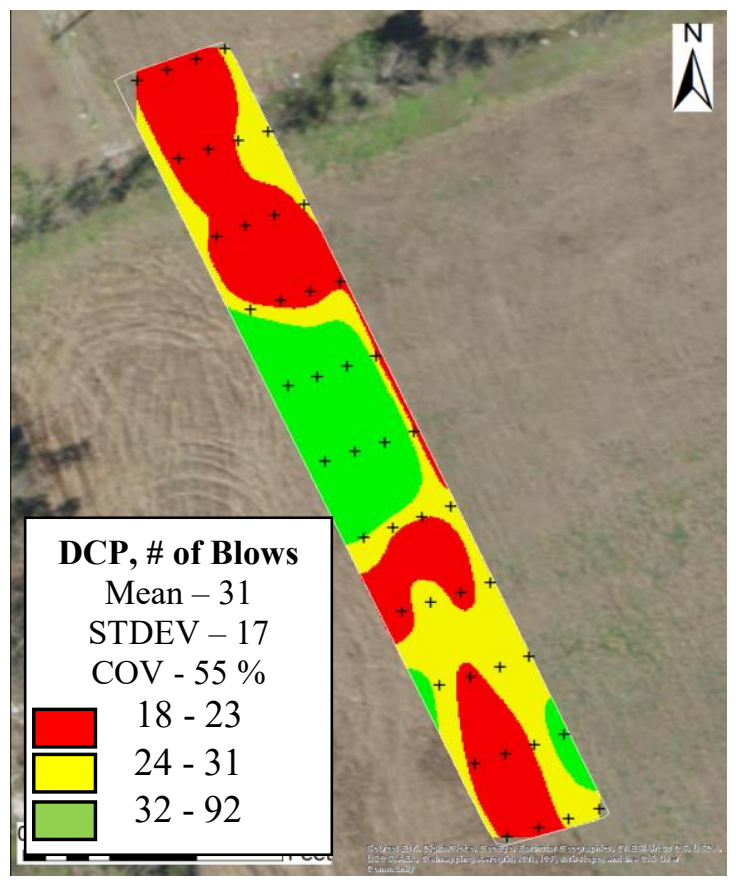

Figure 5.7 - Spatial Distribution of Number of DCP Blows on LTS Layer.

Figure 5.8 illustrates the spatial distribution of the moisture content of the LTS layer. The moisture content varied from $10 \%$ to $16 \%$ with an average of $14 \%$ and a COV of $7 \%$. No welldefined visual relationship is seen between moisture content and CMV nor with the other modulusbased measurements.

A comparison between the LWD moduli and CMV data at different stations is illustrated in Figure 5.9a. Likewise, the comparison using the number of DCP blows and CMV data is shown in Figure 5.9b. A similar trend is evident between CMV and the modulus-based measurements. 


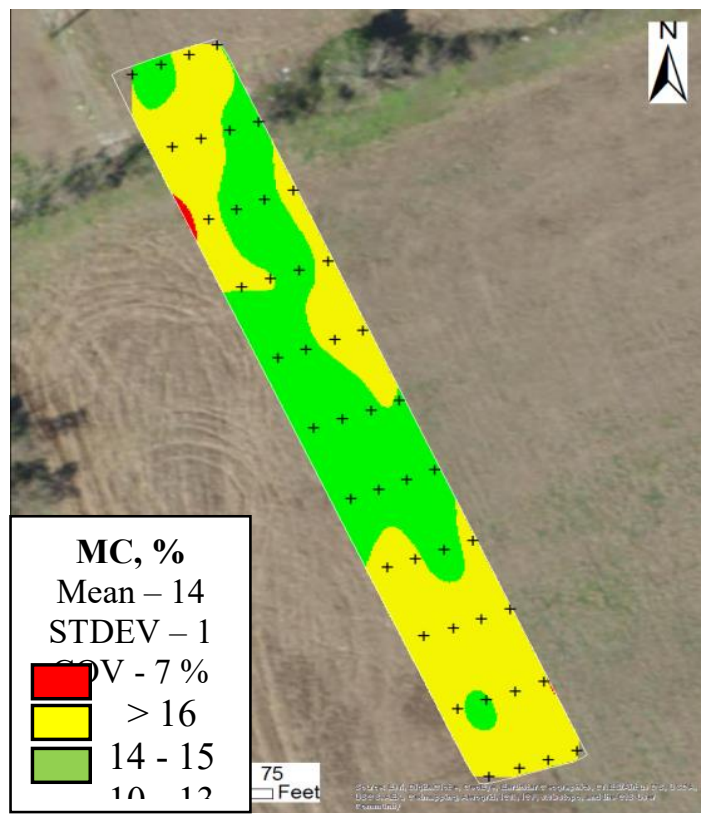

Figure 5.8 - Spatial Distribution of Moisture Content of LTS Layer.
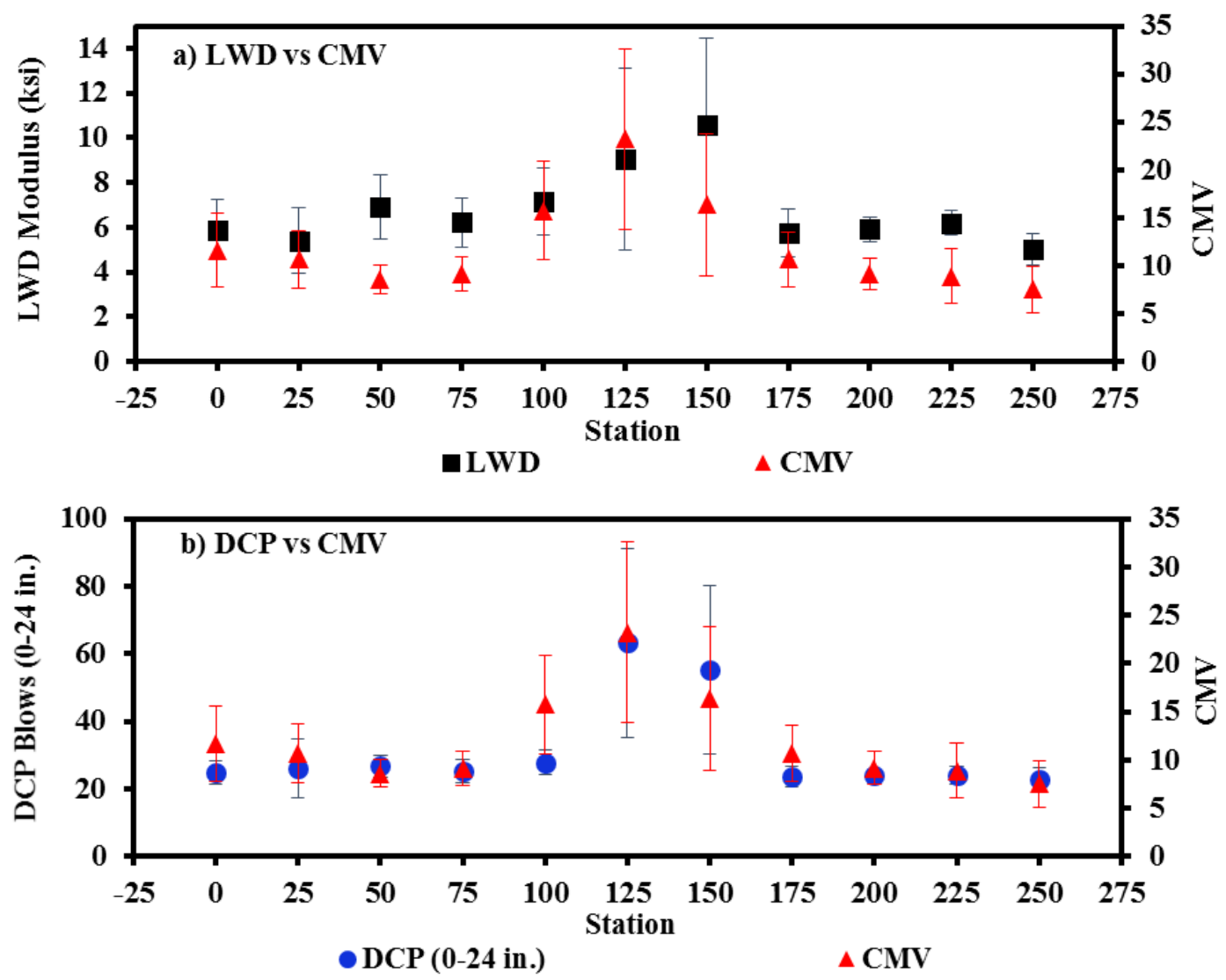

Figure 5.9 - Relationship between Averaged (a) LWD Modulus and (b) Number of DCP Blows vs. Average CMV per Station. 


\subsection{FLEXIBLE BASE}

Figure 5.10a illustrates the spatial distribution of CMV data during the mapping of the base layer. Figure 5.10b shows the spatial distribution of averaged buffered CMVs when the entire section was divided into 28 rectangular buffer areas measuring $8 \mathrm{ft} \times 25 \mathrm{ft}$.

The histogram of the CMV distribution depicted in Figure 5.11 exhibits that the average CMV increased to 61, a magnitude greater than that obtained for the LTS, with a COV of $44 \%$.

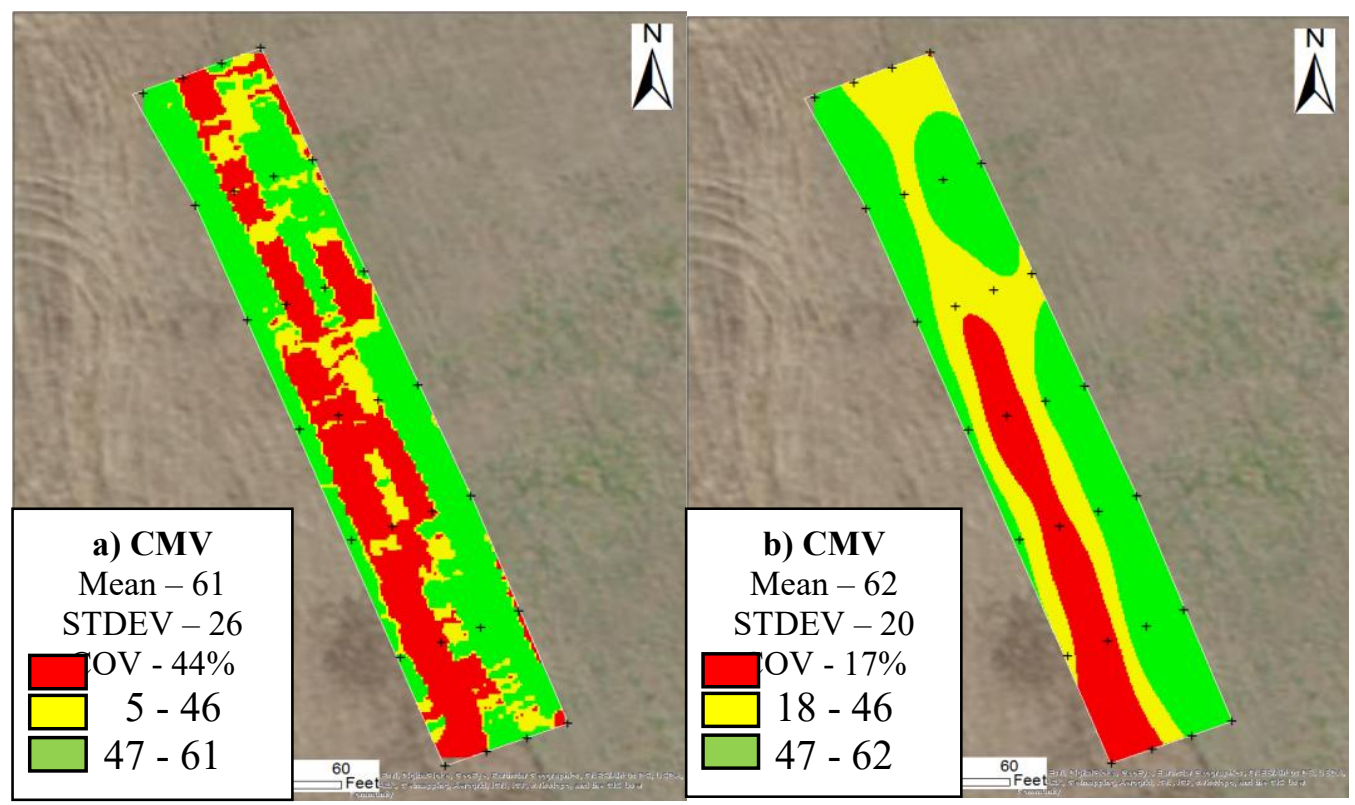

Figure 5.10 - Spatial Distribution of (a) Raw and (b) Square Buffered CMV Data Collected by IC Roller during Proof-Rolling of Flexible Base Layer.

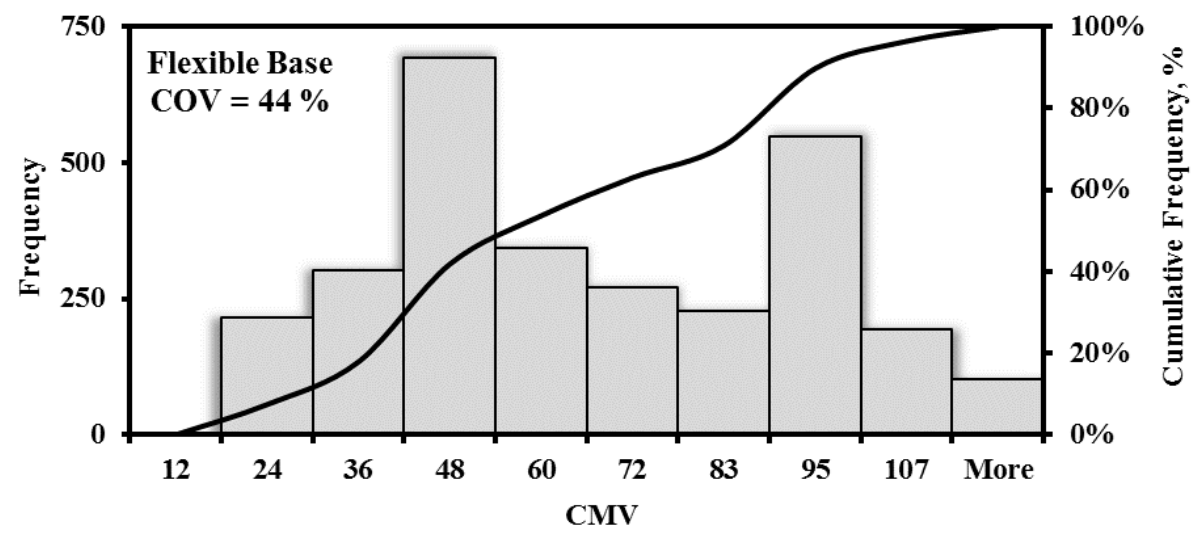

Figure 5.11 - Distribution of CMV Data Collected by IC Roller during Proof-Rolling of Flexible Base Layer. 
The LWD tests were conducted on the spot locations shown in Figure 5.3b within the test section. Figure 5.12 illustrates the spatial distribution of the LWD moduli on top of the compacted base. The LWD moduli varied from $26 \mathrm{ksi}$ to $51 \mathrm{ksi}$, with an average of $35 \mathrm{ksi}$ and COV of $17 \%$. The areas of the test section showing higher LWD moduli are somewhat in accordance with the CMV data shown in Figures 5.10a and 5.10b; however, less stiff areas as determined by the LWD were not in accordance with the CMV.

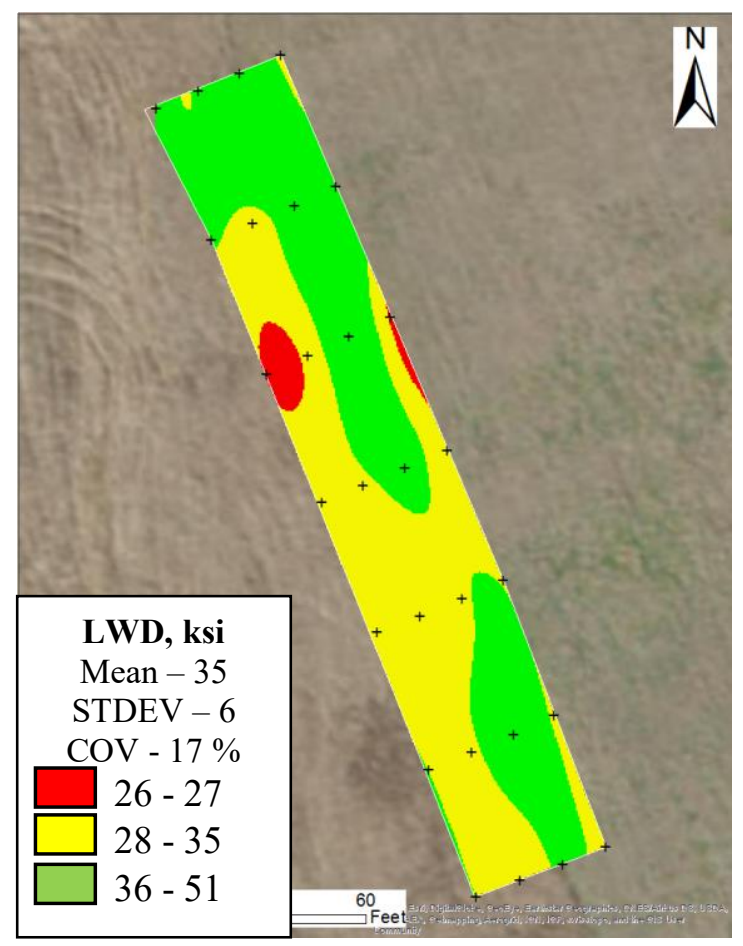

Figure 5.12 - Spatial Distribution of LWD Modulus of Flexible Base Layer.

Figure 5.13 summarizes the DCP results on the compacted base. The estimated number of DCP blows required to penetrate to a depth of 12 in. ranged from 180 blows to 360 blows with an average of 252 blows and a COV of 17\%. Both LWD and DCP indicated that the layer was mostly uniform and stiff, but color maps were not comparable.

Figure 5.14 illustrates the spatial distribution of the moisture content of the Flexible Base layer. The percentage of moisture content varied from $2 \%$ to $5 \%$ with an average of $4 \%$ and a COV 
of $14 \%$. Mapping of moisture content did not bear resemblance to the mapping of any of the other measurements, possibly due to low variation of results and the chosen criterion.

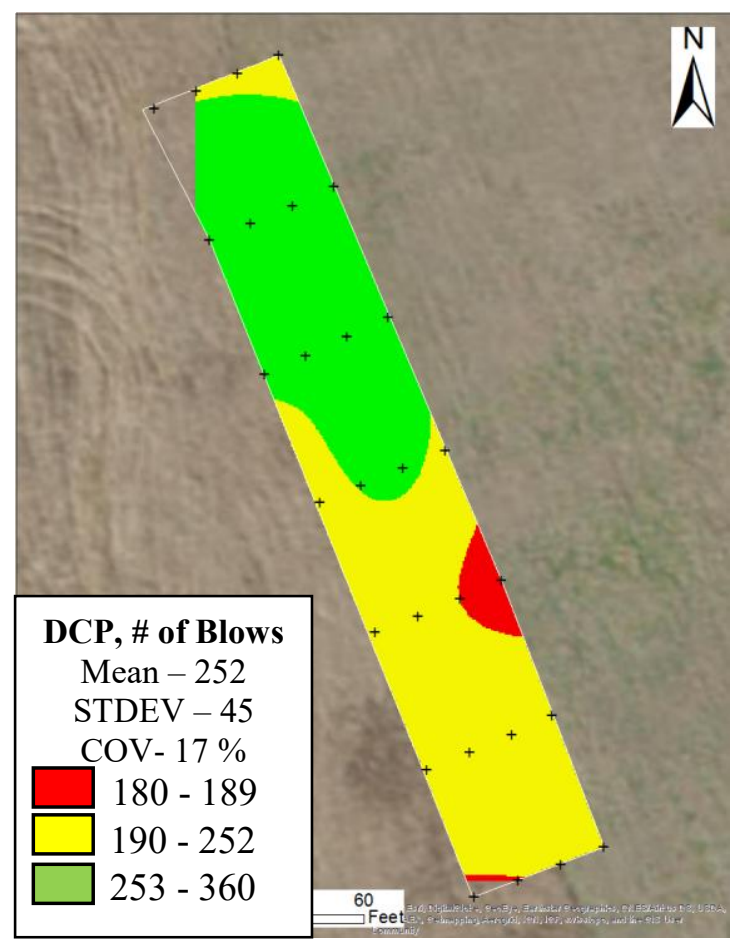

Figure 5.13 - Spatial Distribution of Number of DCP Blows of FB Layer.

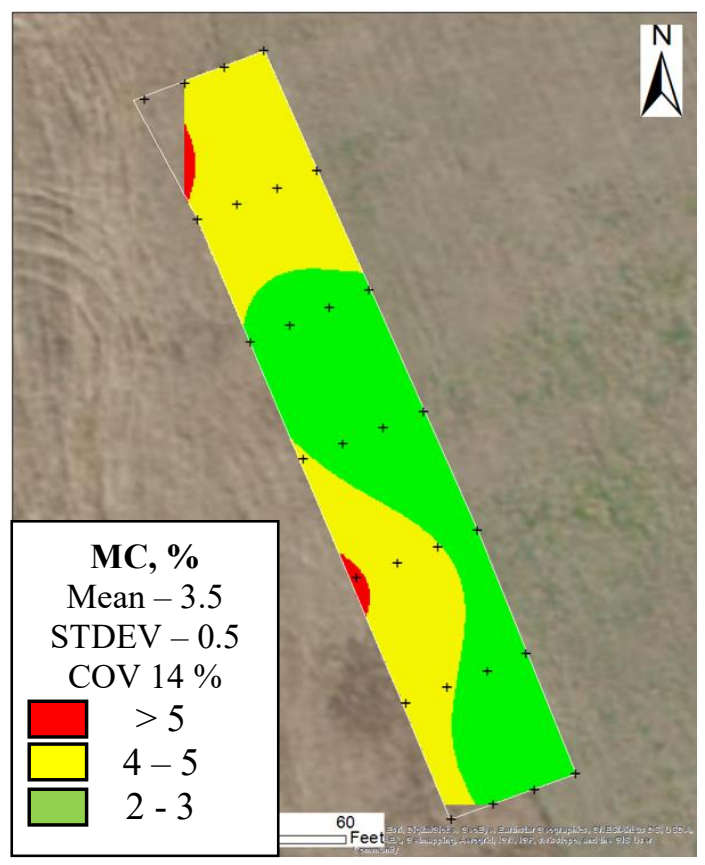

Figure 5.14 - Spatial Distribution of Moisture Content of Flexible Base Layer. 
A comparison between LWD moduli and CMV data at different stations is illustrated in Figure 5.15a. Unlike the mapping, LWD moduli and the CMV results show a similarity in the trends when evaluated with respect to stations. Likewise, the number of DCP blows and CMV data per station, shown in Figure 5.15b, indicates good relationship may be seen between the trends of both measurements.
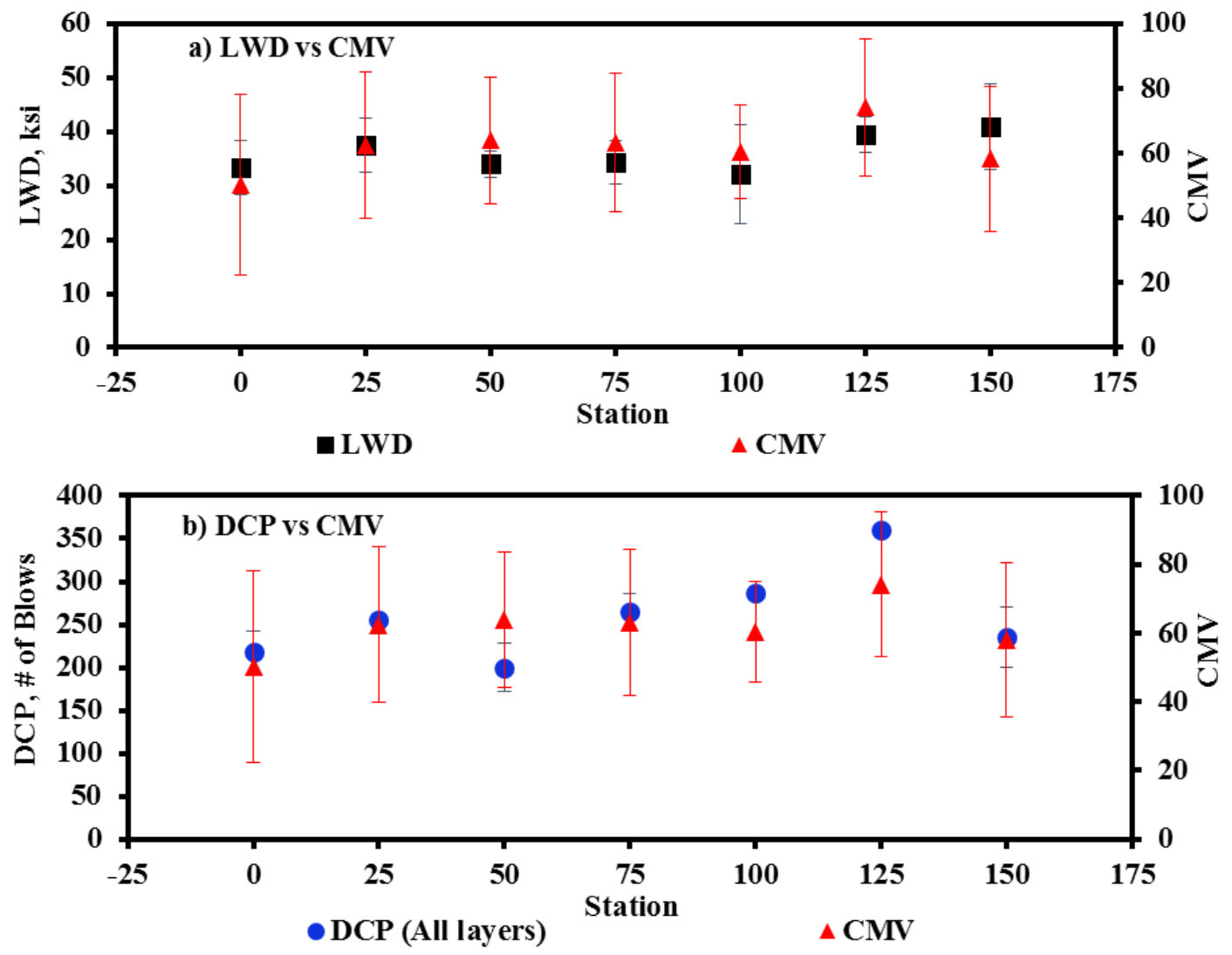

Figure 5.15 - Relationship between Averaged (a) LWD Modulus and (b) Number of DCP Blows vs CMV in Flexible Base. 


\subsection{IMPLEMENTATION OF OPTIMIZATION PROCESS FOR IDENTIFYING LOW STIFF AREAS}

\section{USING IC}

The optimization process described in section 3.7 was applied to attempt to reduce the quantity of mistakenly identified low stiff areas. Table 5.1 shows the percentage of mis-estimated areas on the subgrade layer comparing LWD surface deflections and CMVs. For this particular layer, the IC roller was able to predict almost all less-stiff areas (shaded cells in Table 6.1), when a class-break criteria were set at $65 \%$ of the average CMV (or lower) and at $120 \%$ of the average LWD deflection (or lower). The IC roller prediction improved using the same class-break criteria on the DCP results.

Table 5.1 - Percentage of Mis-Estimated CMV Less-Stiff when Compared to Less-Stiff Areas as Predicted by the LWD Surface Deflection in LTS layer.

\begin{tabular}{|c|c|c|c|c|c|c|c|}
\hline \hline $\begin{array}{c}\text { < \% Average } \\
\text { CMV }\end{array}$ & \multicolumn{7}{|c|}{$>$ \% of Average LWD Surface Deflection, $\boldsymbol{d}_{\boldsymbol{L W D}}$} \\
\cline { 2 - 8 } & $\mathbf{1 1 0}$ & $\mathbf{1 1 5}$ & $\mathbf{1 2 0}$ & $\mathbf{1 2 5}$ & $\mathbf{1 3 0}$ & $\mathbf{1 3 5}$ & $\mathbf{1 4 0}$ \\
\hline $\mathbf{9 0}$ & 23 & 59 & 59 & 59 & 82 & 82 & 82 \\
\hline $\mathbf{8 5}$ & 23 & 59 & 59 & 59 & 82 & 82 & 82 \\
\hline $\mathbf{8 0}$ & 21 & 58 & 58 & 58 & 79 & 79 & 79 \\
\hline $\mathbf{7 5}$ & 21 & 58 & 58 & 58 & 79 & 79 & 79 \\
\hline $\mathbf{7 0}$ & 21 & 50 & 50 & 50 & 71 & 71 & 71 \\
\hline $\mathbf{6 5}$ & 0 & 25 & 25 & 25 & 50 & 50 & 50 \\
\hline $\mathbf{6 0}$ & 0 & 25 & 25 & 25 & 50 & 50 & 50 \\
\hline
\end{tabular}

Table 5.2 - Percentage of Mis-Estimated CMV Less-Stiff when Compared to Less-Stiff Areas as Predicted by the DCP in Subgrade.

\begin{tabular}{|c|c|c|c|c|c|c|c||}
\hline \hline $\begin{array}{c}\text { \% Average } \\
\text { CMV }\end{array}$ & \multicolumn{7}{|c|}{$<$ \% of Average Number of DCP Blows } \\
\cline { 2 - 9 } & $\mathbf{9 0}$ & $\mathbf{8 5}$ & $\mathbf{8 0}$ & $\mathbf{7 5}$ & $\mathbf{7 0}$ & $\mathbf{6 5}$ & $\mathbf{6 0}$ \\
\hline $\mathbf{9 0}$ & 10 & 14 & 29 & 43 & 71 & 90 & 95 \\
\hline $\mathbf{8 5}$ & 10 & 14 & 29 & 43 & 71 & 90 & 95 \\
\hline $\mathbf{8 0}$ & 11 & 16 & 26 & 42 & 68 & 89 & 95 \\
\hline $\mathbf{7 5}$ & 11 & 16 & 26 & 42 & 68 & 89 & 95 \\
\hline $\mathbf{7 0}$ & 7 & 14 & 29 & 43 & 57 & 86 & 93 \\
\hline $\mathbf{6 5}$ & 0 & 0 & 0 & 0 & 0 & 50 & 75 \\
\hline $\mathbf{6 0}$ & 0 & 0 & 0 & 0 & 0 & 50 & 75 \\
\hline
\end{tabular}




\section{Chapter 6: Evaluation of IC Data in Irving, Texas}

\subsection{INTRODUCTION}

A test section along the west-bound TX-183 in Irving, TX was used for this field evaluation. Figure 6.1 shows an aerial view of the test section.

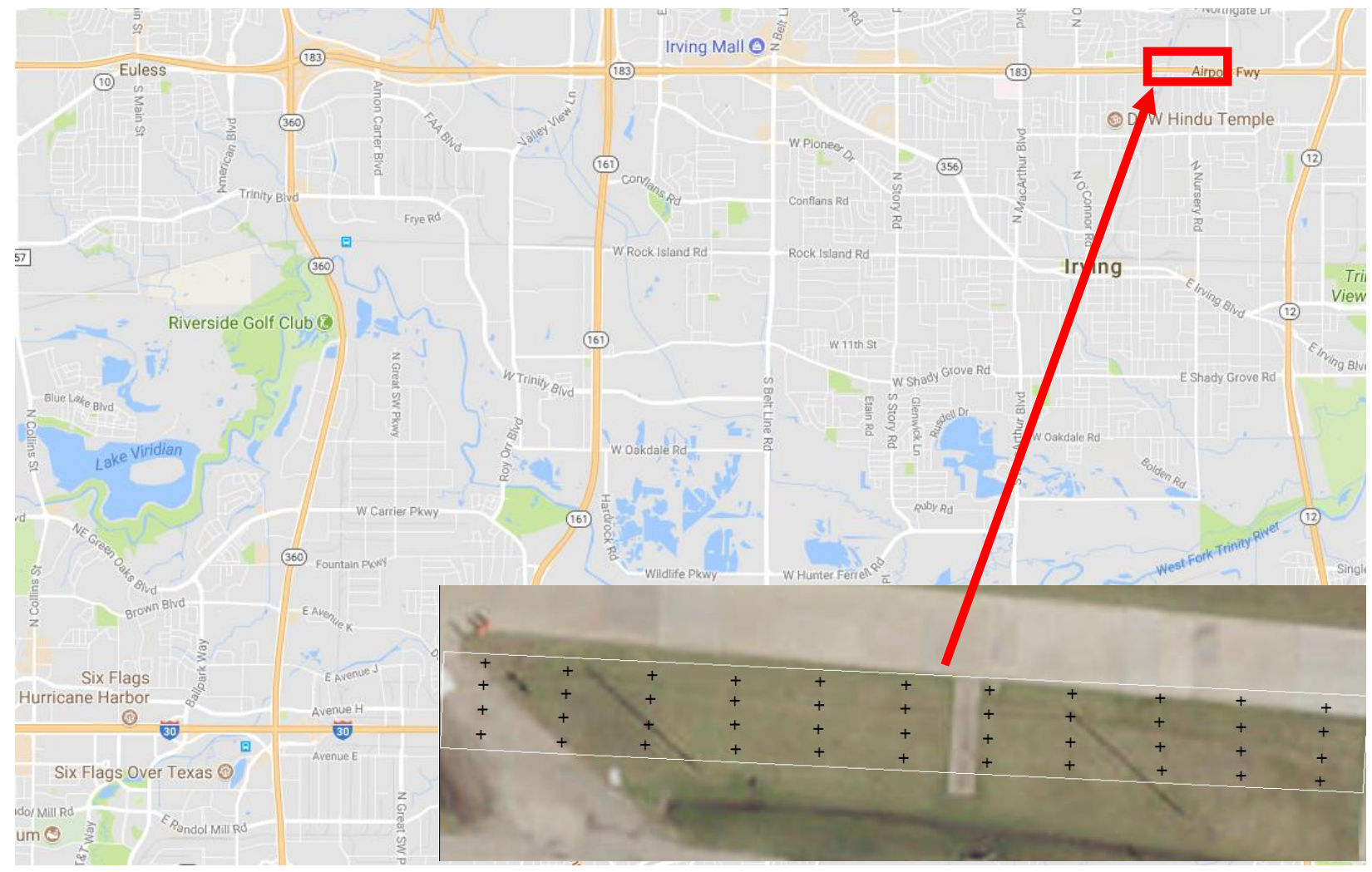

Figure 6.1 - Location of Field Evaluation Site on TX-183 in Irving, TX.

The field evaluation was conducted on two different pavement layers. The first layer consisted of an 8 in. lime-treated subgrade (LTS) on top of subgrade. Field evaluation of the LTS took place on April 25, 2017. The second layer evaluated at this section was a 12 in. flexible base layer as shown in Figure 6.2. IC roller compaction and NDT testing of the base were carried out on May 9, 2017. 


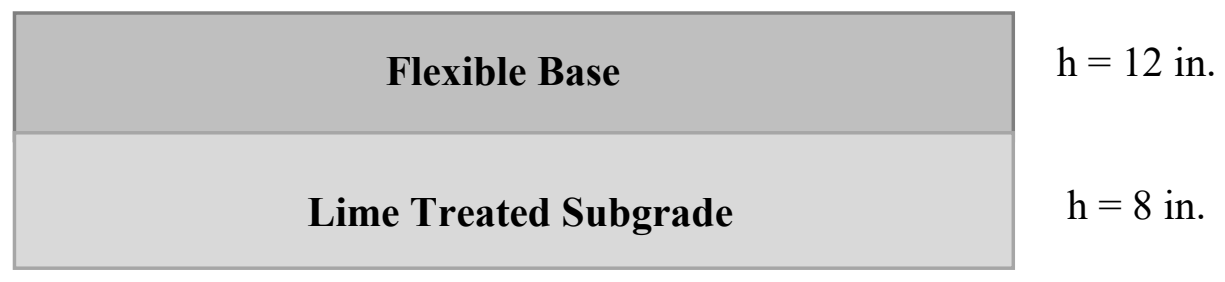

Figure 6.2 - Pavement Structure of Test Section

\subsection{Field Testing Program}

Nondestructive testing (NDT) and proof-rolling was performed on a $250 \mathrm{ft}$.-long and 21 ft.-wide section. To locate the spots to carry out the different tests, a grid consisting of 44 points divided in 4 columns of 11 points each was arranged on the site. The grid was designed with a spacing of $25 \mathrm{ft}$ between each of the 11 points, and a spacing of $7 \mathrm{ft}$ between each column, as shown in Figure 6.3. LWD and DCP tests were carried out at each point as discussed above. In addition, moisture content samples were collected at all test locations.

a)

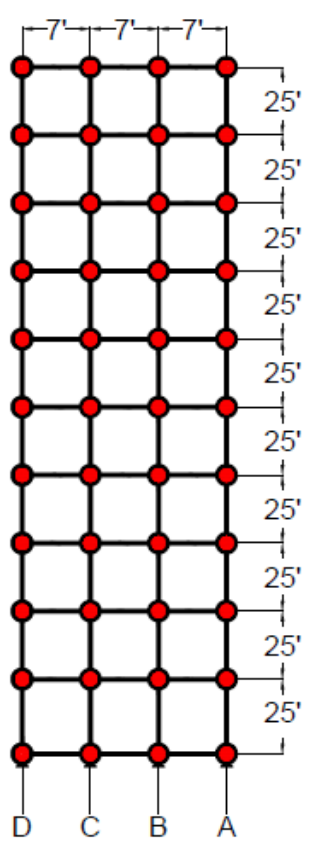

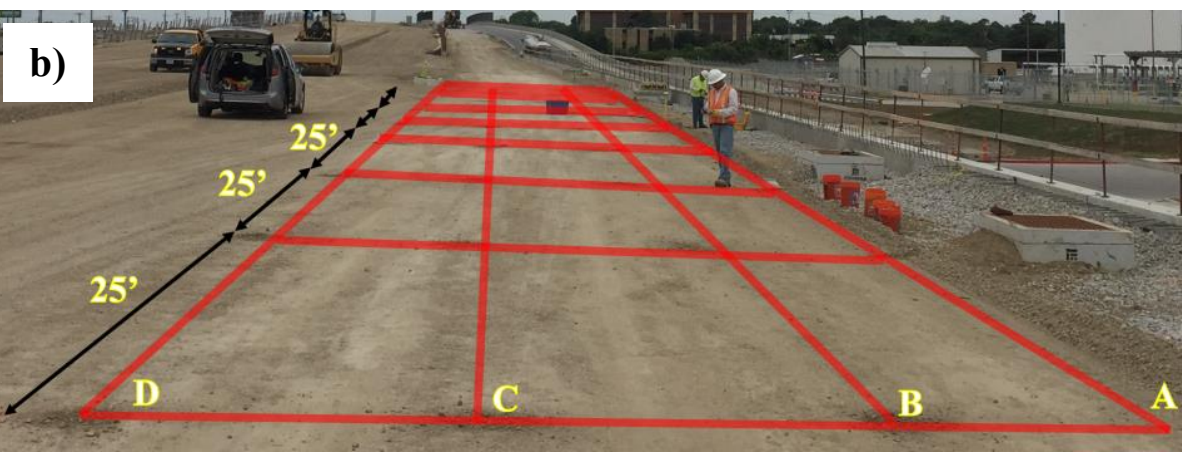

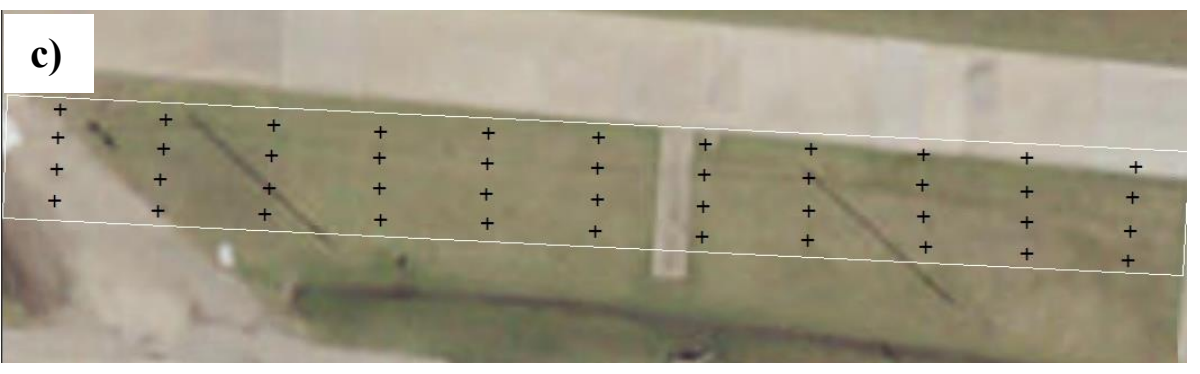

- Spot Test ${ }^{*}$ Not to Scale

Figure 6.3 - (a) Schematic of the Test Section, (b) Site View with Grid Overimposed over Test Section and (c) Satellite View Showing Spot Test Points. 
UTEP's data acquisition system was employed for the proof-mapping during this field evaluation. A map of the IC data obtained by the acquisition system during the proof-mapping of the subgrade is shown on Figure 6.4.

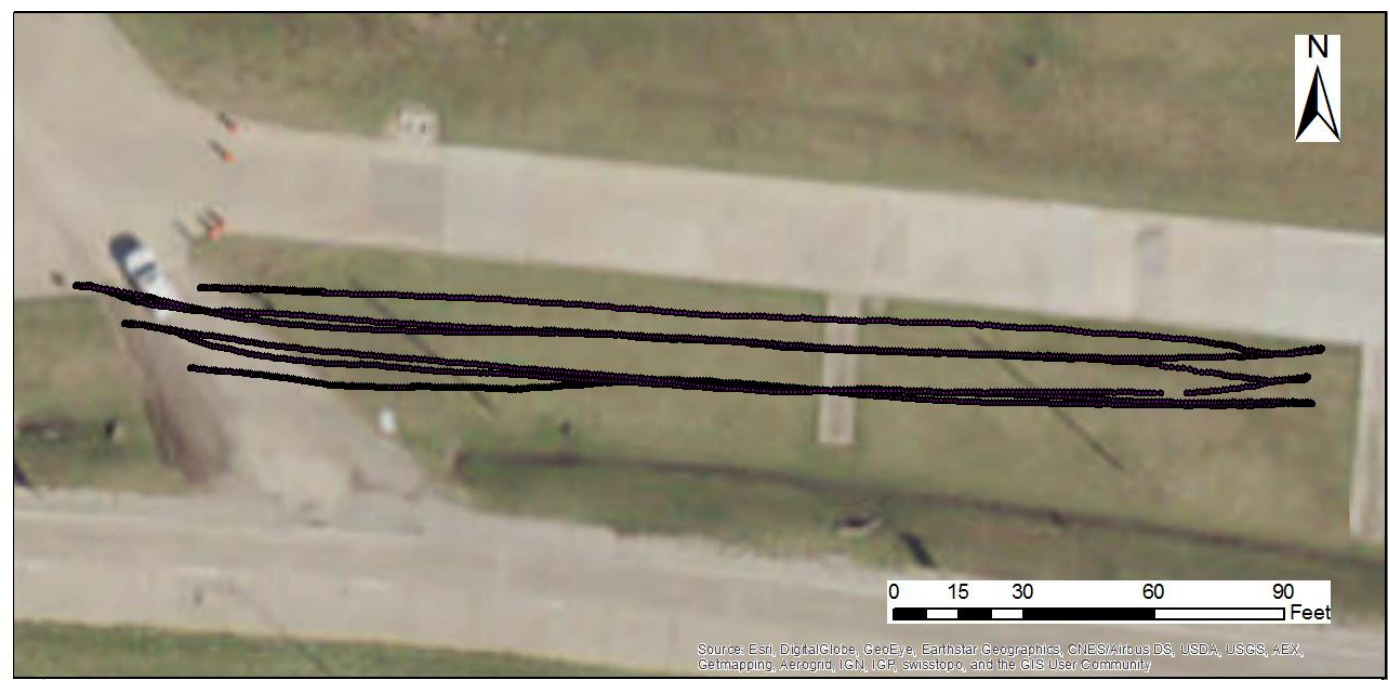

Figure 6.4 - IC Data Points Collected During Proof-Mapping of Subgrade Layer

\subsection{LIME-TREATED SUbGRADE}

The lime-treated subgrade layer was proof-mapped using a padfoot CAT CS78B roller equipped with an IC retrofit kit. The histogram of the mapped CMVs is summarized in Figure 6.5. The average CMV value was 11 with a COV of $86 \%$.

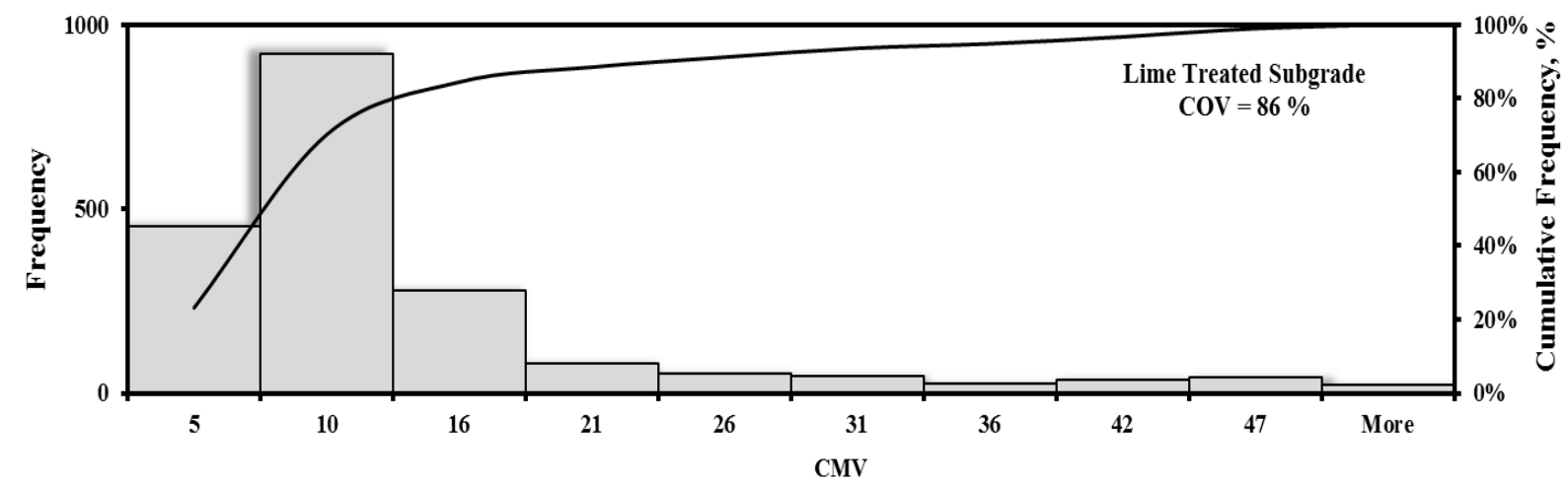

Figure 6.5 - Distribution of CMV Data Collected by IC Roller on top of LTS Layer. 
Based on the 25 by $7 \mathrm{ft}$ spacing between the locations of the LWD spots, rectangular buffered areas were created around each LWD spot location. IC data points found within these blocks was averaged to obtain a unique ICMV to represent that block. In a few cases there were no IC data points found within the limits of the created blocks, as in the case of cells A250, D250, B125, and B150. Color-coded maps, shown in Figure 6.6, were created using the criterion shown in Table 4.1 to compare the values obtained in each block for the IC data and the LWD deflections.

The spatial distribution of the averaged CMVs is shown in Figure 6.6a. The values found in the averaged CMV blocks ranged from a minimum of 5 to a maximum of 179 , with a mean of 33. Figure $6.6 \mathrm{~b}$ illustrates the spatial distribution of the deflections created during the LWD testing on top of the LTS layer. The LWD deflections varied from 8 mils to 47 mils with an average of 22 mils. The LWD deflection map reveals a region that is less-stiff at the upper left section of the site, i.e. between Stations 175 to 250, Lines C-D. This area was not revealed on the CMV map.

The coefficient of variation of CMVs within the buffered revealed that the blocks along Line A and along Stations 0 and 250 had highly variable CMVs, as shown in Figure 6.7. 
$\mathbf{a}$

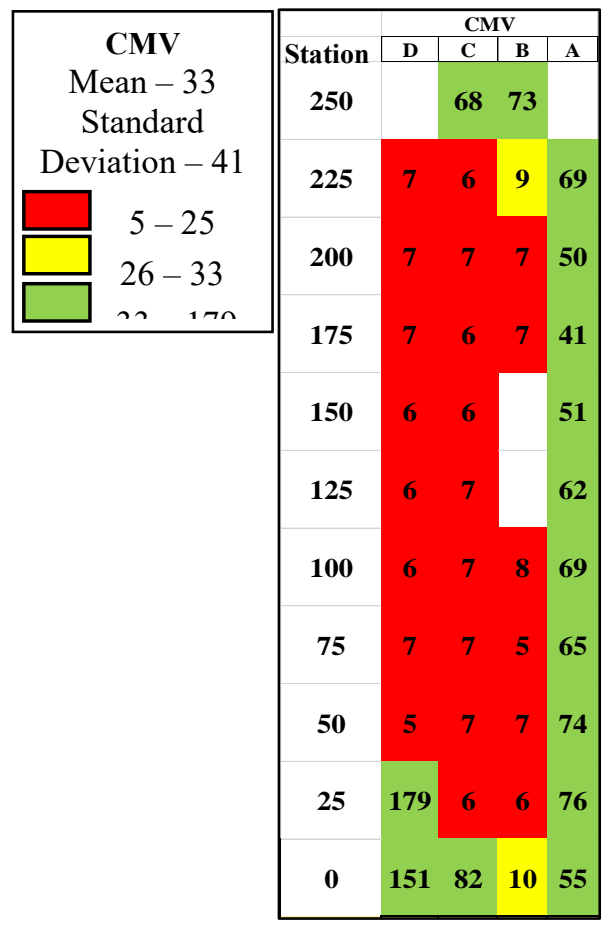

b)

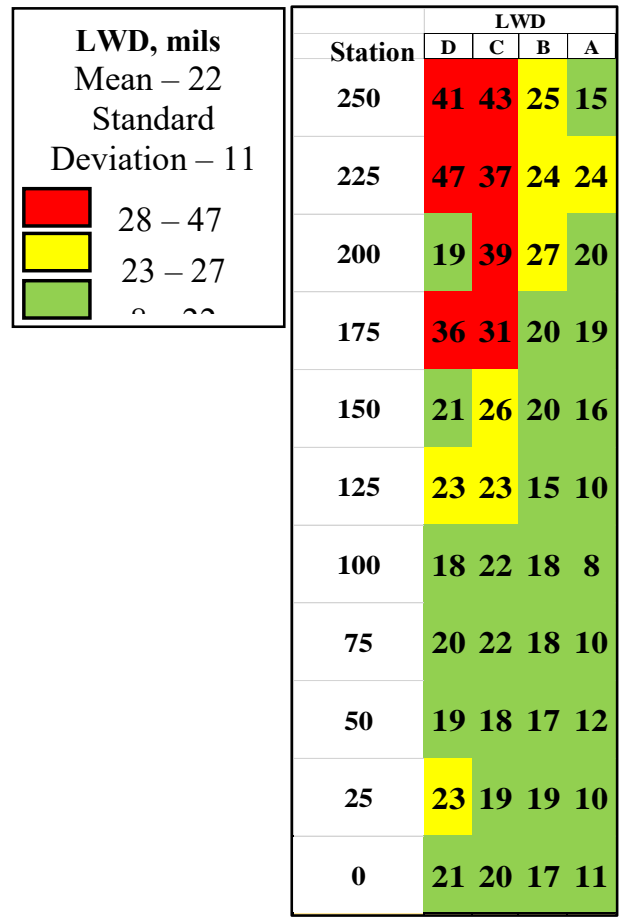

Figure 6.6 - Spatial Variation Comparison between (a) CMV and (b) LWD Deflection.

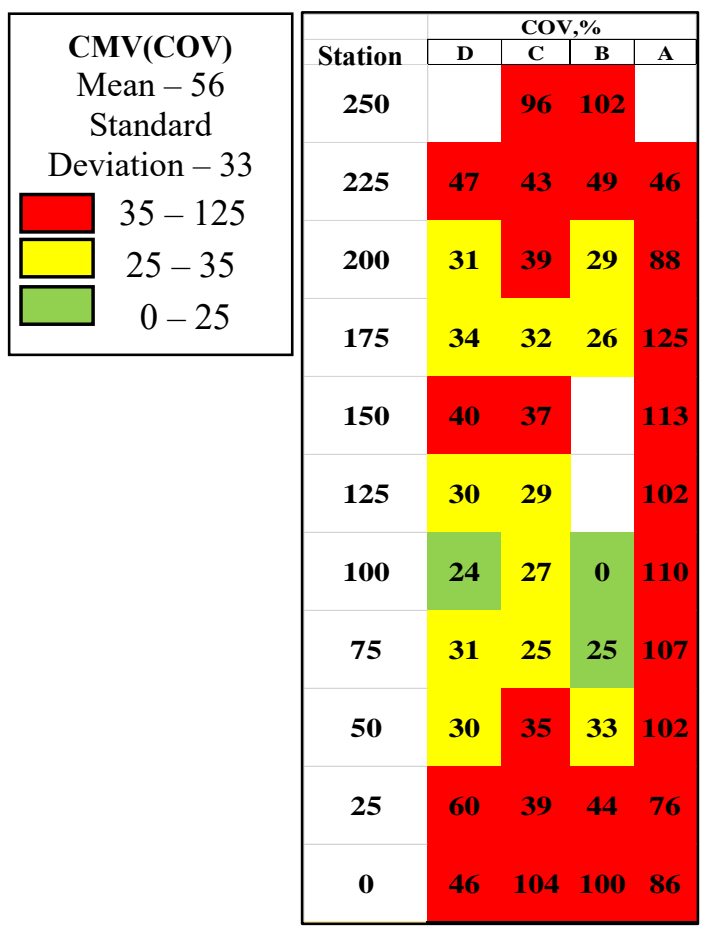

Figure 6.7 - Spatial Variation of Coefficient of Variation of CMV within each Buffered Area. 
Figure 6.8 summarizes the DCP results on the compacted LTS layer. The numbers of DCP blows required to penetrate to a depth of $18 \mathrm{in}$. ranged from 14 blows to 83 blows with an average of 36 blows and a COV of $45 \%$. Similar to LWD, the upper-left part of the distributed map required fewer DCP blows than the rest of the test section and, thus, is identified as a less-stiff area.

Comparison between the LWD and DCP moduli and the CMV data at different stations are illustrated in Figure 6.9. Due to the highly variable nature of the data, it is hard to visualize a correlation among different tests.

a)

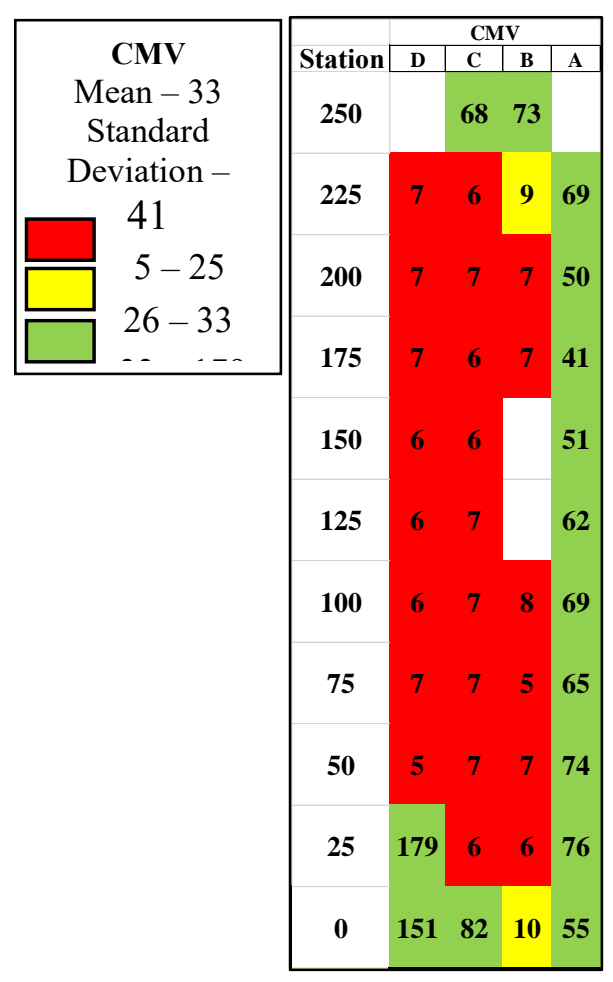

b)

\begin{tabular}{|c|}
\hline $\begin{array}{c}\text { DCP, blows } \\
\text { Mean }-36 \\
\text { Standard } \\
\text { Deviation }-16\end{array}$ \\
\hline $14-26$ \\
\hline $27-35$ \\
\hline $36-83$ \\
\hline
\end{tabular}

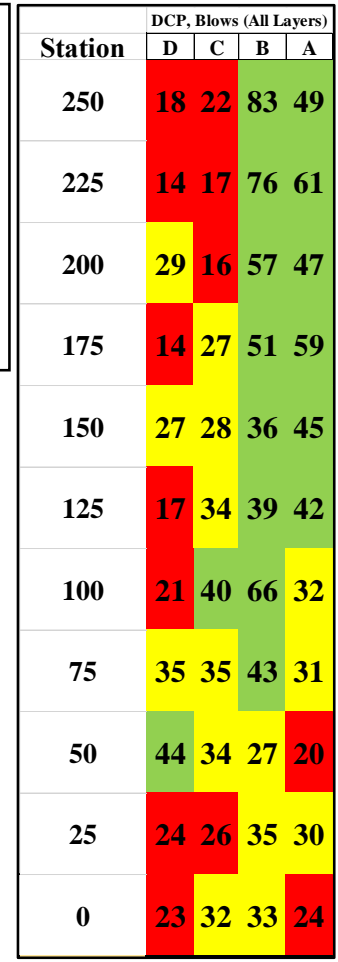

Figure 6.8 - Spatial Variation Comparison between (a) CMV and (b) Number of DCP Blows to Penetrate 18 in. on LTS Layer. 

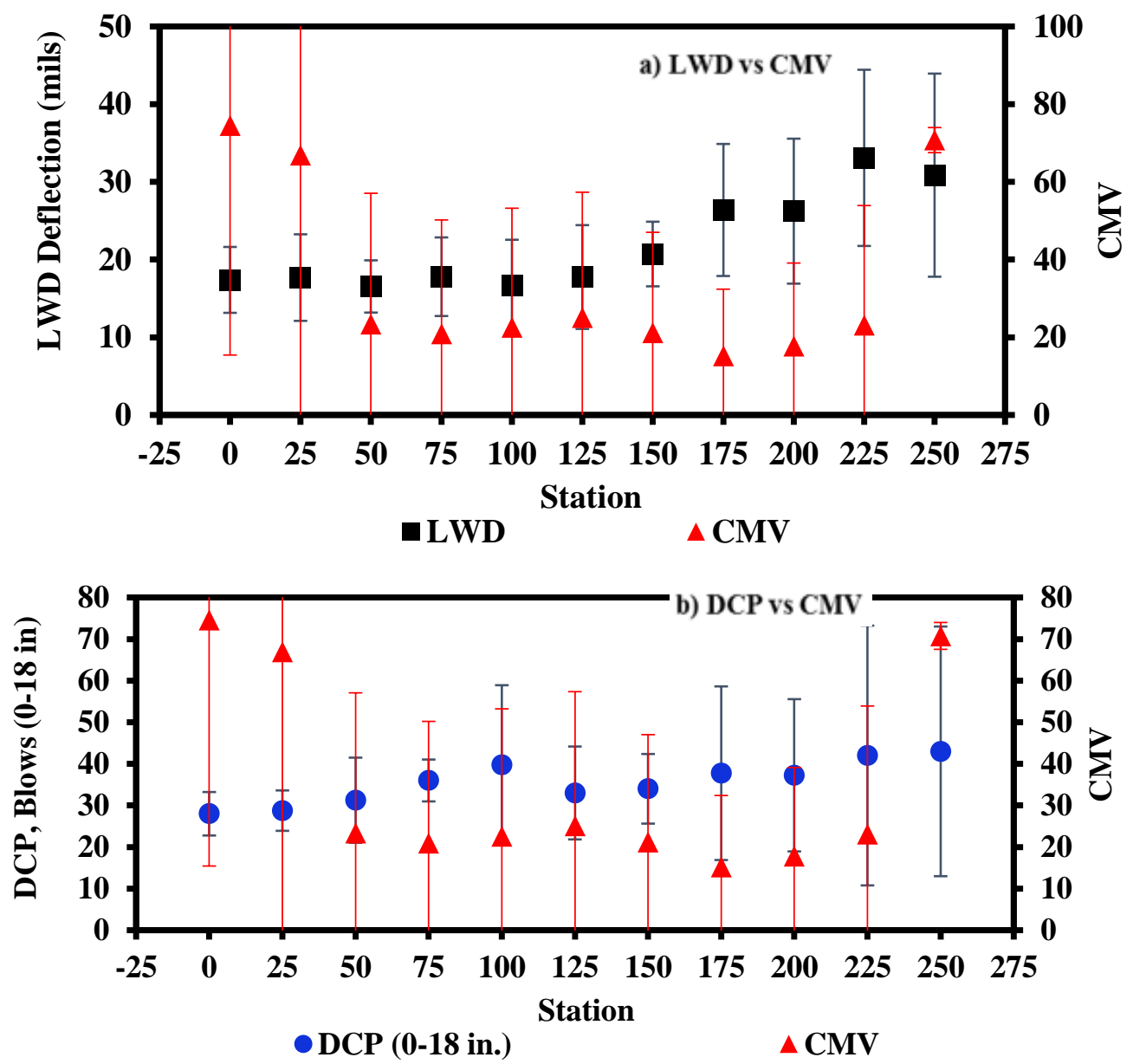

Figure 6.9 - Relationship between Averaged (a) LWD Surface Deflection and (b) Number of DCP Blows to Penetrate 18 in. vs. Average CMV per Station.

Figure 6.10 illustrates the spatial distribution of the moisture content of the LTS layer. The moisture content varied from $9 \%$ to $20 \%$ with an average of $14 \%$. Since moisture content was mostly uniform throughout the test section, very minor areas were marked as red (high moisture content). No well-defined visual relationship is seen between moisture content and CMV nor with the other modulus-based measurements. 


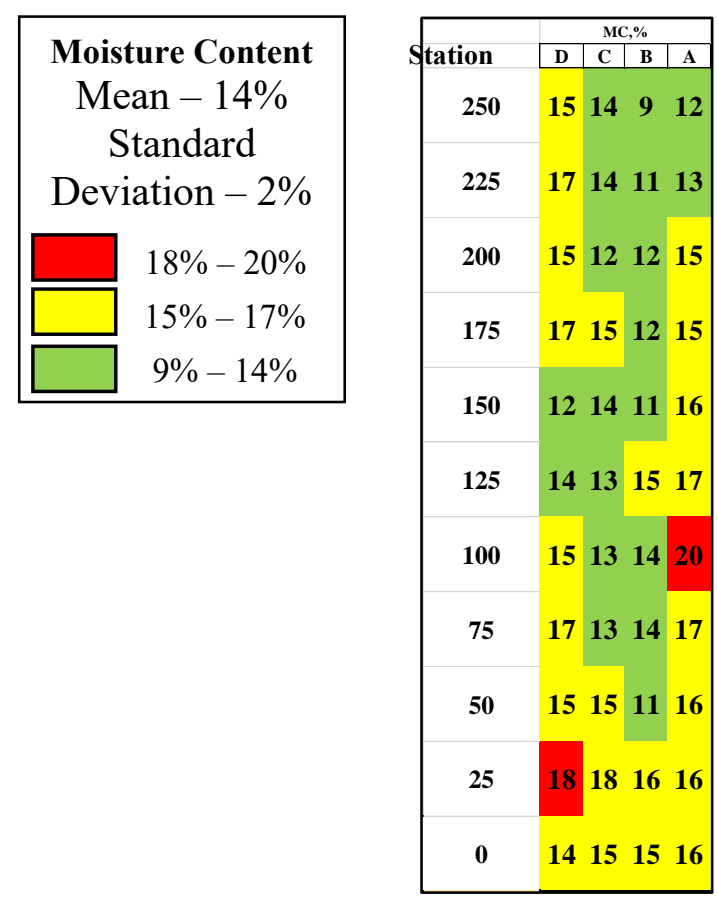

Figure 6.10 - Spatial Distribution of Moisture Content of LTS Layer.

\subsection{FLEXIBLE BASE}

The next phase of the construction consisted of placing and compacting the 8 in. Flexible Base (FB) layer. The tested area for the flexible base was the same area evaluated for the LTS. The histogram of the mapped CMVs is shown in Figure 6.11. The average CMV was 25 with a COV of $45 \%$.

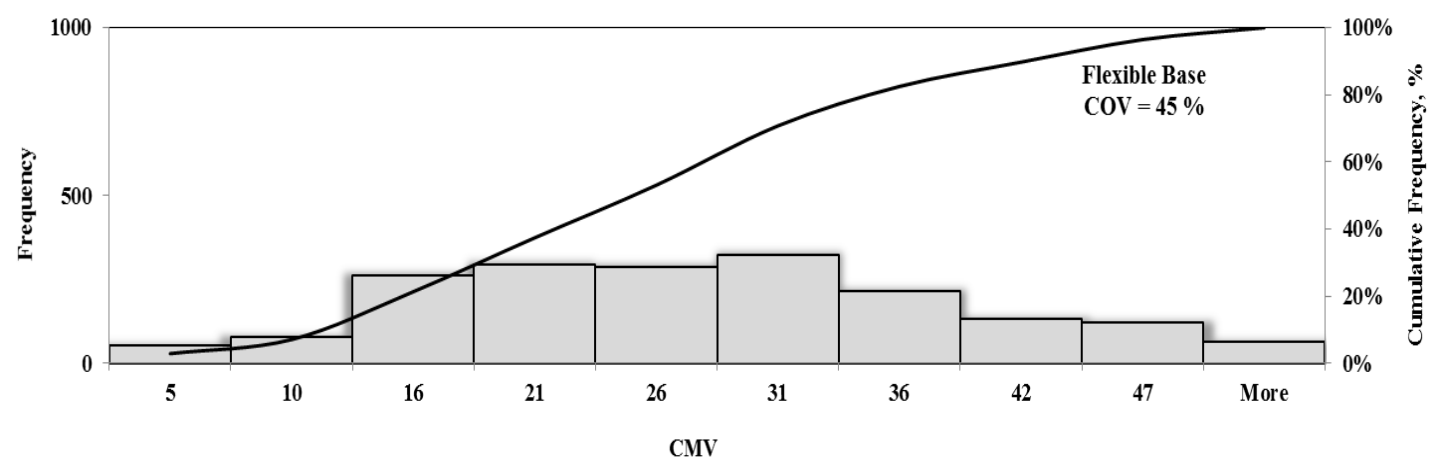

Figure 6.11 - Distribution of CMV Data Collected by IC Roller during Proof-Rolling of Flexible Base Layer. 
Figure 6.12 shows the IC data points collected during the compaction of the layer and the rectangular buffered areas created around the spot tests locations. No data are collected along Line D.

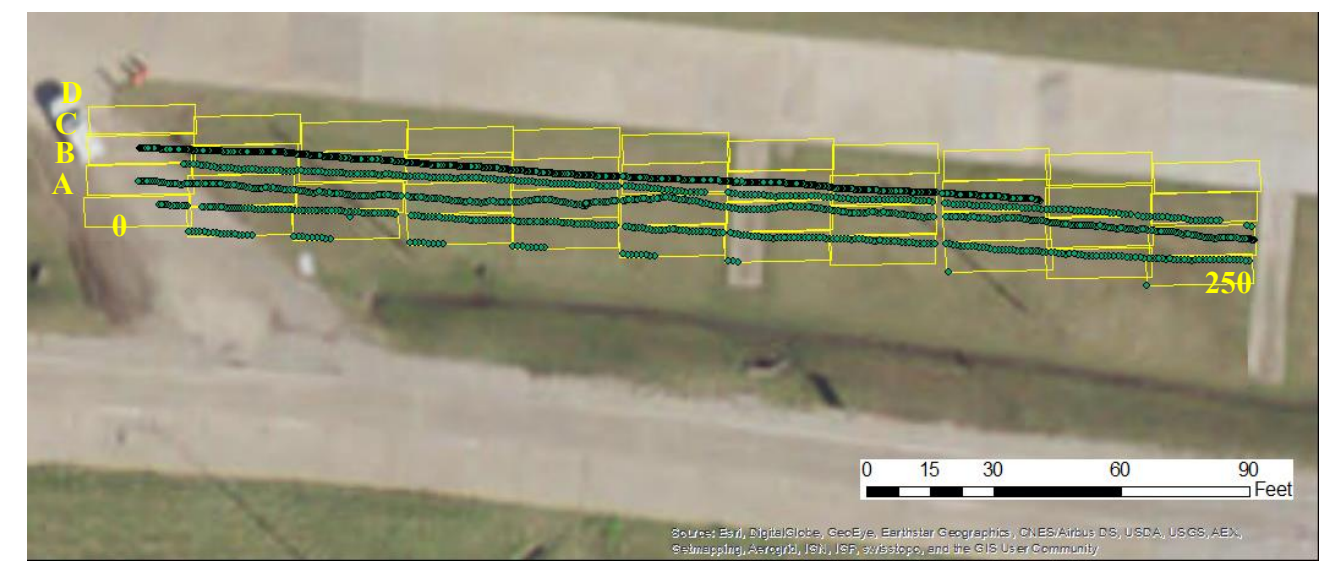

Figure 6.12 - Data Collected by IC Roller on top of Base Divided in Rectangular Buffered Areas. The spatial distribution of averaged CMVs is shown in Figure 6.13a. The values found in the averaged CMV blocks ranged from a minimum of 20 to a maximum of 93 . Figure $6.13 \mathrm{~b}$ illustrates the spatial distribution of the LWD modulus on top of the base layer. The LWD deflections varied from 7 mils to 44 mils with an average of 17 mils. A clear correlation was not found between the two maps. This could be the result of the difference in size of the maps due to the absence of CMV data in some blocks. The LWD map was recreated in Figure 6.14 disregarding the information from the left row to reproduce a color-coded map that resembles more the CMV map. Figure 6.15 shows a map with the coefficient of variation found within each rectangular buffered areas. The lack of a direct correlation between the LWD and CMV may be attributed to the high percentage of variation found in the CMV map. 
a

\begin{tabular}{|c|c|c|c|c|}
\hline \multirow{3}{*}{$\begin{array}{c}\text { CMV } \\
\text { Mean - 38 } \\
\text { Standard } \\
\text { Deviation-20 }\end{array}$} & \multicolumn{4}{|c|}{ CMV } \\
\hline & 250 & 43 & 67 & 30 \\
\hline & 25 & & & \\
\hline $20-28$ & & & & \\
\hline & 200 & 41 & 36 & 36 \\
\hline $29-37$ & & & & \\
\hline $38-93$ & 175 & 25 & 36 & 24 \\
\hline & 150 & 25 & 35 & 20 \\
\hline & 125 & 20 & 67 & 27 \\
\hline & 100 & 21 & 88 & 23 \\
\hline & 75 & 28 & 33 & 21 \\
\hline & 50 & 27 & 28 & 53 \\
\hline & 25 & 27 & 28 & 20 \\
\hline & $\mathbf{0}$ & 43 & 93 & 88 \\
\hline
\end{tabular}

b)

\begin{tabular}{|c|}
\hline LWD, mils \\
Mean - 17 \\
Standard \\
Deviation -9 \\
\\
$22-44$ \\
$18-21$ \\
$7-17$ \\
\hline
\end{tabular}

\begin{tabular}{|c|c|c|c|}
\hline & & & WD \\
\hline Station & D & \begin{tabular}{|l|} 
C \\
\end{tabular} & \begin{tabular}{|l|l|} 
& $\mathbf{A}$ \\
\end{tabular} \\
\hline 250 & 18 & 13 & 1213 \\
\hline 225 & 22 & 16 & 1212 \\
\hline 200 & 14 & 11 & 1811 \\
\hline 175 & & 15 & 109 \\
\hline 150 & & 10 & 911 \\
\hline 125 & & 13 & 1013 \\
\hline 100 & & 14 & 128 \\
\hline 75 & 1 & 14 & 1013 \\
\hline 50 & & 16 & 812 \\
\hline 25 & 16 & 7 & 1016 \\
\hline 0 & & 11 & 1417 \\
\hline
\end{tabular}

Figure 6.13 - Spatial Variation Comparison between (a) CMV and (b) LWD.

a)

\begin{tabular}{|c|c|c|c|c|}
\hline & & \multicolumn{3}{|c|}{ CMV } \\
\hline Cinv & Station & \begin{tabular}{l|l} 
D & C \\
\end{tabular} & B & A \\
\hline $\begin{array}{c}\text { Mean }-38 \\
\text { Standard }\end{array}$ & 250 & 43 & 67 & 30 \\
\hline Deviation- & 225 & 46 & 41 & 29 \\
\hline & 200 & 41 & 36 & 36 \\
\hline $20-28$ & & & & \\
\hline $29-37$ & 175 & 25 & 36 & 24 \\
\hline & 150 & 25 & 35 & 20 \\
\hline & 125 & 20 & 67 & 27 \\
\hline & 100 & 21 & 88 & 23 \\
\hline & 75 & 28 & 33 & 21 \\
\hline & 50 & 27 & 728 & 53 \\
\hline & 25 & 27 & 728 & 20 \\
\hline & 0 & 43 & 93 & 88 \\
\hline
\end{tabular}

b)

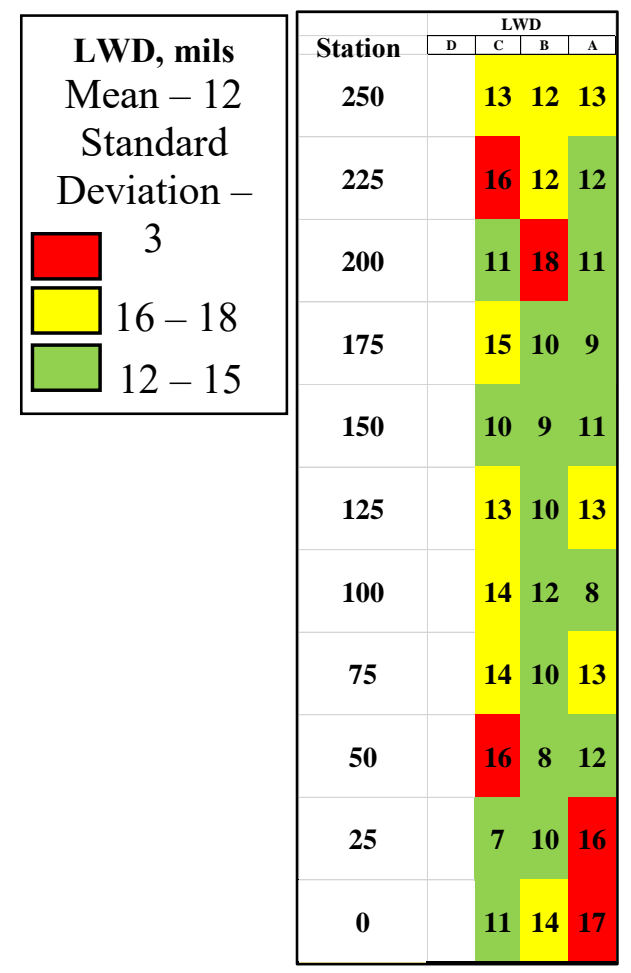

Figure 6.14 - Spatial Variation Comparison between (a) CMV and (b) Recreated LWD. 


\begin{tabular}{|c|c|c|c|c|c|}
\hline CMV(COV \%) & & \multicolumn{4}{|c|}{ cov, \% } \\
\hline Mean - 51 & Station & $\mathbf{D}$ & $\mathrm{c}$ & B & A \\
\hline Standard & 250 & & 18 & 95 & 86 \\
\hline Deviation - 29 & & & & & \\
\hline $36-144$ & 225 & & 18 & 27 & 53 \\
\hline $25-35$ & 200 & & 98 & 19 & 29 \\
\hline $18-25$ & & & & & \\
\hline & & & & & \\
\hline & 150 & & 48 & 29 & 39 \\
\hline & 125 & & 58 & 94 & 19 \\
\hline & 100 & & 70 & 94 & 29 \\
\hline & 75 & & 56 & 32 & 36 \\
\hline & 50 & & 42 & 30 & 50 \\
\hline & 25 & & 31 & 22 & 45 \\
\hline & $\mathbf{0}$ & & 144 & 66 & 79 \\
\hline
\end{tabular}

Figure 6.15 - Spatial Variation of Coefficient of Variation of CMVs within each Buffered Area A comparison between the LWD modulus and the CMV data at different stations is illustrated in Figure 6.16. A visual correlation cannot be easily observed in this figure given the uncertainty due to high COVs.

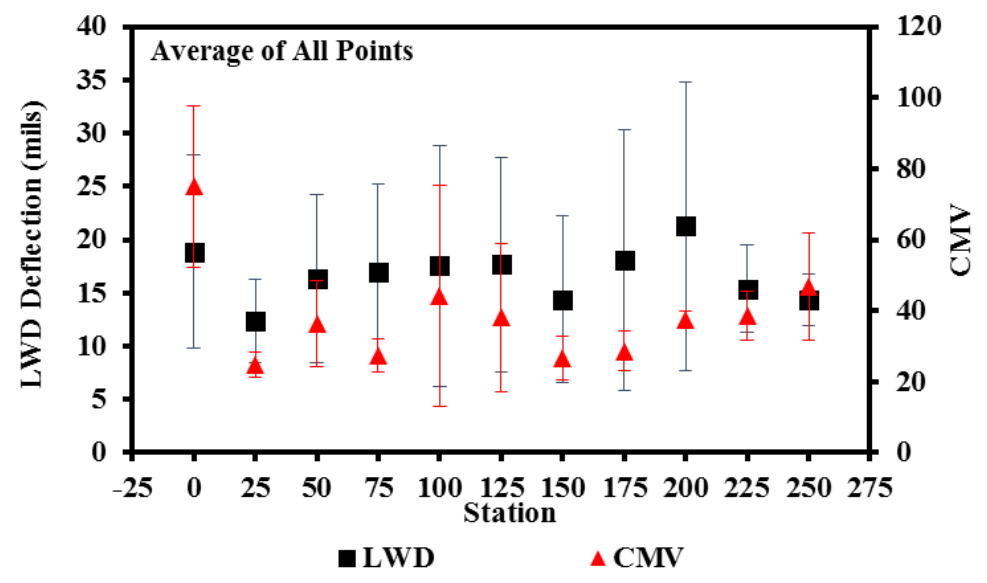

Figure 6.16 - Relationship between Averaged LWD Surface Deflection and vs. Average CMV per Station. 
Figure 6.17 illustrates the spatial distribution of the moisture content of the base layer. The percentage of moisture content varied from $2 \%$ to $5 \%$ with an average of $4 \%$ and a COV of $14 \%$.

\begin{tabular}{|c|c|c|c|c|c|}
\hline \multirow{13}{*}{$\begin{array}{c}\text { CMV } \\
\text { Mean - 14 } \\
\text { Standard } \\
\text { Deviation - 1 } \\
18-20 \\
15-17 \\
\square-14\end{array}$} & Station & \multicolumn{4}{|c|}{ MC, $\%$} \\
\hline & 250 & 5 & 8 & 6 & 7 \\
\hline & & & & & \\
\hline & 225 & 4 & 7 & 7 & 8 \\
\hline & 200 & 5 & 8 & 7 & 8 \\
\hline & 175 & 5 & 8 & 8 & 9 \\
\hline & 150 & 5 & 8 & 5 & 7 \\
\hline & 125 & 8 & 9 & 6 & 7 \\
\hline & 100 & 6 & 7 & 5 & 8 \\
\hline & 75 & 7 & 7 & 6 & 9 \\
\hline & 50 & 7 & 8 & 8 & 9 \\
\hline & 25 & 7 & 8 & 8 & 9 \\
\hline & 0 & 8 & 7 & 7 & 8 \\
\hline
\end{tabular}

Figure 6.17 - Spatial Distribution of Moisture Content of FB Layer.

\subsection{ImPlementation Of OPTIMIZATION Process fOR IDENTIFYING LOW STIFF AREAS USING IC}

The optimization process described in section 3.7 was applied to attempt to reduce the quantity of mistakenly identified low stiff areas. Table 6.1 shows the percentage of mis-estimated areas on the subgrade layer. For this layer a high percentage of mis-estimated less-stiff areas are found using any of the variations of the class-criteria. As mentioned previously on this chapter this could be attributed to the significantly larger CMVs found in a single roller pass (Line A), and the high variability of COVs within each square buffer area (shown in Figure 6.7). A slight decrease in the percentage of mis-estimated less-stiff areas is found when using the optimization process on 
the DCP results found in the subgrade layer (shown in Table 6.2). But there still a high percentage of mis-estimated areas due to the high CMVs found in Line A.

Table 6.1 - Percentage of Mis-Estimated CMV Less-Stiff when Compared to Less-Stiff Areas as Predicted by the LWD Surface Deflection in LTS layer.

\begin{tabular}{|c|c|c|c|c|c|c|c||}
\hline \hline $\begin{array}{c}\text { < \% Average } \\
\text { CMV }\end{array}$ & \multicolumn{7}{|c|}{$>$ \% of Average LWD Surface Deflection, $\boldsymbol{d}_{\boldsymbol{L W D}}$} \\
\cline { 2 - 8 } & $\mathbf{1 1 0}$ & $\mathbf{1 1 5}$ & $\mathbf{1 2 0}$ & $\mathbf{1 2 5}$ & $\mathbf{1 3 0}$ & $\mathbf{1 3 5}$ & $\mathbf{1 4 0}$ \\
\hline $\mathbf{9 0}$ & 72 & 72 & 83 & 89 & 89 & 100 & 100 \\
\hline $\mathbf{8 5}$ & 71 & 71 & 82 & 88 & 88 & 100 & 100 \\
\hline $\mathbf{8 0}$ & 71 & 71 & 82 & 88 & 88 & 100 & 100 \\
\hline $\mathbf{7 5}$ & 67 & 67 & 80 & 87 & 87 & 100 & 100 \\
\hline $\mathbf{7 0}$ & 67 & 67 & 78 & 89 & 89 & 100 & 100 \\
\hline $\mathbf{6 5}$ & 71 & 71 & 86 & 86 & 86 & 100 & 100 \\
\hline $\mathbf{6 0}$ & 67 & 67 & 83 & 83 & 83 & 100 & 100 \\
\hline
\end{tabular}

Table 6.2 - Percentage of Mis-Estimated CMV Less-Stiff when Compared to Less-Stiff Areas as Predicted by the DCP in Subgrade.

\begin{tabular}{|c|c|c|c|c|c|c|c||}
\hline \hline $\begin{array}{c}<\% \text { Average } \\
\text { CMV }\end{array}$ & \multicolumn{7}{|c|}{ <\% of Average Number of DCP Blows } \\
\cline { 2 - 8 } & $\mathbf{9 0}$ & $\mathbf{8 5}$ & $\mathbf{8 0}$ & $\mathbf{7 5}$ & $\mathbf{7 0}$ & $\mathbf{6 5}$ & $\mathbf{6 0}$ \\
\hline $\mathbf{9 0}$ & 52 & 52 & 56 & 72 & 76 & 76 & 76 \\
\hline $\mathbf{8 5}$ & 52 & 52 & 56 & 72 & 76 & 76 & 76 \\
\hline $\mathbf{8 0}$ & 52 & 52 & 56 & 72 & 76 & 76 & 76 \\
\hline $\mathbf{7 5}$ & 52 & 52 & 56 & 72 & 76 & 76 & 76 \\
\hline $\mathbf{7 0}$ & 52 & 52 & 56 & 72 & 76 & 76 & 76 \\
\hline $\mathbf{6 5}$ & 52 & 52 & 56 & 72 & 76 & 76 & 76 \\
\hline $\mathbf{6 0}$ & 52 & 52 & 56 & 72 & 76 & 76 & 76 \\
\hline
\end{tabular}




\section{Chapter 7: Evaluation of IC Data in Victoria, US-77 Highway}

\subsection{INTRODUCTION}

A section of north-bound frontage road of US-77 in Victoria, Texas was used for field evaluation. Figure 7.1 shows an aerial view of the of the test section alongside a map with the location of the test section within the Victoria area. A layer consisting of cement-treated base (CTB) covered with a tack coat was evaluated. The UTEP research team's field testing took place on February 1, 2017.

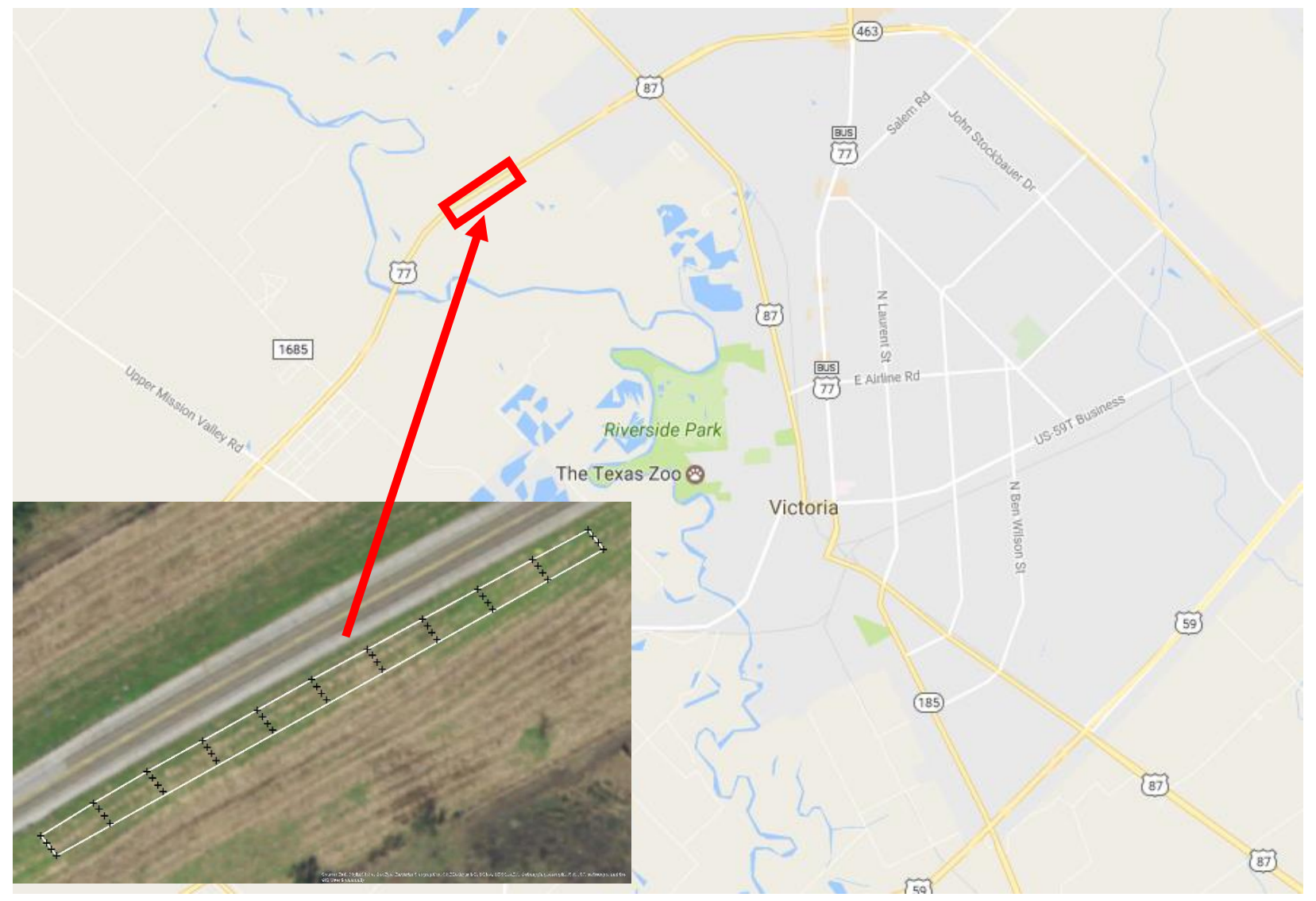

Figure 7.1 - Location of Field Evaluation Site on US-77 in Victoria, TX. 


\subsection{Field Testing Program}

A 500-ft long by 21 -ft wide section was considered in this study. The location of the spot tests was selected over a grid consisting of 44 points divided in four columns of 11 points. The grid was designed with a spacing of $50 \mathrm{ft}$ longitudinally, and a spacing of $7 \mathrm{ft}$ laterally as shown in Figure 7.2. LWD testing was performed on all 44 points on the grid. FWD testing was performed every $25 \mathrm{ft}$.

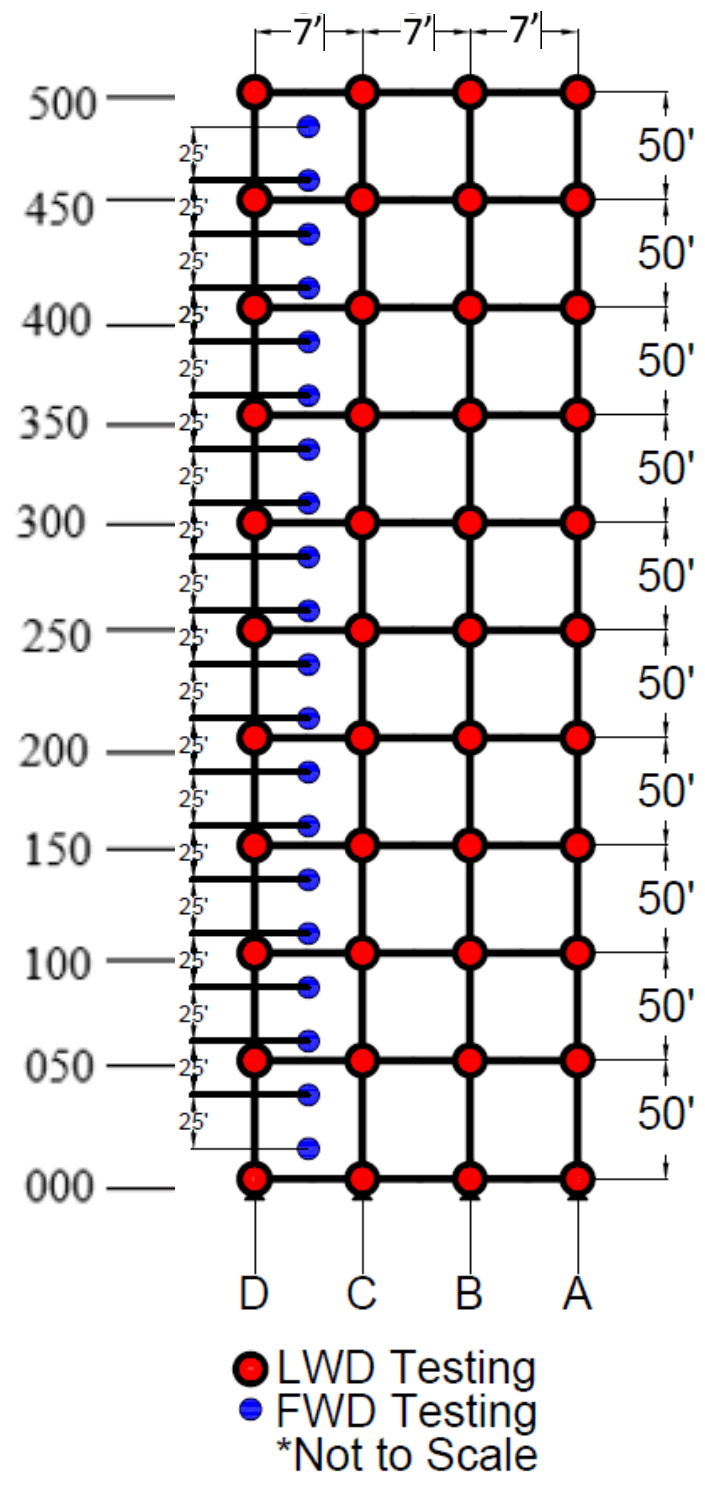

Figure 7.2 Schematic of Test Section 
The layer was mapped using a padfoot HAMM roller equipped with an IC retrofit kit. The histogram of the mapped CMVs is summarized in Figure 7.3. The average CMV value was 86 with a COV of $35 \%$.

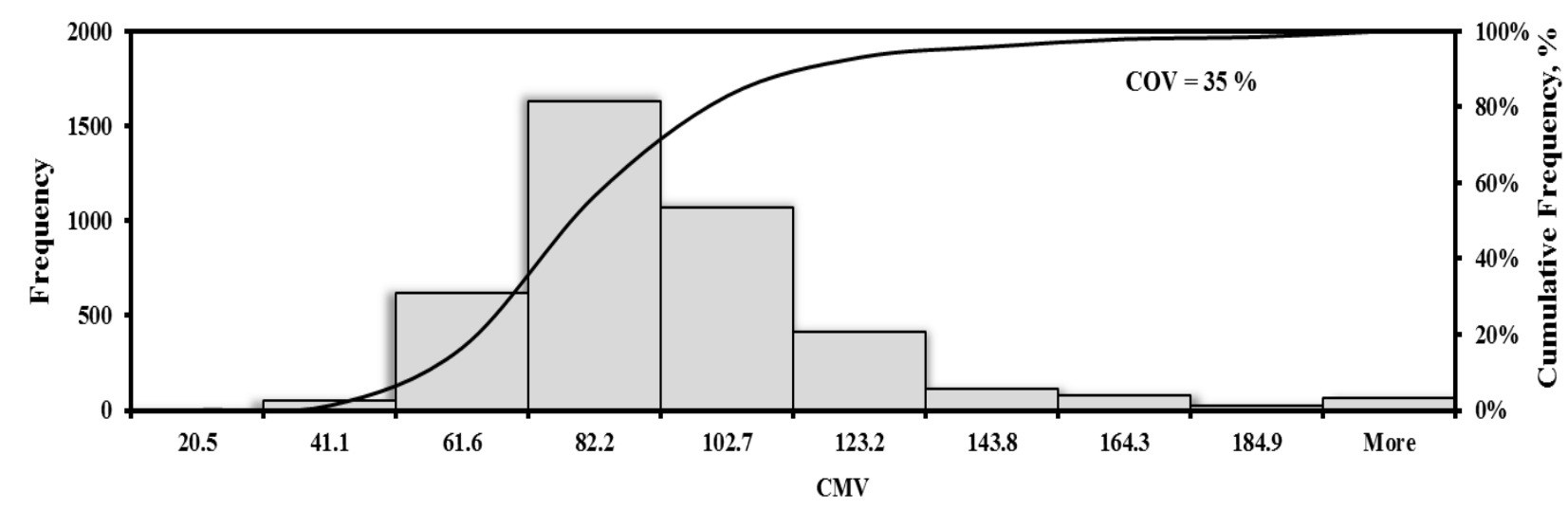

Figure 7.3 - Distribution of CMV Collected by IC Roller during Proof-Rolling of CTB Layer.

Based on the spacing between the locations of the LWD spots, blocks were created around each LWD spot location. IC data points found within these blocks were averaged to obtain one IC measurement to represent that block. Using the IC data results and the LWD moduli color-coded maps were created using three different colors.

The spatial distribution of averaged CMVs is shown in Figure 7.4a. The values found in the averaged CMV blocks ranged from a minimum of 56 to a maximum of 130 . Figure $7.4 \mathrm{~b}$ illustrates the spatial distribution of the LWD modulus on top of the layer. The LWD varied from $19 \mathrm{ksi}$ to $65 \mathrm{ksi}$ with an average of $42 \mathrm{ksi}$.

A comparison between the CMV data and the LWD modulus at different stations is illustrated in Figure 7.5. Some similarity in the trend may be observed throughout the test section with the exception of the beginning and the end parts of the section. This exception was attributed to stop and go operation of the roller toward the beginning and end of the section. The distribution of COVs of the roller CMVs within each of the blocks is shown in Figure 7.6. 


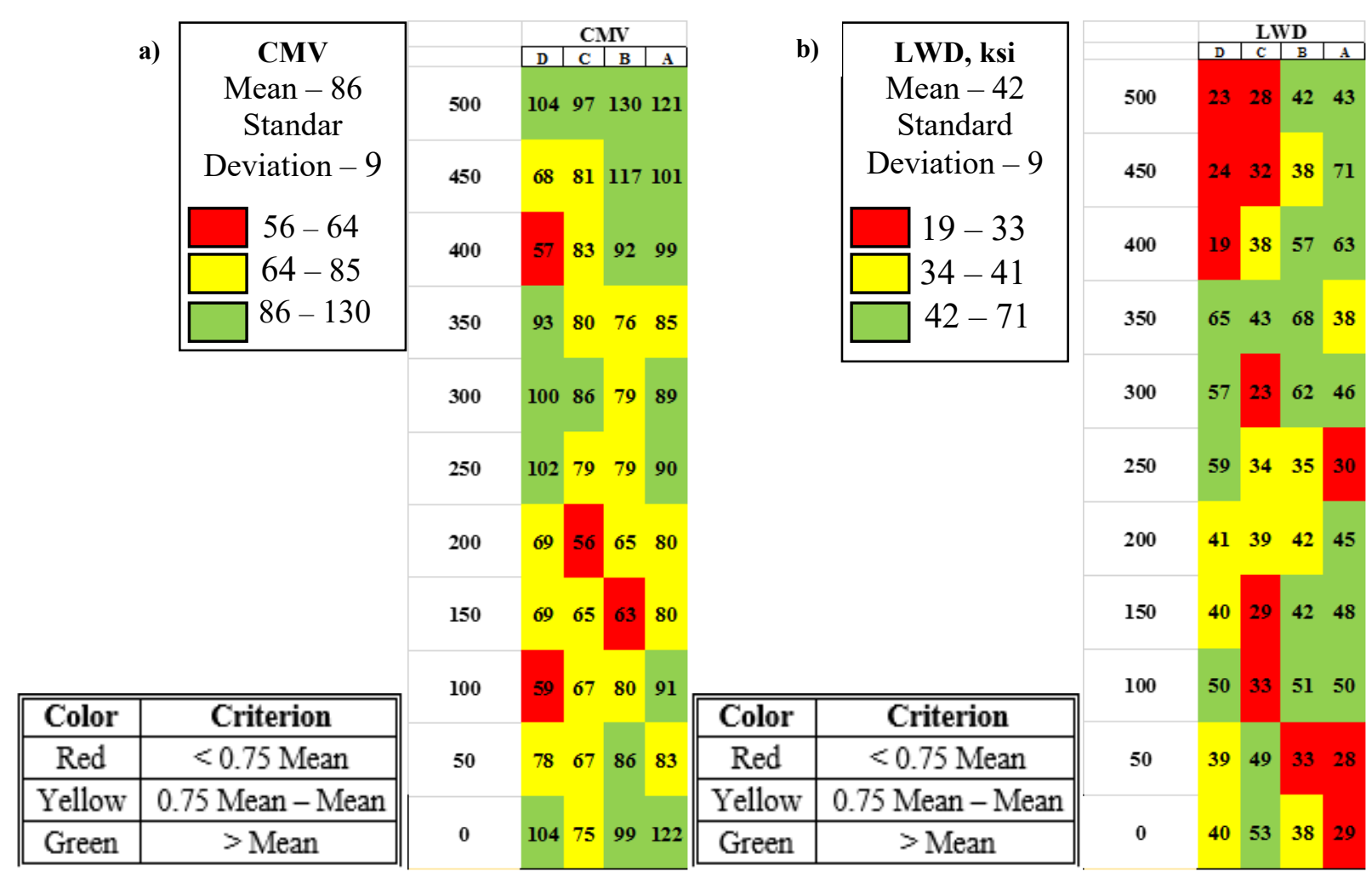

Figure 7.4 - Spatial Variation Comparison between a) CMV and b) LWD.

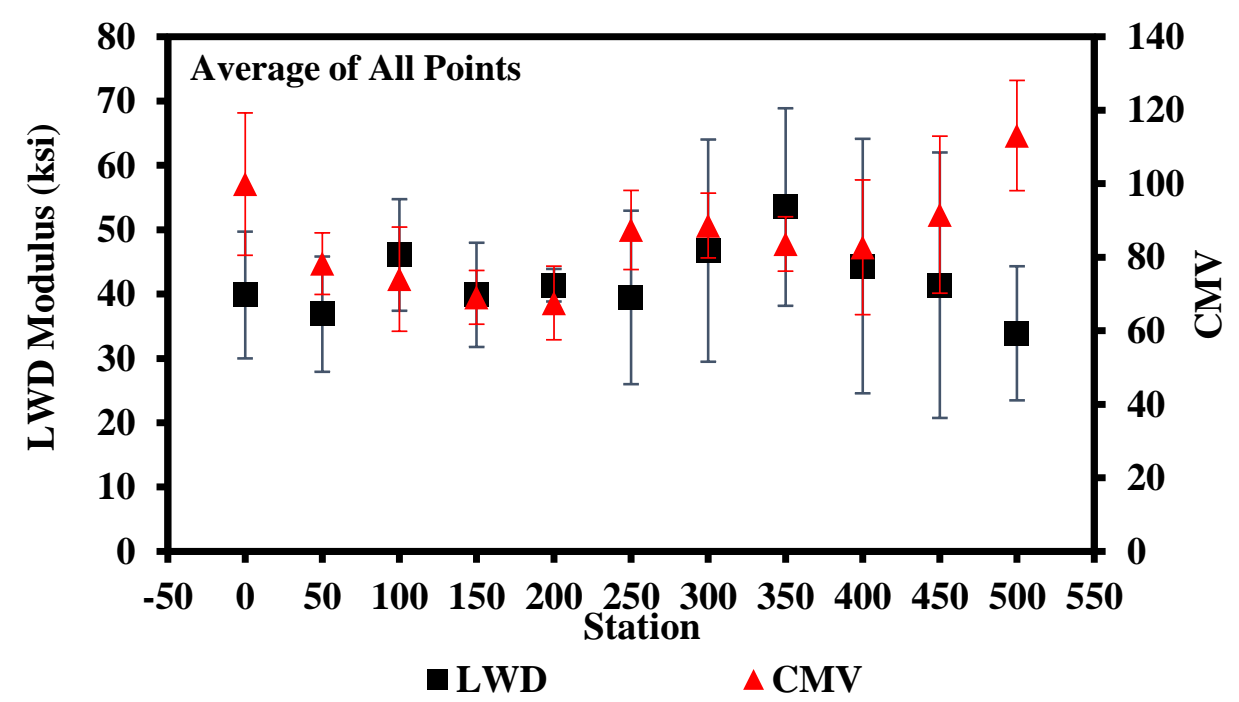

Figure 7.5 - Relationship between Averaged LWD Modulus vs CMV. 


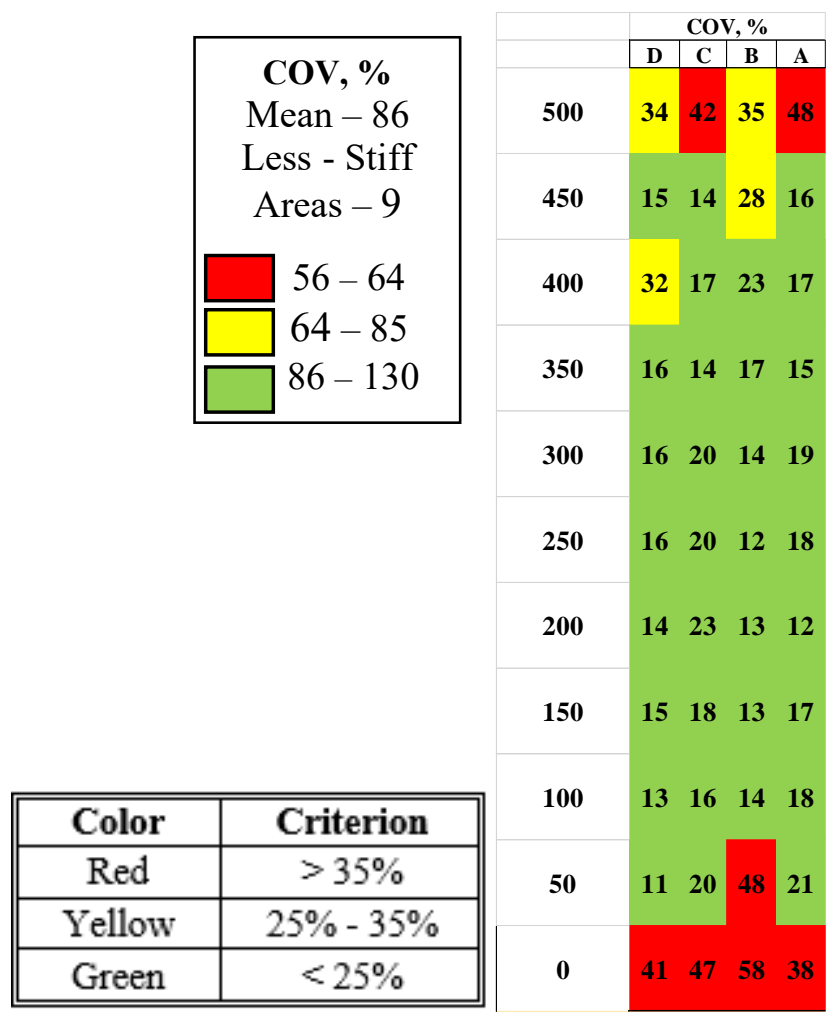

Figure 7.6 - Spatial Variation of Coefficient of Variation of CMV within each Buffered Area.

FWD mapping can be seen in Figure $7.7 \mathrm{~b}$. Surface Modulus of FWD testing $\left(E_{\mathrm{LWD}}\right)$ was calculated using the Boussinesq solution (Terzaghi and Peck 1967):

$$
E_{L W D}=\frac{\left(1-v^{2}\right) a \sigma_{0}}{d_{L W D}} \times f
$$

Where $v$ is Poisson's ratio, $\sigma_{0}$ is the uniformly distributed applied stress, $a$ is the radius of the load plate, $d_{L W D}$ is the soil surface deflection measured below the applied load, and shape factor is assumed to be $f=\pi / 2$. FWD surface modulus varied from $36 \mathrm{ksi}$ to $77 \mathrm{ksi}$. LWD surface modulus do not reflect a clear correlation with the FWD data. One of the possible reasons for the lack of correlation could be that both tests were performed a few days apart from one another. 


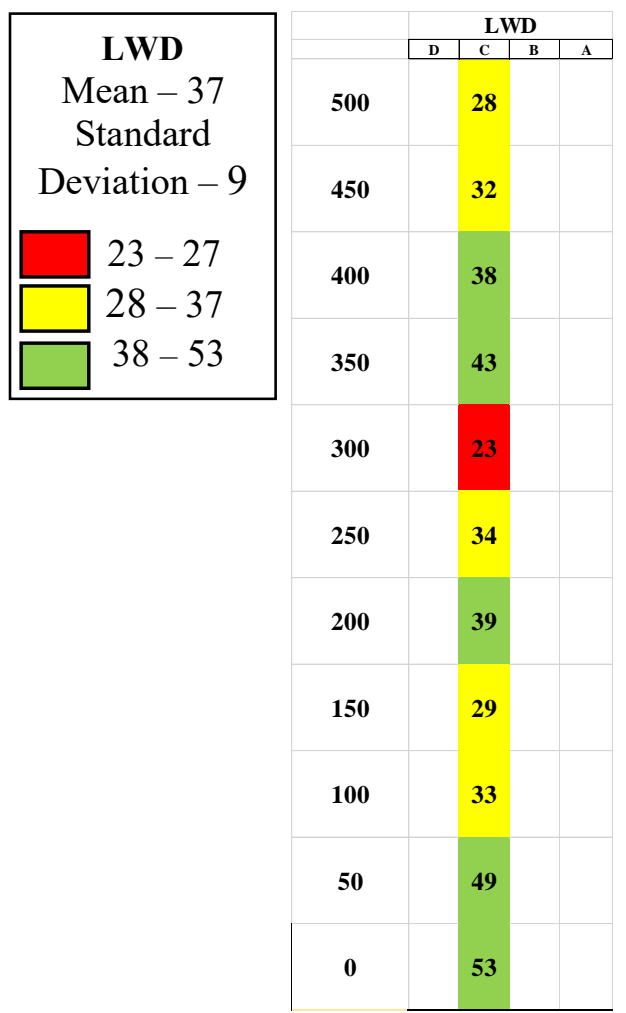

b)

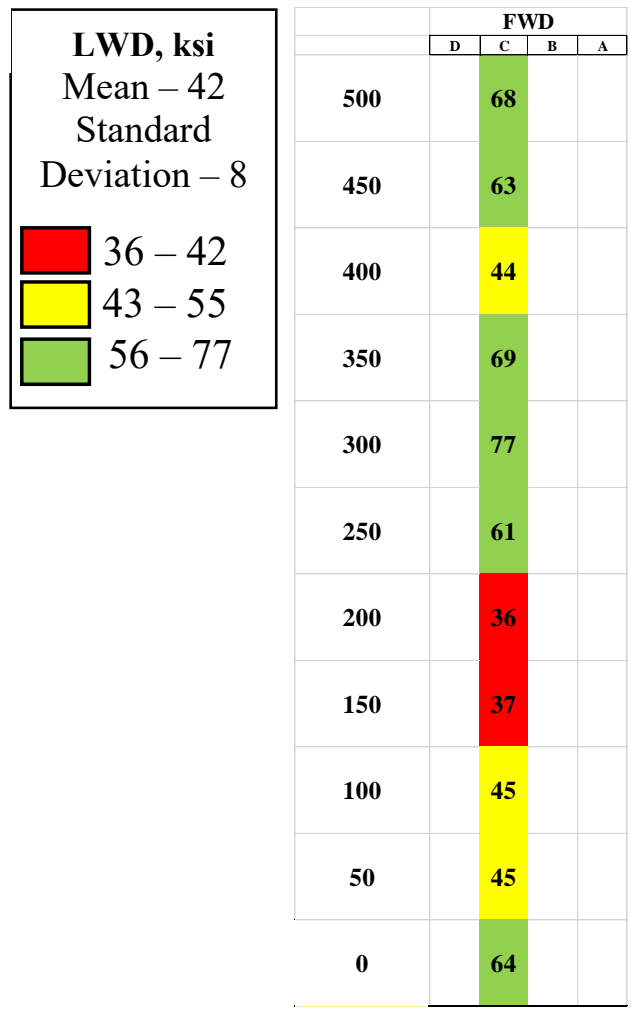

Figure 7.7 - Spatial Variation Comparison between a) LWD and b) FWD. 


\section{Chapter 8: Analyses and Interpretation of Results}

\section{$8.1 \quad$ INTRODUCTION}

The proper identification of less-stiff areas by means of IC is critical for performing evaluation of compaction by means of modulus-based measurements. This chapter summarizes the key findings from the field evaluation of the sites previously listed. The objectives of the evaluation were to investigate relationships among ICMV and various in-situ modulus-based spot test measurements, to identify key factors that affect the relationships, and to evaluate different approaches to improve the relationships for identifying less-stiff areas. The different field evaluations will be designated by the following names in this chapter:

Site 1 - Fort Worth, IH 35W

Site 2 - Georgetown, FM1460

Site 3 - Irving, SH 183

Site 4 - Victoria, US-77

Compacted geomaterials may exhibit spatial variability in their mechanical properties that can be attributed to heterogeneous conditions of underlying layers, moisture content variation and even to limited number of measurements. To evaluate whether a relationship existed between the modulus-based measurements and ICMVs, the grid with 44 spot test points was used. Rectangular buffered areas were superimposed over the spot tests for delimiting the areas with dimensions suitable for rework.

Figure 8.1 shows the relationship between the LWD deflection and the average CMV from the subgrade materials at the four sites. A trend is evident for Sites 1 and 2, indicating CMV increases as LWD deflection decreases (i.e. as subgrade becomes stiffer). The same conclusion 
cannot be inferred from the values shown for the third site because a single roller pass (Line A) exhibited variability with COVs greater than a $100 \%$.

Figure 8.1d, which compiles the data from all sites, reveals that higher CMVs occur when lower LWD deflections are recorded (i.e., material become stiffer). An exponential relationship yielded a reasonable coefficient of determination $\left(\mathrm{R}^{2}\right.$ value) but with significant scatter.
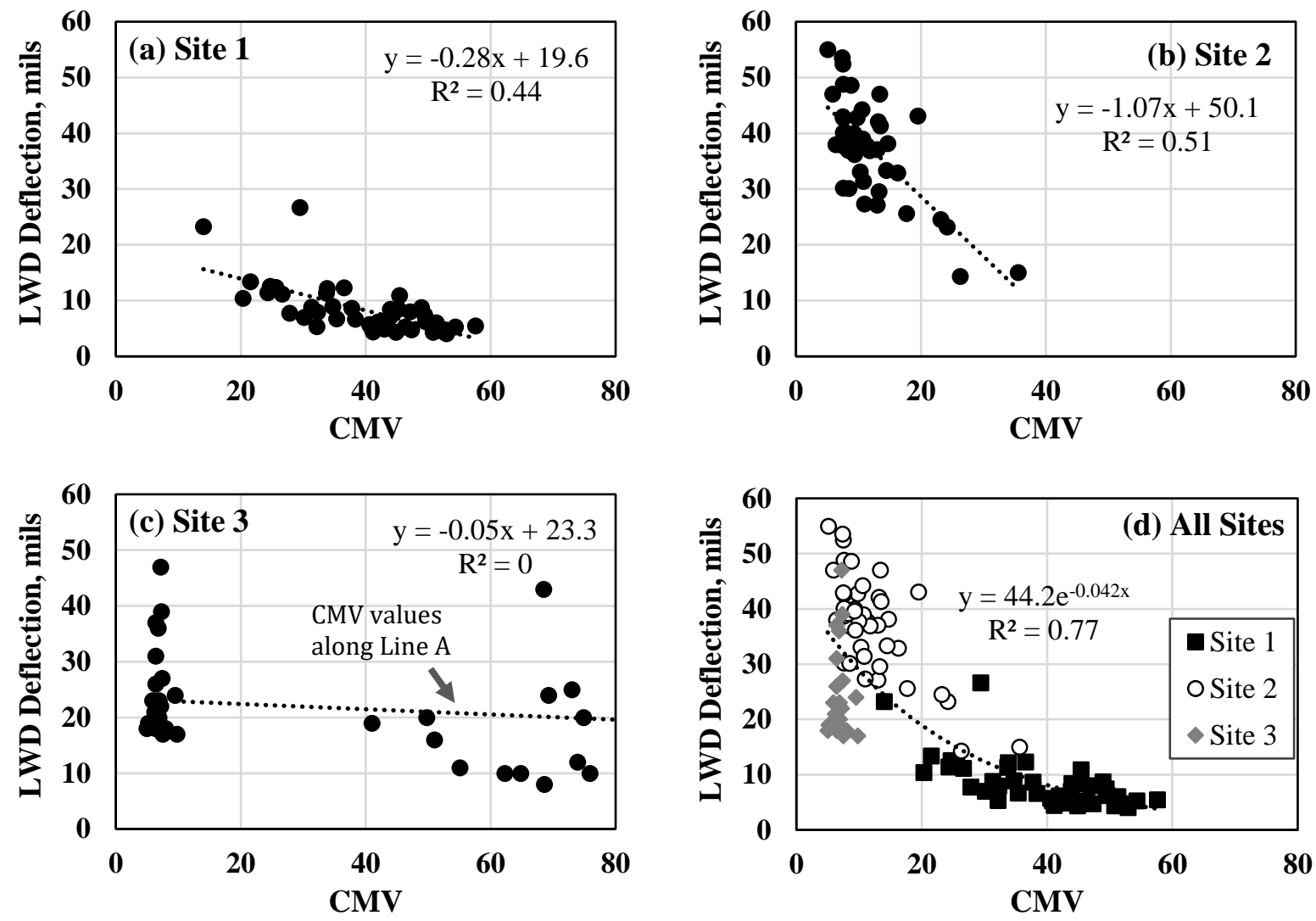

Figure 8.1 - Relationship between CMV and Deflections Measured from LWD Mass Drops in Lime-Treated Subgrade Materials

Figure 8.2 shows the relationship between the LWD deflections and the average CMVs for the flexible base layers at Sites 1 through 3 (Figures 8.2a through 8.2c), and a cement-treated base at Site 4 (Figure 8.2d). An appreciable correlation cannot be observed for any of the sites perhaps due to the high variability of the properties of the layers compacted. When measurements from all sites are compared in Figure 8.2e, the IC measurements for CTB were similar to those obtained 
for the flexible base at Site 1. The LWD deflections measured at Site 4 are small but similar to those measured at Site 2, indicating that the subgrade at Site 4 is perhaps too soft (even though it passed the density tests). This suggests that the IC roller proof-mapping of bases is impacted by subgrade and as such it is prudent to conduct a pre-mapping before mapping the base.
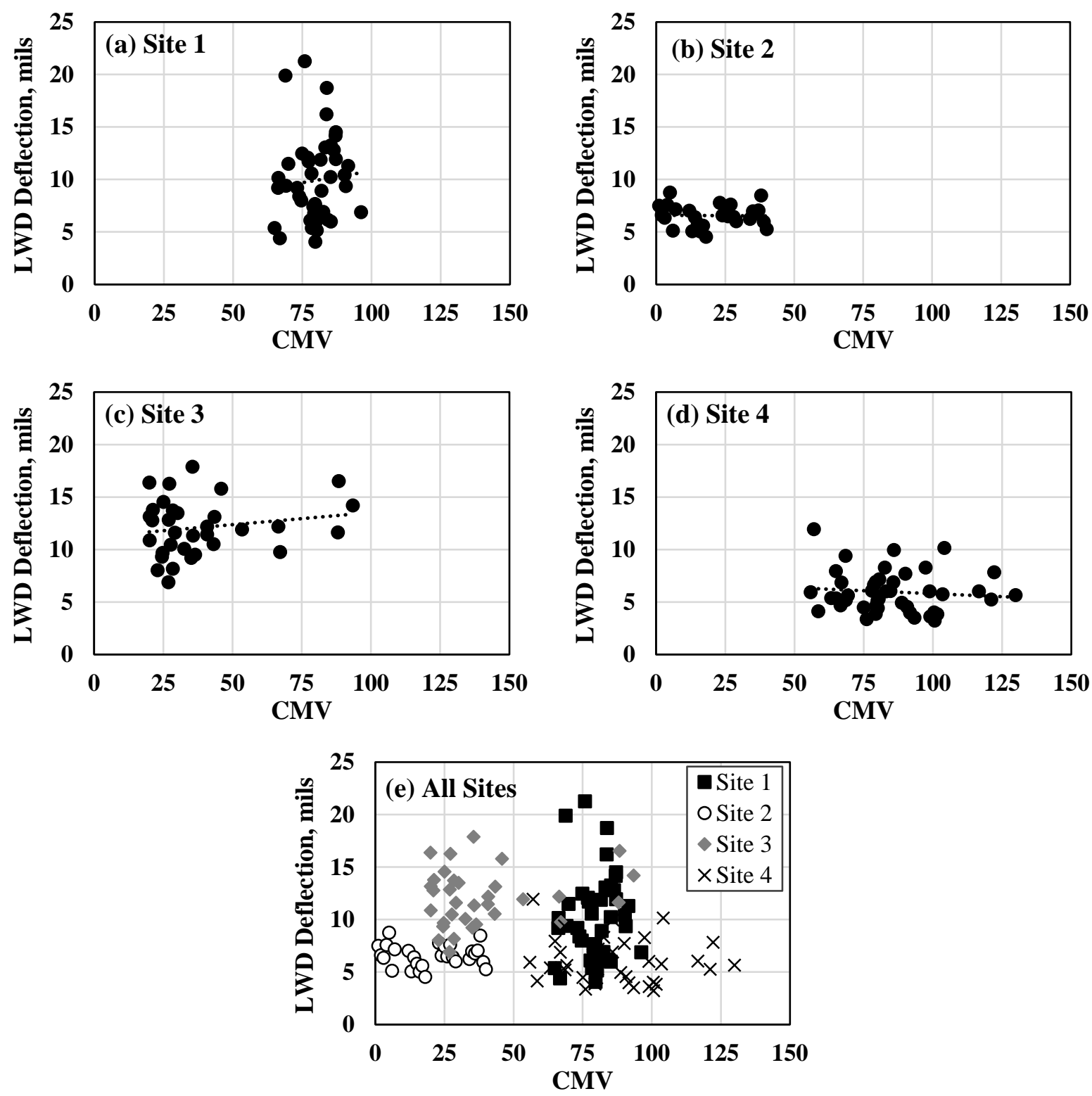

Figure 8.2 - Relationship between CMV and Deflections Measured from LWD Mass Drops in Flexible Base Materials. 
Figure 8.3 shows the relationship observed between the number of DCP blows to penetrate the subgrade to a certain depth (24 in. for Sites 1 and 2, 18 in. for Site 3, no DCP tests carried out at Site 4) and the rectangular buffered areas averaged CMV values for each of the areas in the test sections. Like the relationships observer with LWD deflections in subgrade for Sites 1 and 2, a trend is seen relating both measurements when the COVs of CMVs are reasonable. Site 3 revealed no correlation, mostly due to the high variability observed along the roller pass corresponding to Line A. Data from all sites are compiled in Figure 8.3d, where the dynamic cone penetration index (DCPI) was compared to CMV. The DCP penetrates deeper per blow in areas where lower CMVs are recorded.
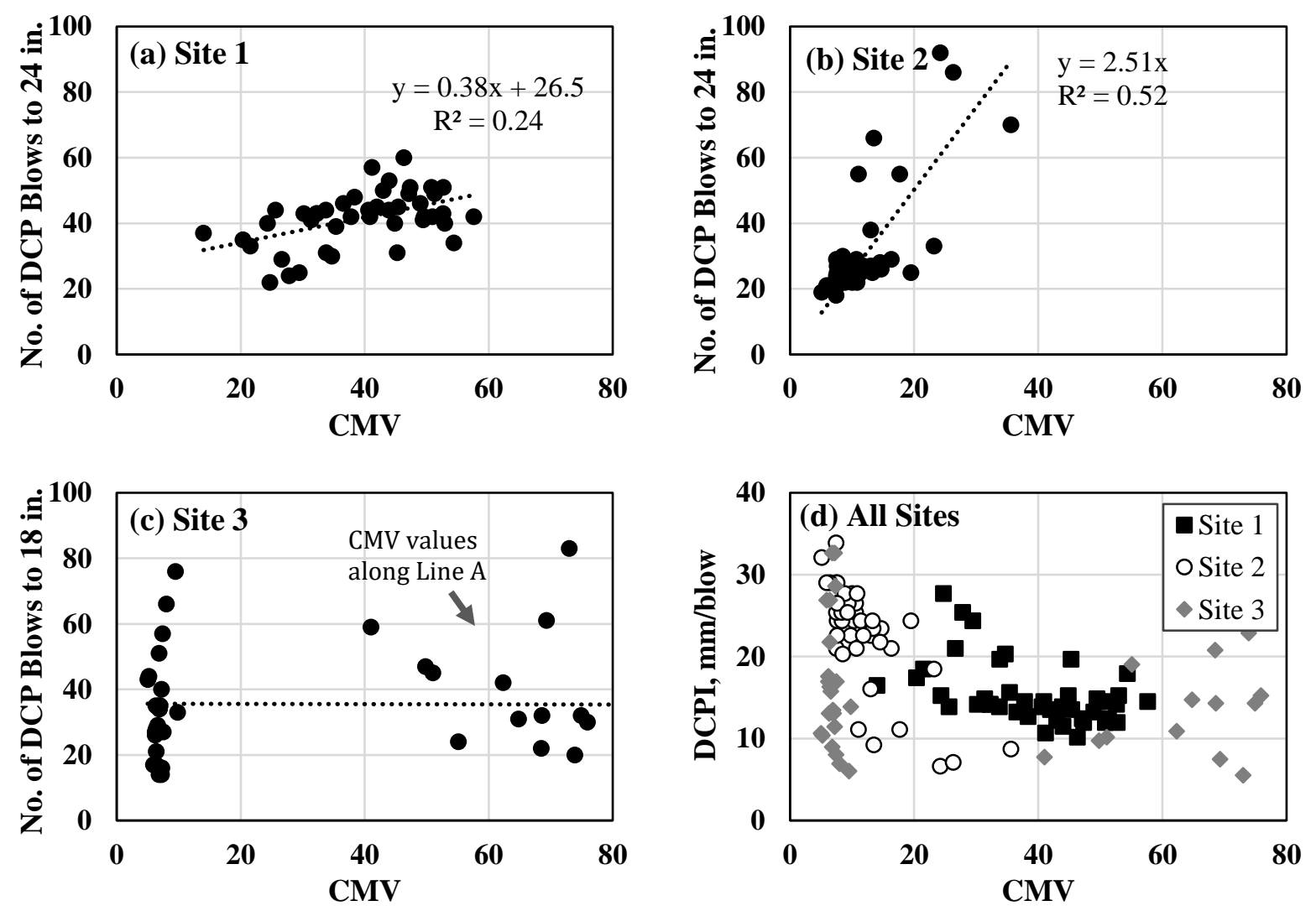

Figure 8.3 - Relationship between CMV and Number of DCP Blows to Penetrate the Indicated Depth in Lime Treated Subgrades. 
DCP tests were also performed at the base layers of Sites 1 and 2. Unlike the subgrade, no relationship was observed for between the DCP and CMVs (see Figure 8.4), again indicating the importance of pre-mapping.

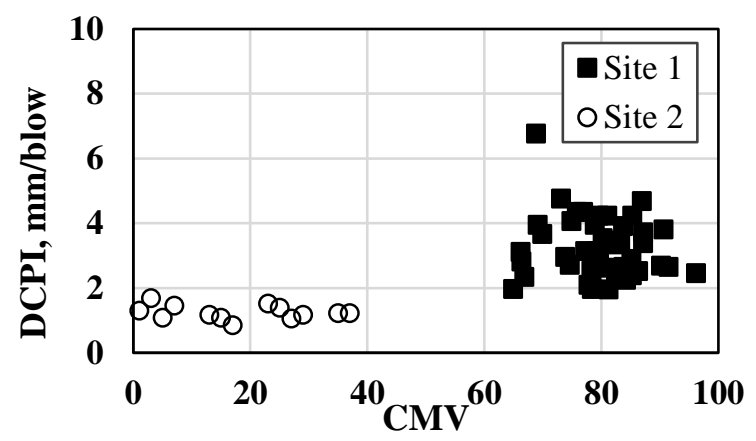

Figure 8.4 - Relationship between CMV and Dynamic Cone Penetration Index (DCPI) in Flexible Base Materials.

In Figure 8.5 data points were averaged by station reducing the amount of data points from 44 points to 11 points for subgrade at Sites 1 through 3 (Figure 8.5 a through $8.5 \mathrm{c}$, respectively). A good trend between the LWD deflection readings and CMV seems to exist. High variability in the measurement is seen in Site 3, as shown by the wide range of the error bars in Figure 8.5c.

Figure 8.6 shows the relation for CMV and the number of DCP blows at every station in subgrade as measured at Sites 1 to 3. Like what was observed for LWD deflections, a good trend seems to exist between the DCP measurement and CMV. Yet again, the high variability in the roller measurements at Site 3, shown in Figure 8.6c, affected the possibility of viewing a relationship between CMV and DCP measurements.

Figure 8.7 shows the relationships among CMV, LWD deflection and DCP penetration, for all layers of the visited sites. A power trend with negative exponential describes the decreasing modulus-based measurements as higher CMVs are obtained, i.e. as the geomaterial gets stiffer. A careful review of Figure 8.7 shows that for very soft materials (e.g., LWD deflections greater than 
20 mils), the intelligent compaction is not very effective. On the other hand, for very stiff materials such as CTB, the deflections are too small to be measured effectively with LWD.
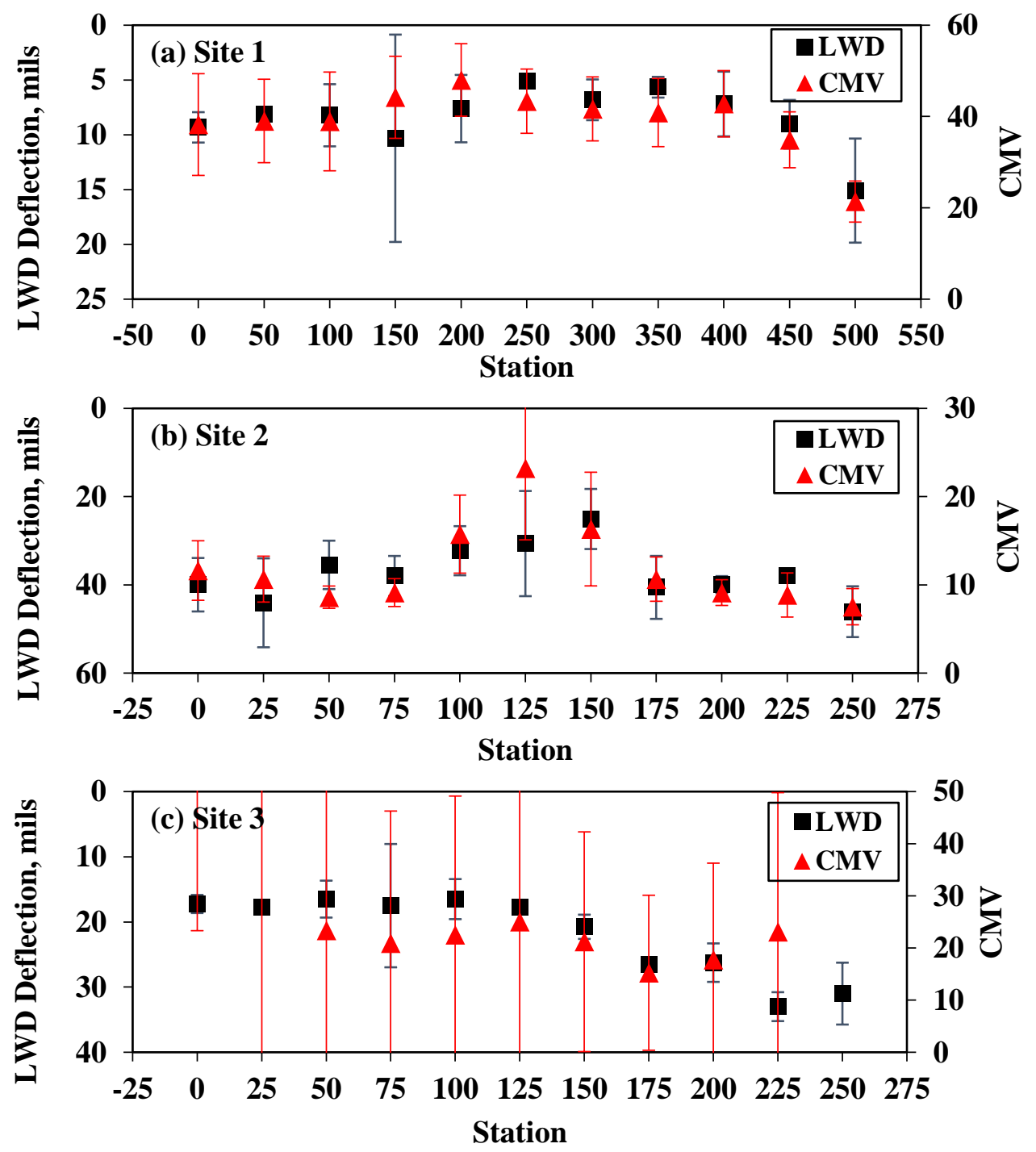

Figure 8.5 - Relationship between CMV and LWD Mass Drop Deflection per Station in Lime Treated Subgrade Materials. 

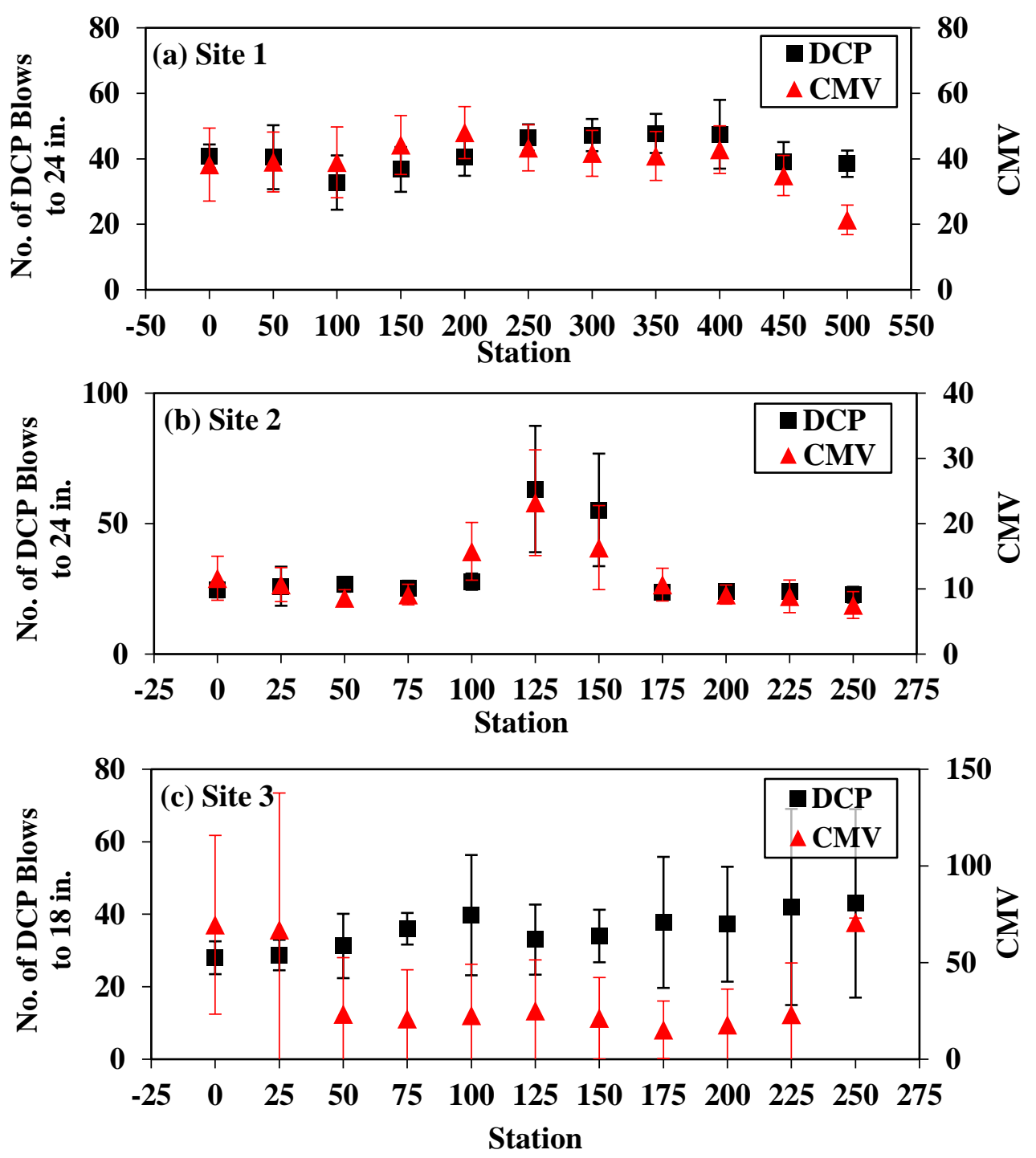

Figure 8.6 - Relationship between CMV and No. of DCP Blows per Station in Lime Treated Subgrade Materials.
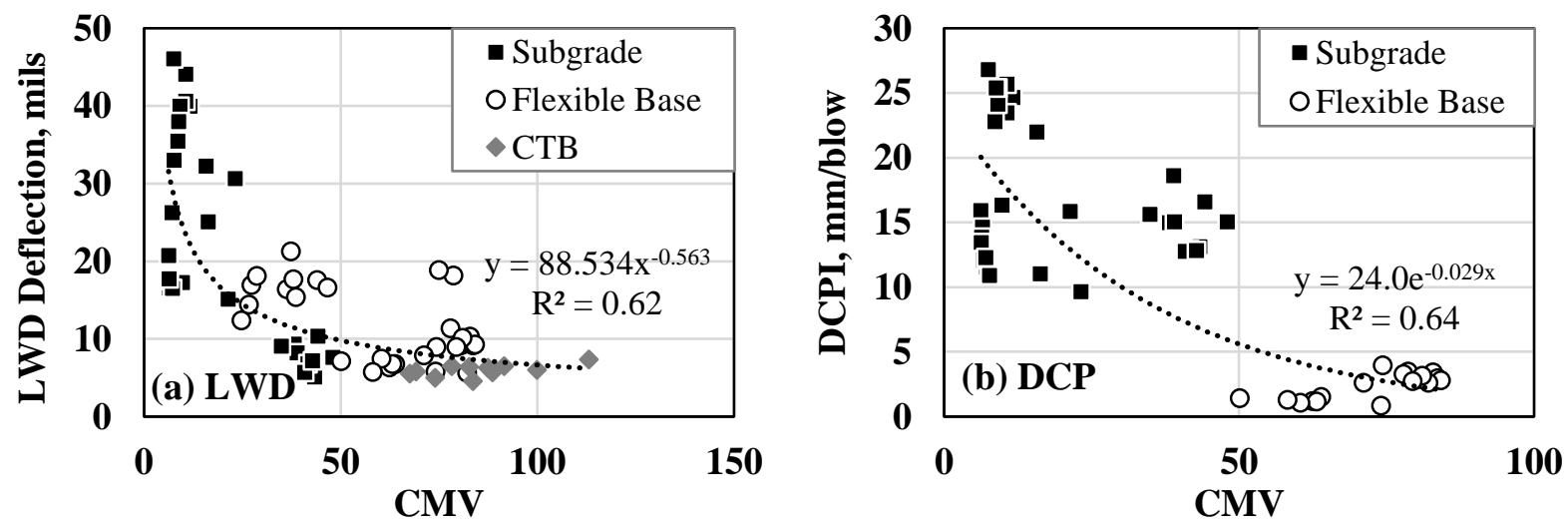

Figure 8.7 - Relationship between CMV and LWD Deflection and and DCPI per Station in All Layers of Evaluated Sites. 


\subsection{Optimization Process FOR Identifying Less Stiff Areas using IC}

In an effort to reduce the number of spot tests, it is necessary to link them to the collected ICMV data. The IC vibration data is collected at a discrete point on the roller. The current IC data analysis programs incorporate various interpolation techniques to extrapolate the ICMV data points over the width of the roller to generate the color-coded maps. The use of these methods enhances the visualization of the data by smoothing the color-coded contours and by filling gaps of information. However, the use of these tools can affect the visual representation of the ICMV data, as outliers can be cropped resulting in arrays with reduced ranges of ICMVs. Kriging, for instance, does not pass through any of the point values and causes interpolated values to be higher or lower than the real values. The spline interpolation does not work well when sample points have extreme differences in magnitude and are close to one another. To overcome these problems, a different approach for developing color-coded maps was followed. This approach consisted of allocating ICMVs into cells of rectangular shape, forming a grid comprised of multiple cells with equidistant dimensions that are aligned over the roller passes. Different color-criteria were implemented to look for better correlations between the color-coded maps.

Figure 8.8 provides the result of the process implemented in the lime-treated subgrade (LTS) of Site 1. Less-stiff areas are identified as those areas with measurements below $75 \%$ the average measurements (being CMV or number of DCP blows). For the case of LWD deflection, since larger deflections occur in less-stiff areas, the criterion was reversed, i.e. less-stiff areas are identified when LWD deflections were greater than $125 \%$ of the mean LWD deflections. The IC roller map shows a total of nine cells with CMVs below $75 \%$ of the mean CMV (marked in red). Seven of these nine areas identified by the roller were marked as less-stiff on the LWD colorcoded map. The rectangular areas enclosed by a blue border indicate the areas identified as less- 
stiff in the CMV map but not in the LWD deflection map. This indicates that $22 \%$ of less-stiff areas spotted in the CMV map were not in agreement with the less-stiff areas found in the LWD map. The percentage of mis-estimated areas increased to $56 \%$ when CMVs are compared to the number of DCP blows to penetrate 24 in. into the subgrade.

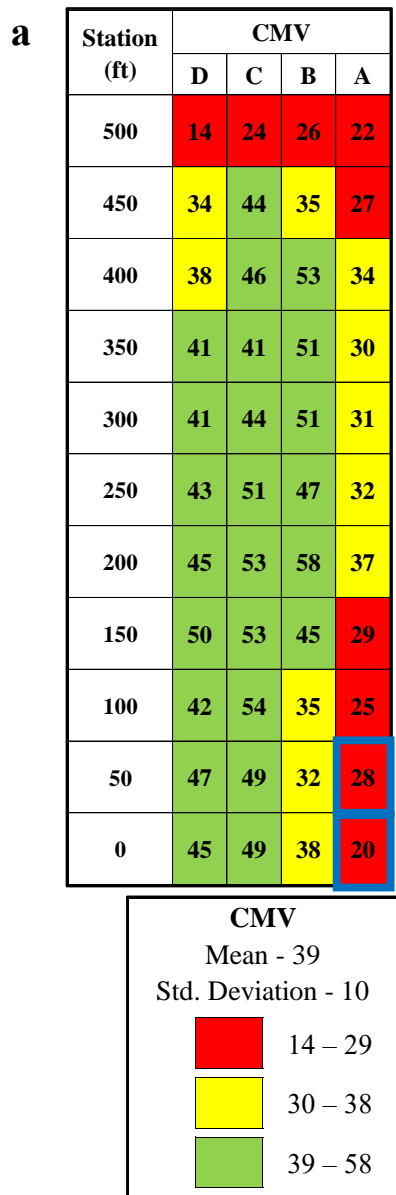

b

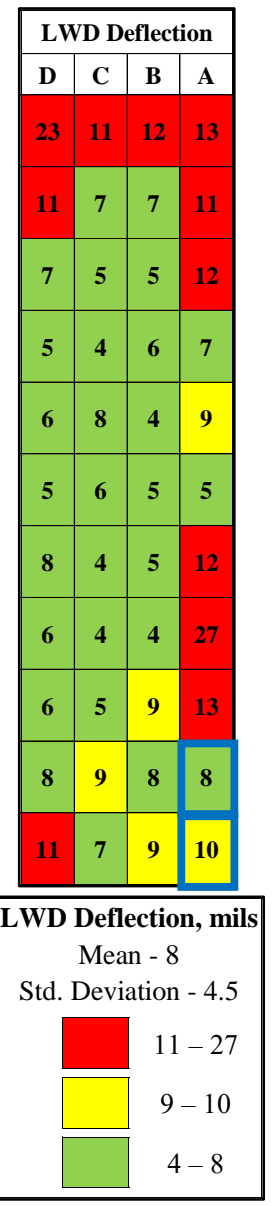

c)

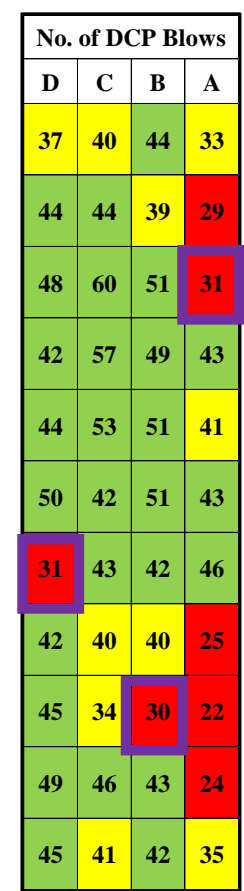

No. of DCP Blows Mean - 42 Std. Deviation - 8

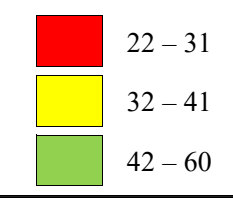

Figure 8.8 - Color-Coded Map Comparison between (a) CMV, (b) LWD Deflection and (c) Number of DCP Blows to Penetrate 24 in. at Site 1 Subgrade.

To reduce the percentage of mis-estimated areas, a systematic search for a different coloring criterion for identifying less-stiff areas was carried out. The color-coded criterion optimization approach consisted of varying the class-break for identifying the less-stiff areas for both the CMV and the spot test measurements. This criterion varied within a range defined from $60 \%$ to $90 \%$ of the average measured values, for the ICMV data and the NDT spot test values. In 
the case of the LWD deflection, as the stiffness trend is reversed, i.e. larger deflections occur in less-stiff materials, less-stiff areas as those that exceeded a percentage of the average LWD deflection. For LWD deflections, a range between $110 \%$ up to $140 \%$ of the average deflection for setting the less-stiff class-break was used.

Table 8.1 shows the percentage of mis-estimated areas by the IC roller in the subgrade for Site 1 when color-coded maps are generated and compared to LWD deflection color-coded maps with a different class-break criterion for identifying the less-stiff areas. For that site, the IC roller was able to predict all less-stiff areas identified by LWD as less-stiff (shaded cells in Table 8.2), when a class-break criterion for identifying less-stiff areas was set at 70\% of the average CMV (or lower) and when set at $120 \%$ of the average LWD deflection (or lower).

Table 8.1 - Percentage of Misestimated Roller Measurements (Rectangular Buffered Areas CMVs) with Respect to LWD Deflection-Based Measurements Based on Different Percentages of Average Measurements for Identification of Less-Stiff (Red) Areas

\begin{tabular}{|c|c|c|c|c|c|c|c|c|}
\hline \multirow{2}{*}{\multicolumn{2}{|c|}{$\begin{array}{l}\text { Percentage of IC Roller } \\
\text { Misestimated Areas }\end{array}$}} & \multicolumn{7}{|c|}{ Less-Stiff (Red) Area Above \% of Average LWD Deflection } \\
\hline & & \multirow{2}{*}{$\frac{110}{41}$} & \multirow{2}{*}{$\frac{115}{41}$} & \multirow{2}{*}{$\frac{\mathbf{1 2 0}}{41}$} & \multirow{2}{*}{$\frac{125}{47}$} & \multirow{2}{*}{$\frac{130}{47}$} & \multirow{2}{*}{$\frac{135}{53}$} & \multirow{2}{*}{$\begin{array}{r}\mathbf{1 4 0} \\
65 \\
\end{array}$} \\
\hline \multirow{7}{*}{ 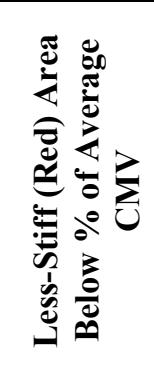 } & 90 & & & & & & & \\
\hline & 85 & 38 & 38 & 38 & 46 & 46 & 54 & 62 \\
\hline & 80 & 27 & 27 & 27 & 36 & 36 & 45 & 55 \\
\hline & 75 & 11 & 11 & 11 & 22 & 22 & 33 & 44 \\
\hline & 70 & 0 & 0 & 0 & 14 & 14 & 29 & 43 \\
\hline & 65 & 0 & 0 & 0 & 17 & 17 & 17 & 33 \\
\hline & 60 & 0 & 0 & 0 & 33 & 33 & 33 & 33 \\
\hline
\end{tabular}

This process was also implemented for the DCP readings. Table 8.3 shows the percentage of mis-estimated areas by the IC roller in subgrade for Site 1 when color-coded maps are generated and compared to the number of DCP blows to a depth of $24 \mathrm{in}$. The shaded area indicating the best combinations of class-break criteria for identifying less-stiff areas as concluded from Table 8.1 is superimposed in Table 8.2. Though the comparison of the roller's CMVs to the DCP 
measurements indicate a larger number of mis-estimated areas by the roller; the optimization process was able to identify the combinations of class-breaks best suited for identifying less-stiff areas for the subgrade in Site 1. The criterion for less-stiff area class break for CMV was lowered to $60 \%$ of the mean. For LWD, the less-stiff areas were those with deflections greater than $120 \%$ of the average LWD displacement, while for the DCP the class break was set at $80 \%$ of the average number of DCP blows for the entire section, as shown in Table 8.3.

Table 8.2 - Percentage of Mis-estimated Roller Measurements (Rectangular Buffered Areas CMVs) with respect to DCP Measurements Based on Different Percentages of Average Measurements for Identification of Less-Stiff (Red) Areas.

\begin{tabular}{|c|c|c|c|c|c|c|c|c|}
\hline \multirow{2}{*}{\multicolumn{2}{|c|}{$\begin{array}{l}\text { Percentage of IC Roller } \\
\text { Misestimated Areas }\end{array}$}} & \multicolumn{7}{|c|}{ Less-Stiff (Red) Area Below \% of Average No. of DCP Blows (0-24 in.) } \\
\hline & & \multirow{2}{*}{$\begin{array}{l}90 \\
47\end{array}$} & \multirow{2}{*}{$\begin{array}{l}85 \\
53 \\
\end{array}$} & \multirow{2}{*}{$\begin{array}{l}80 \\
59 \\
\end{array}$} & \multirow{2}{*}{$\begin{array}{l}75 \\
65\end{array}$} & \multirow{2}{*}{\begin{tabular}{|l|}
70 \\
76
\end{tabular}} & \multirow{2}{*}{$\begin{array}{l}\mathbf{6 5} \\
82\end{array}$} & \multirow{2}{*}{$\begin{array}{l}\mathbf{6 0} \\
88 \\
\end{array}$} \\
\hline \multirow{7}{*}{ 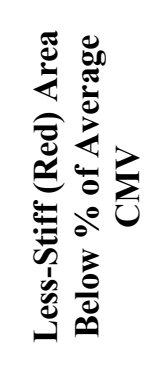 } & 90 & & & & & & & \\
\hline & 85 & 46 & 54 & 62 & 69 & 69 & 77 & 85 \\
\hline & 80 & 36 & 45 & 55 & 64 & 64 & 73 & 82 \\
\hline & 75 & 22 & 33 & 44 & 56 & 56 & 67 & 78 \\
\hline & 70 & 29 & 43 & 57 & 71 & 71 & 86 & 86 \\
\hline & 65 & 33 & 50 & 67 & 83 & 83 & 83 & 83 \\
\hline & 60 & 0 & 33 & 67 & 100 & 100 & 100 & 100 \\
\hline
\end{tabular}

Table 8.3 - Optimized Class-Break Criterion for Color-Coded Maps.

\begin{tabular}{||c|c|c|c||}
\hline Color & Criterion for CMV & $\begin{array}{c}\text { Criterion for LWD } \\
\text { Deflection }\end{array}$ & $\begin{array}{c}\text { Criterion for No. of } \\
\text { DCP Blows }\end{array}$ \\
\hline Red & $<60 \%$ Mean & $>120 \%$ Mean & $<80 \%$ Mean \\
\hline Yellow & $60 \%$ Mean - Mean & Mean $-120 \%$ Mean & $80 \%$ Mean - Mean \\
\hline Green & $>$ Mean & $<$ Mean & $>$ Mean \\
\hline
\end{tabular}

Figure 8.9 shows the new numbers of areas identified as less-stiff, in red color, as estimated by the IC roller, and the LWD and DCP spot test measurements. Lowering the less-stiff criterion for the roller's CMVs reduced the number of areas identified as less-stiff to three, while increasing the number of areas considered as marginally stiff, in yellow. This process allowed the identification of the areas with the lowest CMV values, which correlated well with those areas that 
were identified as less-stiff by the LWD. However, the percentage of mis-estimated areas did not decrease when compared to DCP measurements with the new criteria.

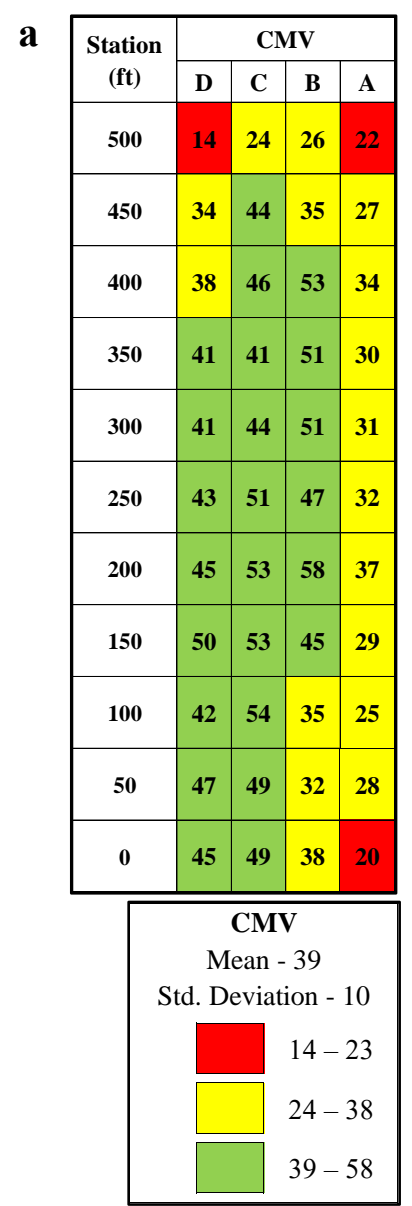
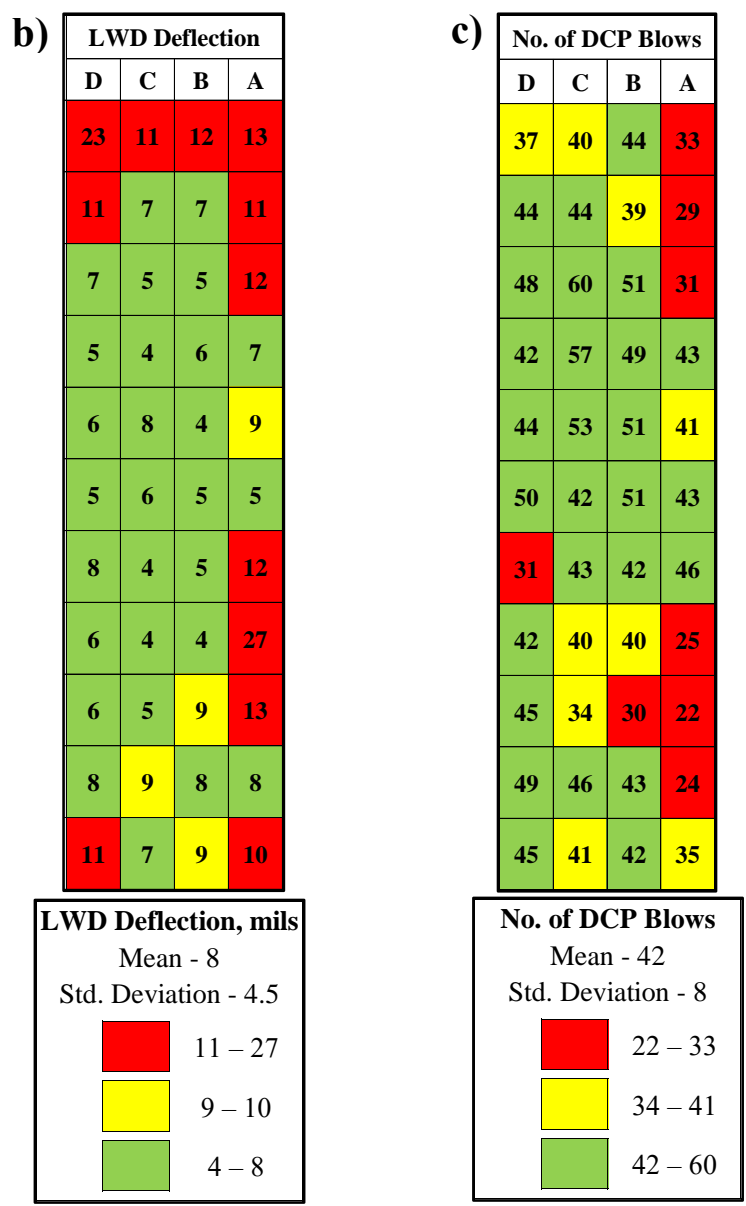

Figure 8.9 - Optimized Color-Coded Map Comparison between (a) CMV, (b) LWD Mass Drop Deflection and (c) Number of DCP Blows to Penetrate 24 in. as Obtained in Lime-Treated Subgrade at Site 1.

The same optimization code was implemented on different sites. The lime-treated subgrade (LTS) layer optimization results of Site 2 can be seen in Table 8.4. The shaded area indicating the best combination of class-break criteria was also super imposed in Table 8.4. For this site, the IC roller was not able to predict all of the less stiff areas identified by the LWD using any percentage combinations, but the percentage of misestimated areas decreased when the criterion was set to $65 \%$ of the average CMV and when set at $120 \%$ of the average LWD deflection. 
Table 8.4 - Percentage of Misestimated Roller Measurements (Rectangular Buffered Areas CMVs) with Respect to LWD Deflection-Based Measurements Based on Different Percentages of Average Measurements for Identification of Less-Stiff (Red) Areas.

\begin{tabular}{|c|c|c|c|c|c|c|c|c|}
\hline \multirow{2}{*}{\multicolumn{2}{|c|}{$\begin{array}{l}\text { Percentage of IC Roller } \\
\text { Misestimated Areas }\end{array}$}} & \multicolumn{7}{|c|}{ Less-Stiff (Red) Area Above \% of Average LWD Deflection } \\
\hline & & \multirow{2}{*}{$\begin{array}{c}110 \\
62\end{array}$} & \multirow{2}{*}{$\begin{array}{c}115 \\
62\end{array}$} & \multirow{2}{*}{$\begin{array}{c}\mathbf{1 2 0} \\
71\end{array}$} & \multirow{2}{*}{$\begin{array}{c}\mathbf{1 2 5} \\
71\end{array}$} & \multirow{2}{*}{$\begin{array}{c}\mathbf{1 3 0} \\
76\end{array}$} & \multirow{2}{*}{$\begin{array}{c}\mathbf{1 3 5} \\
86\end{array}$} & \multirow{2}{*}{$\begin{array}{c}140 \\
90 \\
\end{array}$} \\
\hline \multirow{7}{*}{ 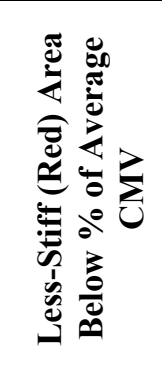 } & 90 & & & & & & & \\
\hline & 85 & 62 & 62 & 71 & 71 & 76 & 86 & 90 \\
\hline & 80 & 58 & 58 & 68 & 68 & 74 & 84 & 89 \\
\hline & 75 & 58 & 58 & 68 & 68 & 74 & 84 & 89 \\
\hline & 70 & 50 & 50 & 64 & 64 & 71 & 79 & 86 \\
\hline & 65 & 25 & 25 & 25 & 25 & 50 & 50 & 50 \\
\hline & 60 & 25 & 25 & 25 & 25 & 50 & 50 & 50 \\
\hline
\end{tabular}

The implementation of the optimization process on the lime-treated subgrade (LTS) layer of Site 3 shown in Table 8.5 did not show a significant improvement on the percentage of misestimated less-stiff areas using any of the color-criterion combinations. This could be attributed to the highly variable nature of the data which does not allow for a clear comparison between the LWD and CMV results.

Table 8.5 - Percentage of Misestimated Roller Measurements (Rectangular Buffered Areas CMVs) with Respect to LWD Deflection-Based Measurements Based on Different Percentages of Average Measurements for Identification of Less-Stiff (Red) Areas.

\begin{tabular}{|c|c|c|c|c|c|c|c|c|}
\hline \multirow{2}{*}{\multicolumn{2}{|c|}{$\begin{array}{l}\text { Percentage of IC Roller } \\
\text { Misestimated Areas }\end{array}$}} & \multicolumn{7}{|c|}{ Less-Stiff (Red) Area Above \% of Average LWD Deflection } \\
\hline & & 110 & 115 & 120 & 125 & 130 & 135 & 140 \\
\hline \multirow{7}{*}{ 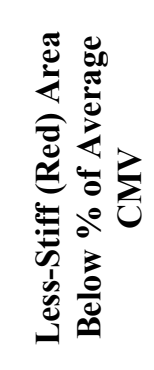 } & 90 & 72 & 72 & 83 & 89 & 89 & 100 & 100 \\
\hline & 85 & 71 & 71 & 82 & 88 & 88 & 100 & 100 \\
\hline & 80 & 71 & 71 & 82 & 88 & 88 & 100 & 100 \\
\hline & 75 & 67 & 67 & 80 & 87 & 87 & 100 & 100 \\
\hline & 70 & 67 & 67 & 78 & 89 & 89 & 100 & 100 \\
\hline & 65 & 71 & 71 & 86 & 86 & 86 & 100 & 100 \\
\hline & 60 & 67 & 67 & 83 & 83 & 83 & 100 & 100 \\
\hline
\end{tabular}

More tables generated for Sites 1 through 3 for flexible base layers with the percentage of mis-estimated roller measurements with respect LWD and DCP measurements are provided in 
Appendix C. Table 8.6 summarizes the percentage of mis-estimated areas in the CMV map for all sites after implementation of the optimized class-break criteria shown in Table 8.1. The use of an optimized class-break allowed a better estimation of the less-stiff areas using the IC data, in some cases predicting all low-stiff areas. However, in some sites and layers the optimized class-break still yielded an estimation of less-stiff areas with high uncertainty, particularly in sections where proof-mapping yielded IC measurements with high variability. This problem occurred mostly with flexible bases. For better assessment of the variability of the measurements, maps can be generated with the coefficient of variation of the collected measurements. Test sections with high coefficient of variation indicate that uniformity was not achieved and may be subject to rework. The identification of less-stiff areas was also difficult to assess in sections with IC data measurements that had very low variability, since there is the possibility that no areas will be marked in red. For most subgrade layers with low coefficients of variation the color-coded maps seemed to predict most of the low-stiff areas when the class-criteria were set at 70\% of the average CMV (or lower) and at $120 \%$ of the average LWD deflection (or lower). Further studies in more pavement layers with could help to determine a more exact color-criteria for identifying less-stiff areas on test sections.

Table 8.6 - Summary of Percentage of Mis-estimated Areas by IC Roller Optimized Class-Break Criterion for Color-Coded Maps

\begin{tabular}{||c|l|c|c||}
\hline \multirow{2}{*}{ Site } & \multirow{2}{*}{ Layer } & \multicolumn{2}{|c|}{$\begin{array}{c}\text { Percentage of IC Roller Misestimated Less- } \\
\text { Stiff Areas As Compared to Spot Test }\end{array}$} \\
\cline { 3 - 4 } & & LWD & DCP \\
\hline \multirow{2}{*}{1} & Subgrade & 0 & 67 \\
\cline { 2 - 4 } & Base & $*$ & $*$ \\
\hline \multirow{2}{*}{2} & Subgrade & 25 & 0 \\
\cline { 2 - 4 } & Base & 75 & 0 \\
\hline \multirow{2}{*}{3} & Subgrade & 76 & 56 \\
\cline { 2 - 4 } & Base & 83 & $\dagger$ \\
\hline
\end{tabular}

* No relationship could be established.

$\uparrow$ No DCP testing performed. 


\section{Chapter 9: Summary of Conclusions}

Intelligent compaction is a promising technology that can be used to assess the stiffness and uniformity of compacted geomaterials in conjunction with NDT spot test measurements. Though one-to-one correlation between the IC data with NDT modulus-based measurements may not yield strong relationships, visual relationships seem to exist between the modulus-based measurements and the ICMV maps.

This thesis documented a summary of the results obtained from field tests performed at four sites. The collected information and its analysis were used for assessing the weaknesses, bottlenecks and shortcomings of the process for implementing deflection-based field tests for project acceptance.

The relationships between in-situ deflection-based NDT measurements and roller-based ICMVs were explored using multiple analyses. The following key factors affect these relationships:

- A relationship can be seen between the LWD deflections and CMVs when the results are averaged within a buffer area as long as the variability of the CMV measurements within a buffer is small. This was also observed when DCP measurements were compared to the average CMVs.

- Higher variability of the roller ICMV measurements occur before the roller reaches its operating frequency and speed.

- The use of the padfoot rollers seem to increase the variability of ICMV measurements when compared to smooth drum rollers. 
- Visual correlations between ICMV and deflection-based measurements can be established using rectangular buffer areas and an established color-criteria.

- An optimization approach to improve the color-criteria was proposed to establish better relationships for identifying less-stiff areas.

- Mis-estimated areas can be attributed to areas with high variability in roller's CMV measurements. To identify areas with high variability, a mapping of the coefficient of variation of the roller measurements can be used for further assessment of the identified less-stiff areas. 


\section{References}

Mooney, M., and Adam, D. (2007). "Vibratory Roller Integrated Measurement of Earthwork Compaction: An Overview." In FMGM 2007: Seventh International Symposium on Field Measurements in Geomechanics, ASCE, pp. 1-12.

Mooney, M. A., Rinehart, R.V., Facas, N. W., Musimbi, O. M., White, D. J. and Vennapusa, P.K.R. (2010), “Intelligent Soil Compaction Systems,” NCHRP Report 676, National Cooperative Highway Research Program, Transportation Research Board, Washington, D.C.

Nazarian, S., Mazari, M., Abdallah, I. N., Puppala, A. J., \& Mohammad, L. N. (2014). "Modulus-Based Construction Specification for Compaction of Earthwork and Unbound Aggregate." NCHRP 10-84 Final Report, Center for Transportation Infrastructure Systems (CTIS), The University of Texas at El Paso, El Paso, TX.

Nazarian, S., Mazari, M., Chang, G., Aldouri, R., and Beltran J. (2015). "Intelligent Compaction Roller Retrofit Kit Validation." Report FHWA TIDP-130(096), Center for Transportation Infrastructure Systems (CTIS), The University of Texas at El Paso, El Paso, TX.

Siddagangaiah, A. K., Aldouri, R., Nazarian,S., Chang, C. M., and Puppala, A. (2013). "Improvement of Base and Soil Construction Quality by Using Intelligent Compaction Technology." Report FHWA/TX-13/0-6740-1, Center for Transportation Infrastructure Systems (CTIS), The University of Texas at El Paso, El Paso, TX.

Tirado, C., Mazari, M., Carrasco, C., and Nazarian, S. (2015). "Evaluating Influence Depth of Light Weight Deflectometer through Finite Element Modeling." Airfield and Highway Pavements 2015, pp. 789-800. 
Vennapusa, P. K., White, D. J., and Morris, M. D. (2009). Geostatistical Analysis for Spatially Referenced Roller-Integrated Compaction Measurements. Journal of Geotechnical and Geoenvironmental Engineering, 136(6), 813-822.

White, D. J., Vennapusa, P. K., and Thompson, M. J. (2007). "Field Validation of Intelligent Compaction Monitoring Technology for Unbound Materials." Report MN/RC-2007-10, Center for Transportation Research and Education (CTRE), Iowa State University, Ames, IA.

White, D. J., Thompson, M. J., Vennapusa, P., and Siekmeier, J. (2008). "Implementing Intelligent Compaction Specification on Minnesota TH-64 Synopsis of Measurement Values, Data Management, and Geostatistical Analysis." Transportation Research Record, Journal of the Transportation Research Board, (2045), pp. 1-9.

White, D. J. and Vennapusa, P. K. R. (2010), “A Review of Roller-Integrated Compaction Monitoring Technologies for Earthworks," Final Report ER10-04, Earthworks Engineering Research Center, Iowa State University, Ames, IA.

White, D. J., Vennapusa, P. K., and Gieselman, H. H. (2011). "Field Assessment and Specification Review for Roller-Integrated Compaction Monitoring Technologies." Advances in Civil Engineering, Vol. 2011. 


\section{Appendix A}

This appendix provides tables generated for all evaluated sites and geomaterials with the percentage of mis-estimated roller measurements with respect LWD and DCP measurements. Test sections are identified in Table A.1.

Table A.1 - Field Test Sites.

\begin{tabular}{|c|c|c|c|}
\hline Site & Location & Length & Section \\
\hline \multirow[t]{2}{*}{1} & \multirow[t]{2}{*}{$\begin{array}{l}\text { I-35W Northbound Frontage } \\
\text { Road in Fort Worth, TX }\end{array}$} & \multirow[t]{2}{*}{$500 \mathrm{ft}$} & $\begin{array}{l}36 \text { in. lime-treated subgrade (LTS) on top of } \\
\text { subgrade. }\end{array}$ \\
\hline & & & $\begin{array}{l}12 \text { in. flexible base (FB) on top of lime-treated } \\
\text { subgrade (LTS). }\end{array}$ \\
\hline \multirow[t]{2}{*}{2} & \multirow[t]{2}{*}{ FM 1460 in Georgetown, TX } & \multirow[t]{2}{*}{$250 \mathrm{ft}$} & $\begin{array}{l}8 \text { in. of lime-treated subgrade (LTS) on top of } \\
\text { subgrade. }\end{array}$ \\
\hline & & & $\begin{array}{l}12 \text { in. flexible base (FB) on top of lime-treated } \\
\text { subgrade (LTS). }\end{array}$ \\
\hline \multirow[t]{2}{*}{3} & \multirow[t]{2}{*}{ SH 183 in Irving, TX } & \multirow[t]{2}{*}{$250 \mathrm{ft}$} & $\begin{array}{l}12 \text { in. lime-treated subgrade (LTS) on top of } \\
\text { subgrade. }\end{array}$ \\
\hline & & & $\begin{array}{l}8 \text { in. flexible base (FB) on top of lime-treated } \\
\text { subgrade (LTS). }\end{array}$ \\
\hline
\end{tabular}




\section{A.1 Evaluation of IC Roller Prediction of Less-Stiff Areas on Subgrade}

\section{MATERIAL}

Tables A.2 through A.4 show the percentage of IC roller mis-estimated less-stiff areas in subgrade for Sites 1 through 3 with respect LWD and DCP measurements.

Table A.2 - Percentage of Mis-Estimated CMV Less-Stiff when Compared to Less-Stiff Areas as Predicted by the LWD Surface Modulus in Subgrade

\begin{tabular}{|c|c|c|c|c|c|c|c|c|}
\hline \multirow{2}{*}{ Site } & \multirow{2}{*}{$\begin{array}{c}<\% \text { Average } \\
\text { CMV }\end{array}$} & \multicolumn{7}{|c|}{$<\%$ of Average LWD Modulus $E_{L W D}$} \\
\hline & & 90 & 85 & 80 & 75 & 70 & 65 & 60 \\
\hline \multirow{7}{*}{1} & 90 & 24 & 29 & 29 & 47 & 47 & 53 & 65 \\
\hline & 85 & 23 & 31 & 31 & 46 & 46 & 54 & 62 \\
\hline & 80 & 18 & 18 & 18 & 36 & 36 & 45 & 55 \\
\hline & 75 & 11 & 11 & 11 & 22 & 22 & 33 & 44 \\
\hline & 70 & 0 & 0 & 0 & 14 & 14 & 29 & 43 \\
\hline & 65 & 0 & 0 & 0 & 17 & 17 & 17 & 33 \\
\hline & 60 & 0 & 0 & 0 & 33 & 33 & 33 & 33 \\
\hline \multirow{7}{*}{2} & 90 & 23 & 59 & 59 & 59 & 82 & 82 & 82 \\
\hline & 85 & 23 & 59 & 59 & 59 & 82 & 82 & 82 \\
\hline & 80 & 21 & 58 & 58 & 58 & 79 & 79 & 79 \\
\hline & 75 & 21 & 58 & 58 & 58 & 79 & 79 & 79 \\
\hline & 70 & 21 & 50 & 50 & 50 & 71 & 71 & 71 \\
\hline & 65 & 0 & 25 & 25 & 25 & 50 & 50 & 50 \\
\hline & 60 & 0 & 25 & 25 & 25 & 50 & 50 & 50 \\
\hline \multirow{7}{*}{3} & 90 & 72 & 72 & 76 & 80 & 80 & 80 & 80 \\
\hline & 85 & 72 & 72 & 76 & 80 & 80 & 80 & 80 \\
\hline & 80 & 72 & 72 & 76 & 80 & 80 & 80 & 80 \\
\hline & 75 & 72 & 72 & 76 & 80 & 80 & 80 & 80 \\
\hline & 70 & 72 & 72 & 76 & 80 & 80 & 80 & 80 \\
\hline & 65 & 72 & 72 & 76 & 80 & 80 & 80 & 80 \\
\hline & 60 & 72 & 72 & 76 & 80 & 80 & 80 & 80 \\
\hline
\end{tabular}


Table A.3 - Percentage of Mis-Estimated CMV Less-Stiff when Compared to Less-Stiff Areas as Predicted by the LWD Surface Deflection in Subgrade

\begin{tabular}{|c|c|c|c|c|c|c|c|c|}
\hline \multirow{2}{*}{ Site } & \multirow{2}{*}{$\begin{array}{c}<\% \text { Average } \\
\text { CMV }\end{array}$} & \multicolumn{7}{|c|}{$>\%$ of Average LWD Surface Deflection, $d_{L W D}$} \\
\hline & & 110 & 115 & 120 & 125 & 130 & 135 & 140 \\
\hline \multirow{7}{*}{1} & 90 & 41 & 41 & 41 & 47 & 47 & 53 & 65 \\
\hline & 85 & 38 & 38 & 38 & 46 & 46 & 54 & 62 \\
\hline & 80 & 27 & 27 & 27 & 36 & 36 & 45 & 55 \\
\hline & 75 & 11 & 11 & 11 & 22 & 22 & 33 & 44 \\
\hline & 70 & 0 & 0 & 0 & 14 & 14 & 29 & 43 \\
\hline & 65 & 0 & 0 & 0 & 17 & 17 & 17 & 33 \\
\hline & 60 & 0 & 0 & 0 & 33 & 33 & 33 & 33 \\
\hline \multirow{7}{*}{2} & 90 & 62 & 62 & 71 & 71 & 76 & 86 & 90 \\
\hline & 85 & 62 & 62 & 71 & 71 & 76 & 86 & 90 \\
\hline & 80 & 58 & 58 & 68 & 68 & 74 & 84 & 89 \\
\hline & 75 & 58 & 58 & 68 & 68 & 74 & 84 & 89 \\
\hline & 70 & 50 & 50 & 64 & 64 & 71 & 79 & 86 \\
\hline & 65 & 25 & 25 & 25 & 25 & 50 & 50 & 50 \\
\hline & 60 & 25 & 25 & 25 & 25 & 50 & 50 & 50 \\
\hline \multirow{7}{*}{3} & 90 & 44 & 56 & 76 & 76 & 80 & 80 & 80 \\
\hline & 85 & 44 & 56 & 76 & 76 & 80 & 80 & 80 \\
\hline & 80 & 44 & 56 & 76 & 76 & 80 & 80 & 80 \\
\hline & 75 & 44 & 56 & 76 & 76 & 80 & 80 & 80 \\
\hline & 70 & 44 & 56 & 76 & 76 & 80 & 80 & 80 \\
\hline & 65 & 44 & 56 & 76 & 76 & 80 & 80 & 80 \\
\hline & 60 & 44 & 56 & 76 & 76 & 80 & 80 & 80 \\
\hline
\end{tabular}


Table A.4 - Percentage of Mis-Estimated CMV Less-Stiff when Compared to Less-Stiff Areas as Predicted by the DCP in Subgrade

\begin{tabular}{|c|c|c|c|c|c|c|c|c|}
\hline \multirow{2}{*}{ Site } & \multirow{2}{*}{$\begin{array}{c}<\% \text { Average } \\
\text { CMV }\end{array}$} & \multicolumn{7}{|c|}{$<\%$ of Average Number of DCP Blows } \\
\hline & & 90 & 85 & 80 & 75 & 70 & 65 & 60 \\
\hline \multirow{7}{*}{1} & 90 & 47 & 53 & 59 & 65 & 76 & 82 & 88 \\
\hline & 85 & 46 & 54 & 62 & 69 & 69 & 77 & 85 \\
\hline & 80 & 36 & 45 & 55 & 64 & 64 & 73 & 82 \\
\hline & 75 & 22 & 33 & 44 & 56 & 56 & 67 & 78 \\
\hline & 70 & 29 & 43 & 57 & 71 & 71 & 86 & 86 \\
\hline & 65 & 33 & 50 & 67 & 83 & 83 & 83 & 83 \\
\hline & 60 & 0 & 33 & 67 & 100 & 100 & 100 & 100 \\
\hline \multirow{7}{*}{2} & 90 & 10 & 14 & 29 & 43 & 71 & 90 & 95 \\
\hline & 85 & 10 & 14 & 29 & 43 & 71 & 90 & 95 \\
\hline & 80 & 11 & 16 & 26 & 42 & 68 & 89 & 95 \\
\hline & 75 & 11 & 16 & 26 & 42 & 68 & 89 & 95 \\
\hline & 70 & 7 & 14 & 29 & 43 & 57 & 86 & 93 \\
\hline & 65 & 0 & 0 & 0 & 0 & 0 & 50 & 75 \\
\hline & 60 & 0 & 0 & 0 & 0 & 0 & 50 & 75 \\
\hline \multirow{7}{*}{3} & 90 & 52 & 52 & 56 & 72 & 76 & 76 & 76 \\
\hline & 85 & 52 & 52 & 56 & 72 & 76 & 76 & 76 \\
\hline & 80 & 52 & 52 & 56 & 72 & 76 & 76 & 76 \\
\hline & 75 & 52 & 52 & 56 & 72 & 76 & 76 & 76 \\
\hline & 70 & 52 & 52 & 56 & 72 & 76 & 76 & 76 \\
\hline & 65 & 52 & 52 & 56 & 72 & 76 & 76 & 76 \\
\hline & 60 & 52 & 52 & 56 & 72 & 76 & 76 & 76 \\
\hline
\end{tabular}




\section{A.2 Evaluation of IC Roller Prediction of Less-Stiff Areas on FleXible Base}

\section{Material}

Tables C.2 through C.4 show the percentage of IC roller mis-estimated less-stiff areas in flexible base for Sites 1 through 3 with respect LWD and DCP measurements. Cells with not a number $(\mathrm{NaN})$ indicate that no less-stiff $\mathrm{CMV}$ areas were identified by the IC roller for that particular class-break.

Table A.5 - Percentage of Mis-Estimated CMV Less-Stiff when Compared to Less-Stiff Areas as Predicted by the LWD Surface Modulus in Flexible Base

\begin{tabular}{|c|c|c|c|c|c|c|c|c|}
\hline \multirow{2}{*}{ Site } & \multirow{2}{*}{$\begin{array}{c}<\% \text { Average } \\
\text { CMV }\end{array}$} & \multicolumn{7}{|c|}{$<\%$ of Average LWD Modulus $E_{L W D}$} \\
\hline & & 90 & 85 & 80 & 75 & 70 & 65 & 60 \\
\hline \multirow{7}{*}{1} & 90 & 71 & 71 & 71 & 86 & 86 & 86 & 86 \\
\hline & 85 & 100 & 100 & 100 & 100 & 100 & 100 & 100 \\
\hline & 80 & $\mathrm{NaN}$ & $\mathrm{NaN}$ & $\mathrm{NaN}$ & $\mathrm{NaN}$ & $\mathrm{NaN}$ & $\mathrm{NaN}$ & $\mathrm{NaN}$ \\
\hline & 75 & $\mathrm{NaN}$ & $\mathrm{NaN}$ & $\mathrm{NaN}$ & $\mathrm{NaN}$ & $\mathrm{NaN}$ & $\mathrm{NaN}$ & $\mathrm{NaN}$ \\
\hline & 70 & $\mathrm{NaN}$ & $\mathrm{NaN}$ & $\mathrm{NaN}$ & $\mathrm{NaN}$ & $\mathrm{NaN}$ & $\mathrm{NaN}$ & $\mathrm{NaN}$ \\
\hline & 65 & $\mathrm{NaN}$ & $\mathrm{NaN}$ & $\mathrm{NaN}$ & $\mathrm{NaN}$ & $\mathrm{NaN}$ & $\mathrm{NaN}$ & $\mathrm{NaN}$ \\
\hline & 60 & $\mathrm{NaN}$ & $\mathrm{NaN}$ & $\mathrm{NaN}$ & $\mathrm{NaN}$ & $\mathrm{NaN}$ & $\mathrm{NaN}$ & $\mathrm{NaN}$ \\
\hline \multirow{7}{*}{2} & 90 & 64 & 82 & 100 & 100 & 100 & 100 & 100 \\
\hline & 85 & 60 & 80 & 100 & 100 & 100 & 100 & 100 \\
\hline & 80 & 50 & 75 & 100 & 100 & 100 & 100 & 100 \\
\hline & 75 & 50 & 83 & 100 & 100 & 100 & 100 & 100 \\
\hline & 70 & 50 & 83 & 100 & 100 & 100 & 100 & 100 \\
\hline & 65 & 75 & 75 & 100 & 100 & 100 & 100 & 100 \\
\hline & 60 & 75 & 75 & 100 & 100 & 100 & 100 & 100 \\
\hline \multirow{7}{*}{3} & 90 & 50 & 50 & 56 & 61 & 67 & 72 & 72 \\
\hline & 85 & 53 & 53 & 59 & 65 & 71 & 71 & 71 \\
\hline & 80 & 53 & 53 & 59 & 65 & 71 & 71 & 71 \\
\hline & 75 & 53 & 53 & 53 & 60 & 67 & 67 & 67 \\
\hline & 70 & 56 & 56 & 56 & 67 & 67 & 67 & 67 \\
\hline & 65 & 57 & 57 & 57 & 71 & 71 & 71 & 71 \\
\hline & 60 & 67 & 67 & 67 & 83 & 83 & 83 & 83 \\
\hline
\end{tabular}


Table A.6 - Percentage of Mis-Estimated CMV Less-Stiff when Compared to Less-Stiff Areas as Predicted by the LWD Surface Deflection in Flexible Base

\begin{tabular}{|c|c|c|c|c|c|c|c|c|}
\hline \multirow{2}{*}{ Site } & \multirow{2}{*}{$\begin{array}{c}<\% \text { Average } \\
\text { CMV }\end{array}$} & \multicolumn{7}{|c|}{$>\%$ of Average LWD Surface Deflection, $d_{L W D}$} \\
\hline & & 110 & 115 & 120 & 125 & 130 & 135 & 140 \\
\hline \multirow{7}{*}{1} & 90 & 71 & 71 & 71 & 71 & 71 & 71 & 71 \\
\hline & 85 & 50 & 50 & 50 & 50 & 50 & 50 & 50 \\
\hline & 80 & $\mathrm{NaN}$ & $\mathrm{NaN}$ & $\mathrm{NaN}$ & $\mathrm{NaN}$ & $\mathrm{NaN}$ & $\mathrm{NaN}$ & $\mathrm{NaN}$ \\
\hline & 75 & $\mathrm{NaN}$ & $\mathrm{NaN}$ & $\mathrm{NaN}$ & $\mathrm{NaN}$ & $\mathrm{NaN}$ & $\mathrm{NaN}$ & $\mathrm{NaN}$ \\
\hline & 70 & $\mathrm{NaN}$ & $\mathrm{NaN}$ & $\mathrm{NaN}$ & $\mathrm{NaN}$ & $\mathrm{NaN}$ & $\mathrm{NaN}$ & $\mathrm{NaN}$ \\
\hline & 65 & $\mathrm{NaN}$ & $\mathrm{NaN}$ & $\mathrm{NaN}$ & $\mathrm{NaN}$ & $\mathrm{NaN}$ & $\mathrm{NaN}$ & $\mathrm{NaN}$ \\
\hline & 60 & $\mathrm{NaN}$ & $\mathrm{NaN}$ & $\mathrm{NaN}$ & $\mathrm{NaN}$ & $\mathrm{NaN}$ & $\mathrm{NaN}$ & $\mathrm{NaN}$ \\
\hline \multirow{7}{*}{2} & 90 & 82 & 82 & 82 & 100 & 100 & 100 & 100 \\
\hline & 85 & 80 & 80 & 80 & 100 & 100 & 100 & 100 \\
\hline & 80 & 75 & 75 & 75 & 100 & 100 & 100 & 100 \\
\hline & 75 & 83 & 83 & 83 & 100 & 100 & 100 & 100 \\
\hline & 70 & 83 & 83 & 83 & 100 & 100 & 100 & 100 \\
\hline & 65 & 75 & 75 & 75 & 100 & 100 & 100 & 100 \\
\hline & 60 & 75 & 75 & 75 & 100 & 100 & 100 & 100 \\
\hline \multirow{7}{*}{3} & 90 & 72 & 72 & 83 & 89 & 89 & 100 & 100 \\
\hline & 85 & 71 & 71 & 82 & 88 & 88 & 100 & 100 \\
\hline & 80 & 71 & 71 & 82 & 88 & 88 & 100 & 100 \\
\hline & 75 & 67 & 67 & 80 & 87 & 87 & 100 & 100 \\
\hline & 70 & 67 & 67 & 78 & 89 & 89 & 100 & 100 \\
\hline & 65 & 71 & 71 & 86 & 86 & 86 & 100 & 100 \\
\hline & 60 & 67 & 67 & 83 & 83 & 83 & 100 & 100 \\
\hline
\end{tabular}


Table A.7 - Percentage of Mis-Estimated CMV Less-Stiff when Compared to Less-Stiff Areas as Predicted by the DCP in Flexible Base

\begin{tabular}{|c|c|c|c|c|c|c|c|c|}
\hline \multirow{2}{*}{ Site } & \multirow{2}{*}{$\begin{array}{c}<\% \text { Average } \\
\text { CMV }\end{array}$} & \multicolumn{7}{|c|}{$<\%$ of Average Number of DCP Blows } \\
\hline & & 90 & 85 & 80 & 75 & 70 & 65 & 60 \\
\hline \multirow{7}{*}{1} & 90 & 57 & 57 & 71 & 86 & 86 & 86 & 86 \\
\hline & 85 & 100 & 100 & 100 & 100 & 100 & 100 & 100 \\
\hline & 80 & $\mathrm{NaN}$ & $\mathrm{NaN}$ & $\mathrm{NaN}$ & $\mathrm{NaN}$ & $\mathrm{NaN}$ & $\mathrm{NaN}$ & $\mathrm{NaN}$ \\
\hline & 75 & $\mathrm{NaN}$ & $\mathrm{NaN}$ & $\mathrm{NaN}$ & $\mathrm{NaN}$ & $\mathrm{NaN}$ & $\mathrm{NaN}$ & $\mathrm{NaN}$ \\
\hline & 70 & $\mathrm{NaN}$ & $\mathrm{NaN}$ & $\mathrm{NaN}$ & $\mathrm{NaN}$ & $\mathrm{NaN}$ & $\mathrm{NaN}$ & $\mathrm{NaN}$ \\
\hline & 65 & $\mathrm{NaN}$ & $\mathrm{NaN}$ & $\mathrm{NaN}$ & $\mathrm{NaN}$ & $\mathrm{NaN}$ & $\mathrm{NaN}$ & $\mathrm{NaN}$ \\
\hline & 60 & $\mathrm{NaN}$ & $\mathrm{NaN}$ & $\mathrm{NaN}$ & $\mathrm{NaN}$ & $\mathrm{NaN}$ & $\mathrm{NaN}$ & $\mathrm{NaN}$ \\
\hline \multirow{7}{*}{2} & 90 & 50 & 67 & 83 & 100 & 100 & 100 & 100 \\
\hline & 85 & 50 & 67 & 83 & 100 & 100 & 100 & 100 \\
\hline & 80 & 25 & 50 & 75 & 100 & 100 & 100 & 100 \\
\hline & 75 & 0 & 33 & 67 & 100 & 100 & 100 & 100 \\
\hline & 70 & 0 & 33 & 67 & 100 & 100 & 100 & 100 \\
\hline & 65 & 0 & 0 & 0 & 100 & 100 & 100 & 100 \\
\hline & 60 & 0 & 0 & 0 & 100 & 100 & 100 & 100 \\
\hline
\end{tabular}




\section{Vita}

Luis Alberto Lemus was born in Ciudad Juarez, Mexico, and pursued all his studies in Mexico until middle school. He graduated from Lydia Patterson Institute as salutatorian in 2009. He attended Texas Tech University where he received a Bachelor's in Mathematics and a Bacherlor's in Spanish in the spring of 2013. After that he pursued a Civil Engineering degree from The University of Texas at El Paso (UTEP). As an undergraduate student he worked as a mathematics tutor and worked at the Center for Transportation and Infrastructure Systems (CTIS) where he had the opportunity to get involved with multiple research projects working with asphalt mixtures. He was also enrolled in different organizations such as Chi Epsilon National Civil Engineering Honor Society and the American Society of Civil Engineering.

He decided to enroll in the Master's program at UTEP. During his master's he had the opportunity to work in a research projects sponsored by the Federal Highway Administration and the Texas Department of Transportation. As a graduate student, he was selected as a Dwight D. Eisenhower Transportation Fellow. He completed a Master's Degree in Civil Engineering in the spring of 2018.

Permanent address: 809 Argentina St.

El Paso, Texas, 79903

This thesis was typed by Luis Lemus. 